\title{
Cochrane
}

Library

Cochrane Database of Systematic Reviews

\section{Transient neurological symptoms (TNS) following spinal anaesthesia with lidocaine versus other local anaesthetics in adult surgical patients: a network meta-analysis (Review)}

Forget P, Borovac JA, Thackeray EM, Pace NL

Forget P, Borovac JA, Thackeray EM, Pace NL.

Transient neurological symptoms (TNS) following spinal anaesthesia with lidocaine versus other local anaesthetics in adult surgical patients: a network meta-analysis.

Cochrane Database of Systematic Reviews 2019, Issue 12. Art. No.: CD003006.

DOI: 10.1002/14651858.CD003006.pub4.

www.cochranelibrary.com

Transient neurological symptoms (TNS) following spinal anaesthesia with lidocaine versus other local anaesthetics in adult surgical patients: a network meta-analysis (Review)

Copyright $\odot 2019$ The Cochrane Collaboration. Published by John Wiley \& Sons, Ltd. 
HEADER 1

ABSTRACT

PLAIN LANGUAGE SUMMARY

SUMMARY OF FINDINGS

Figure 1.

Figure 2.

Figure 3.

Figure 4.

Figure 5.

Figure 6.

Figure 7.

BACKGROUND

OBJECTIVES

METHODS

RESULTS

Figure 8.

Figure 9.

Figure 10.

DISCUSSION

AUTHORS' CONCLUSIONS

ACKNOWLEDGEMENTS

REFERENCES

CHARACTERISTICS OF STUDIES

DATA AND ANALYSES

Analysis 1.1. Comparison 1 One local anaesthetic versus a different local anaesthetic, Outcome 1 Presence of any transient neurological symptoms.

ADDITIONAL TABLES

APPENDICES

WHAT'S NEW

HISTORY

CONTRIBUTIONS OF AUTHORS

DECLARATIONS OF INTEREST

SOURCES OF SUPPORT

DIFFERENCES BETWEEN PROTOCOL AND REVIEW

INDEX TERMS

\section{TABLE OF CONTENTS}


[Intervention Review]

\section{Transient neurological symptoms (TNS) following spinal anaesthesia with lidocaine versus other local anaesthetics in adult surgical patients: a network meta-analysis}

Patrice Forget ${ }^{1,2}$, Josip A Borovac ${ }^{3}$, Elizabeth M Thackeray ${ }^{4}$, Nathan L Pace ${ }^{4}$

1Institute of Applied Health Sciences, Epidemiology Group, School of Medicine, Medical Sciences and Nutrition, University of Aberdeen, Aberdeen, UK. ${ }^{2}$ Department of Anaesthesia, NHS Grampian, Aberdeen, UK. ${ }^{3}$ School of Medicine, University of Split, Split, Croatia. ${ }^{4}$ Department of Anesthesiology, University of Utah, Salt Lake City, UT, USA

Contact address: Patrice Forget, Institute of Applied Health Sciences, Epidemiology Group, School of Medicine, Medical Sciences and Nutrition, University of Aberdeen, Aberdeen, UK. forgetpatrice@yahoo.fr.

Editorial group: Cochrane Anaesthesia Group

Publication status and date: Edited (no change to conclusions), published in Issue 12, 2019.

Citation: Forget P, Borovac JA, Thackeray EM, Pace NL. Transient neurological symptoms (TNS) following spinal anaesthesia with lidocaine versus other local anaesthetics in adult surgical patients: a network meta-analysis. Cochrane Database of Systematic Reviews 2019, Issue 12. Art. No.: CD003006. DOI: 10.1002/14651858.CD003006.pub4.

Copyright $@ 2019$ The Cochrane Collaboration. Published by John Wiley \& Sons, Ltd.

\section{A B S T R A C T}

\section{Background}

Spinal anaesthesia has been implicated as one of the possible causes of neurological complications following surgical procedures. This painful condition, occurring during the immediate postoperative period, is termed transient neurological symptoms (TNS) and is typically observed after the use of spinal lidocaine. Alternatives to lidocaine that can provide high-quality anaesthesia without TNS development are needed. This review was originally published in 2005, and last updated in 2009.

\section{Objectives}

To determine the frequency of TNS after spinal anaesthesia with lidocaine and compare it with other types of local anaesthetics by performing a meta-analysis for all pair-wise comparisons, and conducting network meta-analysis (NMA) to rank interventions.

\section{Search methods}

We searched CENTRAL, MEDLINE, Elsevier Embase, and LILACS on 25 November 2018. We searched clinical trial registries and handsearched the reference lists of trials and review articles.

\section{Selection criteria}

We included randomized and quasi-randomized controlled trials comparing the frequency of TNS after spinal anaesthesia with lidocaine to other local anaesthetics. Studies had to have two or more arms that used distinct local anaesthetics (irrespective of the concentration and baricity of the solution) for spinal anaesthesia in preparation for surgery.

We included adults who received spinal anaesthesia and considered all pregnant participants as a subgroup. The follow-up period for TNS was at least 24 hours.

\section{Data collection and analysis}

Four review authors independently assessed studies for inclusion. Three review authors independently evaluated the quality of the relevant studies and extracted the data from the included studies. We performed meta-analysis for all pair-wise comparisons of local anaesthetics, as well as NMA.

Transient neurological symptoms (TNS) following spinal anaesthesia with lidocaine versus other local anaesthetics in adult surgical 
We used an inverse variance weighting for summary statistics and a random-effects model as we expected methodological and clinical heterogeneity across the included studies resulting in varying effect sizes between studies of pair-wise comparisons. The NMA used all included studies based on a graph theoretical approach within a frequentist framework. Finally, we ranked the competing treatments by P scores.

\section{Main results}

The analysis included 24 trials reporting on 2226 participants of whom 239 developed TNS. Two studies are awaiting classification and one is ongoing. Included studies mostly had unclear to high risk of bias.

The NMA included 24 studies and eight different local anaesthetics; the number of pair-wise comparisons was 32 and the number of different pair-wise comparisons was 11 . This analysis showed that, compared to lidocaine, the risk ratio (RR) of TNS was lower for bupivacaine, levobupivacaine, prilocaine, procaine, and ropivacaine with RRs in the range of 0.10 to 0.23 while 2-chloroprocaine and mepivacaine did not differ in terms of RR of TNS development compared to lidocaine.

Pair-wise meta-analysis showed that compared with lidocaine, most local anaesthetics were associated with a reduced risk of TNS development (except 2-chloroprocaine and mepivacaine) (bupivacaine: RR 0.16, 95\% confidence interval (Cl) 0.09 to 0.28 ; 12 studies; moderate-quality evidence; 2-chloroprocaine: RR 0.09, 95\% Cl 0.01 to 1.51; 2 studies; low-quality evidence; levobupivacaine: RR 0.13 , 95\% $\mathrm{Cl} 0.02$ to 0.69 ; 2 studies; low-quality evidence; mepivacaine: RR 1.01, 95\% Cl 0.18 to 5.82; 4 studies; very low-quality evidence; prilocaine: RR $0.18,95 \% \mathrm{Cl} 0.07$ to 0.49 ; 4 studies; moderate-quality evidence; procaine: RR $0.14,95 \% \mathrm{Cl} 0.04$ to $0.52 ; 2$ studies; moderate-quality evidence; ropivacaine: $\mathrm{RR} 0.10,95 \% \mathrm{Cl} 0.01$ to 0.78 ; 2 studies; low-quality evidence).

We were unable to perform any of our planned subgroup analyses due to the low number of TNS events.

\section{Authors' conclusions}

Results from both NMA and pair-wise meta-analysis indicate that the risk of developing TNS after spinal anaesthesia is lower when bupivacaine, levobupivacaine, prilocaine, procaine, and ropivacaine are used compared to lidocaine. The use of 2-chloroprocaine and mepivacaine had a similar risk to lidocaine in terms of TNS development after spinal anaesthesia.

Patients should be informed of TNS as a possible adverse effect of local anaesthesia with lidocaine and the choice of anaesthetic agent should be based on the specific clinical context and parameters such as the expected duration of the procedure and the quality of anaesthesia.

Due to the very low- to moderate-quality evidence (GRADE), future research efforts in this field are required to assess alternatives to lidocaine that would be able to provide high-quality anaesthesia without TNS development. The two studies awaiting classification and one ongoing study may alter the conclusions of the review once assessed.

\section{PLAIN LANGUAGE SUMMARY}

\section{Occurrence of transient neurological symptoms following spinal anaesthesia with lidocaine versus other local anaesthetics in adults undergoing surgery}

\section{Review question}

We aimed to determine if transient neurological symptoms (TNS) occur more frequently after recovery from spinal anaesthesia with lidocaine than with other local anaesthetics in adults. The symptoms are mild to severe pain in the buttocks and legs that can last for days. We also looked for longer-lasting sensory or motor disturbances caused by nerve damage by local anaesthetics, known as neurological complications.

\section{Background}

Mild pain in the lower back is a common complaint following spinal anaesthesia (where a local anaesthetic is injected into the spinal column rather than using general anaesthetic into the whole body). People may also experience headache and low blood pressure. TNS symptoms are different. They appear within a few hours up to 24 hours after spinal anaesthesia and may last up to two to five days.

Lidocaine (a local anaesthetic) continues to be used for spinal anaesthesia because of its unique short duration of action, intense blockade, quick recovery, and suitability for day-case surgery, but alternatives are needed.

This review was originally published in 2005 and previously updated in 2009.

\section{Study characteristics}

We included all randomized trials and quasi-randomized trials comparing the frequency of TNS and neurological complications after spinal anaesthesia with lidocaine compared to other local anaesthetic agents. Randomized trials compare two or more treatments where the treatments are allocated to participants in a random manner that cannot be predicted by the study organizers. Quasi-randomized

Transient neurological symptoms (TNS) following spinal anaesthesia with lidocaine versus other local anaesthetics in adult surgical 
studies are similar but are not truly random, but carry a greater likelihood that the study organizer can predict which treatment the participants receive (e.g. based on date of birth or the order in which people were recruited).

The evidence is current to 25 November 2018.

\section{Key results}

We included 24 trials reporting on 2226 participants, 239 of whom developed TNS. There was no evidence TNS was associated with any specific neurological disease and symptoms disappeared spontaneously by the fifth postoperative day. The risk of developing TNS with lidocaine for spinal anaesthesia was increased compared to bupivacaine, prilocaine, or procaine; and similar compared to 2chloroprocaine and mepivacaine.

Specifically, when alternative local anaesthetics were compared directly to lidocaine, the risk of developing TNS was reduced by between $82 \%$ and $90 \%$ when bupivacaine, levobupivacaine, prilocaine, procaine, and ropivacaine were used rather than lidocaine. There were no clear differences in TNS between lidocaine and 2-chloroprocaine or mepivacaine. In the case of 2-chloroprocaine, TNS occurred in only one study and the results varied greatly for the small number of participants. Painful symptoms stopped by the fifth postoperative day in all participants. Among pregnant women undergoing surgery, only 3/310 women developed TNS; no conclusions could be drawn on whether symptoms were more likely with lidocaine.

The authors also used the statistical method of network meta-analysis to compare the various local anaesthetics. This analysis similarly showed that the risk of TNS was lower for bupivacaine, levobupivacaine, prilocaine, procaine, and ropivacaine, while 2-chloroprocaine and mepivacaine did not differ in risk of TNS compared to lidocaine.

\section{Quality of the evidence}

Due to the very low- to moderate-quality of evidence among currently available studies, future research efforts in this field are needed to assess alternatives to lidocaine that can provide high-quality anaesthesia without TNS development.

\section{Conclusion}

Lidocaine has been the drug of choice for inducing spinal anaesthesia in ambulatory surgery (or day surgery) because of its rapid onset of action, intense nerve blockade, and short duration of action. The present review shows that lidocaine is more likely to cause TNS than bupivacaine, prilocaine, and procaine. However, these drugs produce longer local anaesthetic effects and therefore are not desirable for ambulatory patients.

Our results suggest that 2-chloroprocaine might be a viable alternative to lidocaine for day surgery of short duration and obstetric procedures since this local anaesthetic has a rapid onset of action, is quickly metabolized, and has low toxicity. However, this conclusion is based on only two studies and low-quality evidence. 


\section{SUMMARYOF FINDINGS}

Summary of findings for the main comparison. Risk of transient neurological symptoms with spinal lidocaine compared to other local anaesthetic in adults undergoing surgery

Risk of transient neurological symptoms (TNS) with spinal lidocaine compared to other local anaesthetics in adults undergoing surgery $a$

Patient or population: adult undergoing surgery

Settings: hospital or ambulatory surgery setting (Belgium, Brazil, Canada, Denmark, Egypt, Finland, Iran, Italy, Lebanon, Nepal, the Netherlands, Norway, Spain, Switzerland, Turkey, USA)

Intervention: spinal lidocaine

Comparison: other local anaesthetics as indicated

\begin{tabular}{|c|c|c|c|c|c|c|}
\hline \multirow[t]{2}{*}{ Outcomes } & \multicolumn{2}{|c|}{ Anticipated absolute effects ${ }^{b}(95 \% \mathrm{Cl})$} & \multirow{2}{*}{$\begin{array}{l}\text { Relative ef- } \\
\text { fect }(95 \mathrm{Cl})\end{array}$} & \multirow{2}{*}{$\begin{array}{l}\text { № of partici- } \\
\text { pants } \\
\text { (studies) }\end{array}$} & \multirow{2}{*}{$\begin{array}{l}\text { Quality of the } \\
\text { evidence } \\
\text { (GRADE) }\end{array}$} & \multirow[t]{2}{*}{ Comments } \\
\hline & $\begin{array}{l}\text { Risk with li- } \\
\text { docaine }\end{array}$ & $\begin{array}{l}\text { Risk difference with the } \\
\text { other local anaesthetic }\end{array}$ & & & & \\
\hline $\begin{array}{l}\text { Presence of any TNS -lidocaine vs } \\
\text { bupivacaine } \\
\text { Follow-up: range 1-30 days }\end{array}$ & 210 per 1000 & $\begin{array}{l}176 \text { fewer per } 1000 \text { ( } 191 \\
\text { fewer to } 151 \text { fewer) }\end{array}$ & $\begin{array}{l}\mathbf{R R} \mathbf{0 . 1 6} \\
(0.09 \text { to } 0.28)\end{array}$ & 1220 (12 RCTs) & $\begin{array}{l}\oplus \oplus \oplus \ominus \\
\text { Moderate }^{c}\end{array}$ & $\begin{array}{l}\text { Bupivacaine probably } \\
\text { reduced the risk of TNS } \\
\text { compared to lidocaine. }\end{array}$ \\
\hline $\begin{array}{l}\text { Presence of any TNS - lidocaine vs 2- } \\
\text { chloroprocaine } \\
\text { Follow-up: range 1-7 days }\end{array}$ & 106 per 1000 & $\begin{array}{l}97 \text { fewer per } 1000 \text { ( } 105 \text { few- } \\
\text { er to } 54 \text { more) }\end{array}$ & $\begin{array}{l}\mathbf{R R} \mathbf{0 . 0 9} \\
(0.01 \text { to } 1.51)\end{array}$ & 94 (2 RCTs) & $\begin{array}{l}\oplus \oplus \ominus \ominus \\
\text { Lowc,d }\end{array}$ & $\begin{array}{l}\text { 2-chloroprocaine may } \\
\text { have resulted in no dif- } \\
\text { ference in the risk of TNS } \\
\text { compared to lidocaine. }\end{array}$ \\
\hline $\begin{array}{l}\text { Presence of any TNS - lidocaine vs lev- } \\
\text { obupivacaine } \\
\text { Follow-up: range } 2-7 \text { days }\end{array}$ & 183 per 1000 & $\begin{array}{l}159 \text { fewer per } 1000 \text { ( } 180 \\
\text { fewer to } 57 \text { fewer) }\end{array}$ & $\begin{array}{l}\text { RR } 0.13 \\
(0.02 \text { to } 0.69)\end{array}$ & 120 (2 RCTs) & $\begin{array}{l}\oplus \oplus \ominus \ominus \\
\text { Lowe }^{e, f}\end{array}$ & $\begin{array}{l}\text { Levobupivacaine may } \\
\text { have reduced the risk of } \\
\text { TNS compared to lido- } \\
\text { caine. }\end{array}$ \\
\hline $\begin{array}{l}\text { Presence of any TNS - lidocaine vs } \\
\text { mepivacaine } \\
\text { Follow-up: range } 1-5 \text { days }\end{array}$ & 95 per 1000 & $\begin{array}{l}1 \text { more per } 1000 \text { ( } 78 \text { fewer to } \\
457 \text { more) }\end{array}$ & $\begin{array}{l}\text { RR } 1.01 \\
(0.18 \text { to } 5.82)\end{array}$ & 274 (4 RCTs) & $\begin{array}{l}\oplus \odot \odot \odot \\
\text { Very low } d, e, f\end{array}$ & $\begin{array}{l}\text { Mepivacaine may have re- } \\
\text { sulted in no difference in } \\
\text { the risk of TNS compared } \\
\text { to lidocaine but the evi- } \\
\text { dence was very uncertain. }\end{array}$ \\
\hline
\end{tabular}




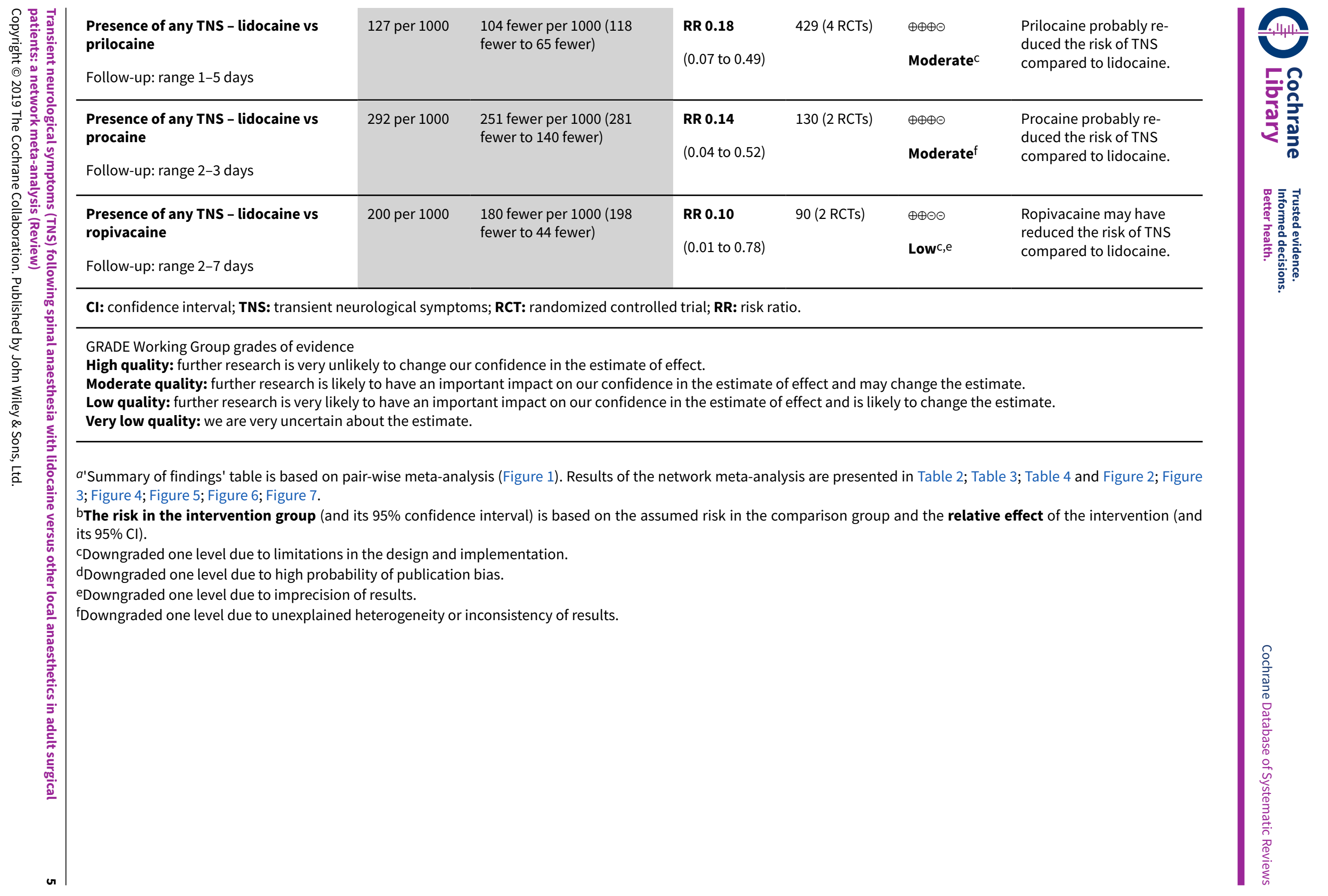


igure 1. Forest plot of comparison: 1 Lidocaine versus other local anaesthetic, outcome: 1.1 Transient neurological symptoms.

\begin{tabular}{|c|c|c|}
\hline \\
\hline \multirow{2}{*}{\multicolumn{3}{|c|}{$\begin{array}{l}\text { Study or Subgroup Events } \\
\text { 1.1.1 Bupivacaine vs lidocaine }\end{array}$}} \\
\hline & & \\
\hline Ali Hassan 2015 & 0 & 25 \\
\hline Aouad 2001 & 0 & 100 \\
\hline Etezadi 2013 & 14 & 125 \\
\hline Hampl 1995a & 0 & 16 \\
\hline Hampl 1998 & 0 & 30 \\
\hline Imbelloni 2010 & 0 & 75 \\
\hline Keld 2000 & 1 & 35 \\
\hline Philip 2001 & 2 & 28 \\
\hline Pollock 1996 & 0 & 52 \\
\hline Pradhan 2010 & 0 & 26 \\
\hline Salmela 1998 & 0 & 30 \\
\hline Teunkens 2016 & 0 & 35 \\
\hline Subtotal (95\% Cl) & & 577 \\
\hline
\end{tabular}

\begin{tabular}{cr}
\multicolumn{2}{c}{$\begin{array}{c}\text { Local anaesthetic } \\
\text { Events }\end{array}$} \\
\\
5 & 0 \\
0 & 0 \\
5 & 85 \\
6 & 9 \\
0 & 9 \\
5 & 0 \\
5 & 9 \\
8 & 1 \\
2 & 16 \\
6 & 0 \\
0 & 6 \\
5 & 0 \\
7 &
\end{tabular}

\begin{tabular}{ccc} 
Risk Ratio & \\
Total & Weight & IV, Random, $95 \% \mathrm{Cl}$ \\
\hline
\end{tabular}

Risk Ratio

Risk of Bias

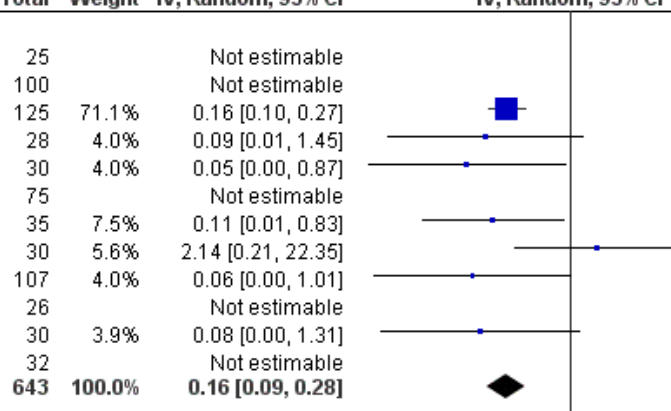

+4? ?

? ? ४९૯૯?

$\hookrightarrow$ ? $\div 8 \div \div$ ?

? ?

๑े๑९?९?

? ? $\odot \odot \odot \odot ?$

? ? $\odot \odot \odot \odot$ ?

?

Total events

Heterogeneity: Tau $^{2}=0.05 ; \mathrm{Chi}^{2}=6.31, \mathrm{df}=6(\mathrm{P}=0.39) ; \mathrm{I}^{2}=5 \%$

$643 \quad 100.0 \% \quad$ Not estimab

$++\odot+\odot \div$

Test for overall effect $Z=635(P<0.00001)$

Chlorprocaine vs lidocaine

Casati 2007

Teunkens 2016

15
32
47

$15100.0 \%$

$\begin{array}{ll}32 & 100.0 \%\end{array}$

$0.09[0.01,1.51]$

Not estimable
$0.09[0.01,1.51]$

Total events

geneity: Not applicable

Test for overall effect: $Z=1.67(P=0.09)$

1.1.3 Levobupivacaine vs lidocaine

Breebart 2003

Gozdemir 2010

30
60

Total events

8
11

(1)

$30 \quad 32.3 \%$

$\begin{array}{lr}30 & 67.7 \% \\ \mathbf{6 0} & \mathbf{1 0 0 . 0 \%}\end{array}$

$0.14[0.01,2.65]$

$0.13[0.02,0.94]$
$\mathbf{0 . 1 3}[0.02,0.69]$

Heterogeneity $\mathrm{Tau}^{2}=0.00 \cdot \mathrm{Chi}^{2}=0.01, \mathrm{df}=1(\mathrm{P}=0.94)^{2} \mathrm{I}^{2}=0.0 \%$

Test for overall effect $Z=2.41(P=0.02)$

\subsubsection{Mepivacaine vs lidocaine}

Liguori 1998

Pawlowski 2012

Salazar 2001

Salmela 1998

$\begin{array}{rr}0 & 30 \\ 0 & 37 \\ 3 & 40 \\ 11 & 30\end{array}$

30
37
40
30
137

Total events

14

$T^{2}=1.45 ; 012=511, d f=2(P=0,13$

Test for overall effect: $Z=0.02(P=0.99)$

1.1.5 Prilocaine vs lidocaine

de Weert 200

de Weert 2000

Martinez-Bourio 1998

Østgaard 2000

$\begin{array}{ll}0 & 35 \\ 1 & 30 \\ 1 & 102\end{array}$

35
30
102

35
30
102
50

50
217

Total events

4

27

Heterogeneity: $\operatorname{Tau}^{2}=0.00 ; \mathrm{Chi}^{2}=1.09, \mathrm{df}=3(\mathrm{P}=0.78) ; \mathrm{I}^{2}=0$

Test for overall effect: $Z=3.38(P=0.0007)$

1.1.6 Procaine vs lidocaine

Hodgson 2000

Le Truong 2001

$\begin{array}{rrr}2 & 35 & 11 \\ 0 & 30 & 8 \\ & 65 & \end{array}$

Total events

19

$35 \quad 79.4 \%$

$\begin{array}{cr}30 & 20.6 \% \\ \mathbf{6 5} & \mathbf{1 0 0 . 0 \%}\end{array}$

$\begin{array}{ll}27 & 22.5 \% \\ 40 & \\ 40 & 29.1 \% \\ 30 & 48.4 \%\end{array}$

$\begin{array}{rr}30 & 48.4 \% \\ 137 & 100.0 \%\end{array}$

$0.07[0.00,1.18]$
Not estimable
$3.00[0.33,27.63]$
$1.83[0.78,4.32]$
$1.01[0.18,5.82]$

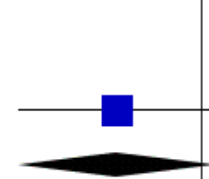

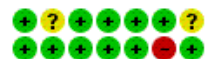

Heterogeneity: $\mathrm{Tau}^{2}=0.00 ; \mathrm{Chi}^{2}=0.49, \mathrm{df}=1(\mathrm{P}=0.48) ; \mathrm{I}^{2}=0 \%$

Test for owerall effect: $Z=2.98(P=0.003)$

1.1.7 Ropivacaine vs lidocaine

Breebaart 2003

30

3

$30 \quad 47.7 \% \quad 0.14[0.01,2.65]$

$\begin{array}{lll}35 & 12.3 \% & 0.07[0.00,1.12] \\ 30 & 24.5 \% & 0.11[0.01,0.82] \\ 98 & 20.8 \% & 0.24[0.03,2.11]\end{array}$

$\begin{array}{rrr}49 & 42.4 \% & 0.28[0.06,1.28] \\ 212 & \mathbf{1 0 0 . 0 \%} & \mathbf{0 . 1 8}[0.07,0.49]\end{array}$

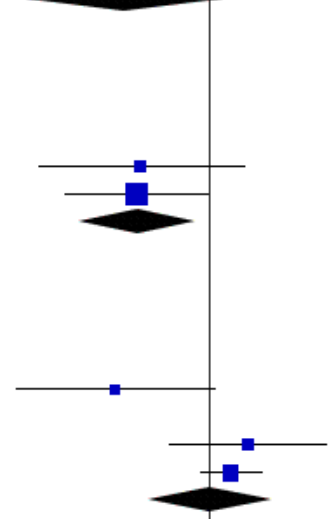

() ? $\odot \odot \odot \odot ?$

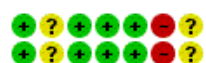

$4 ?$

? ? ?

0

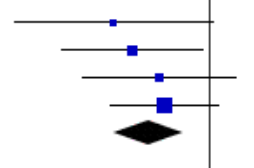

?? ????

$\leftrightarrow ? \oplus \oplus \oplus \oplus ?$

?๑??๑??

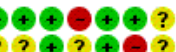

$0.18[0.04,0.76]$

$0.06[0.000,0.98]$

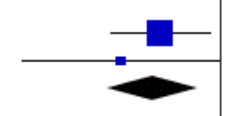

ว ใ๑? ९อ? 


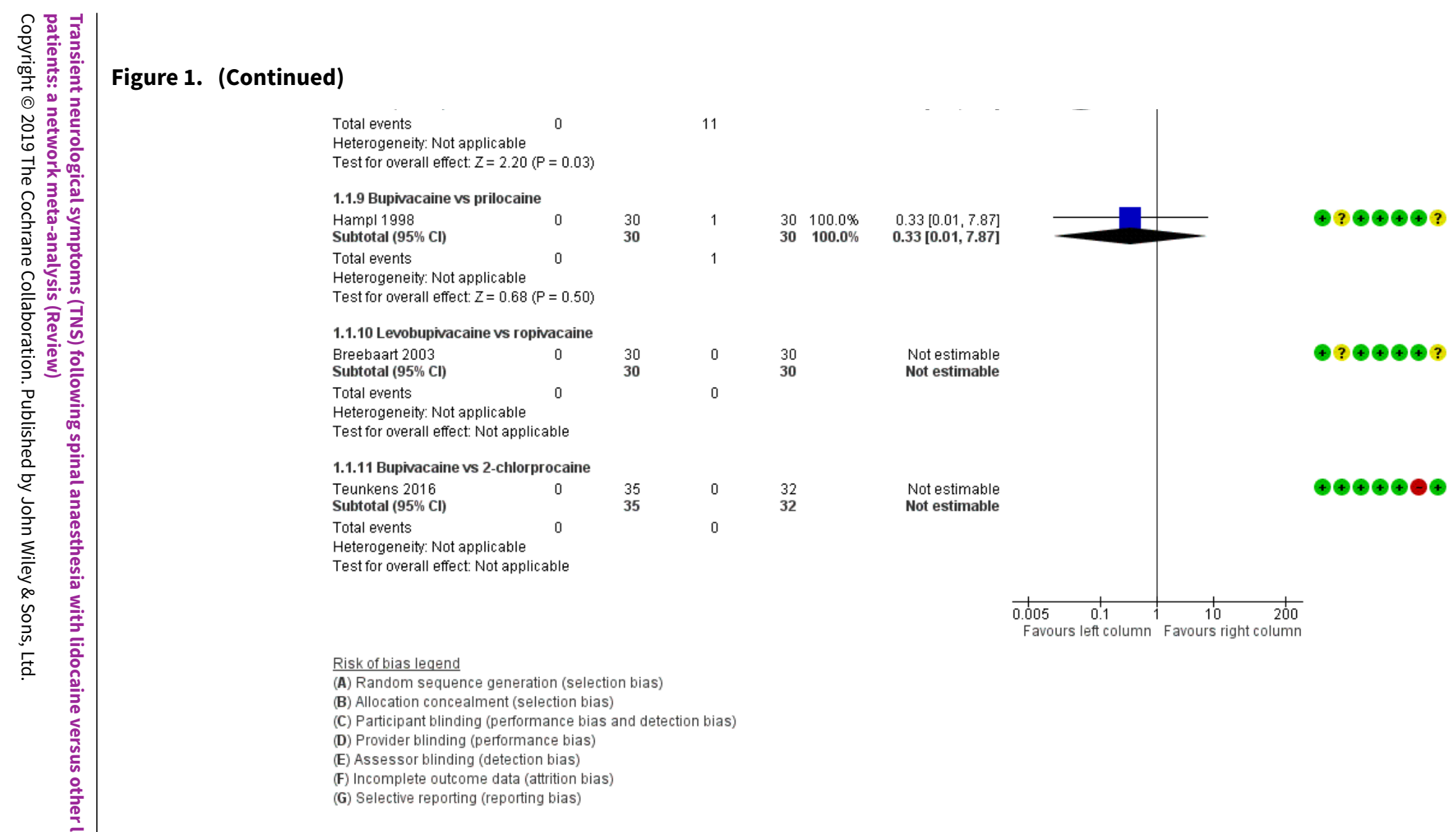


Figure 2. Network meta-analysis plot of interactions among included studies displayed for a random-effects, risk ratio model, regarding the risk of transient neurological symptoms following spinal anaesthesia with lidocaine versus other local anaesthetics in adults undergoing surgery. Each node represents an individual local anaesthetic. The node size is proportional to the number of studies.

The node colours are determined by the individual study 'Risk of bias' assessment (green: no concerns; yellow: some concerns; red: major concerns). The width of the edges is proportional to the inverse variance of the effect size. The edge colours reflect the average risk of bias. bupi: bupivacaine; chloro: 2-chloroprocaine; levo: levobupivacaine; lido: lidocaine; mepi: mepivacaine; prilo: prilocaine; pro: procaine; ropi: ropivacaine.

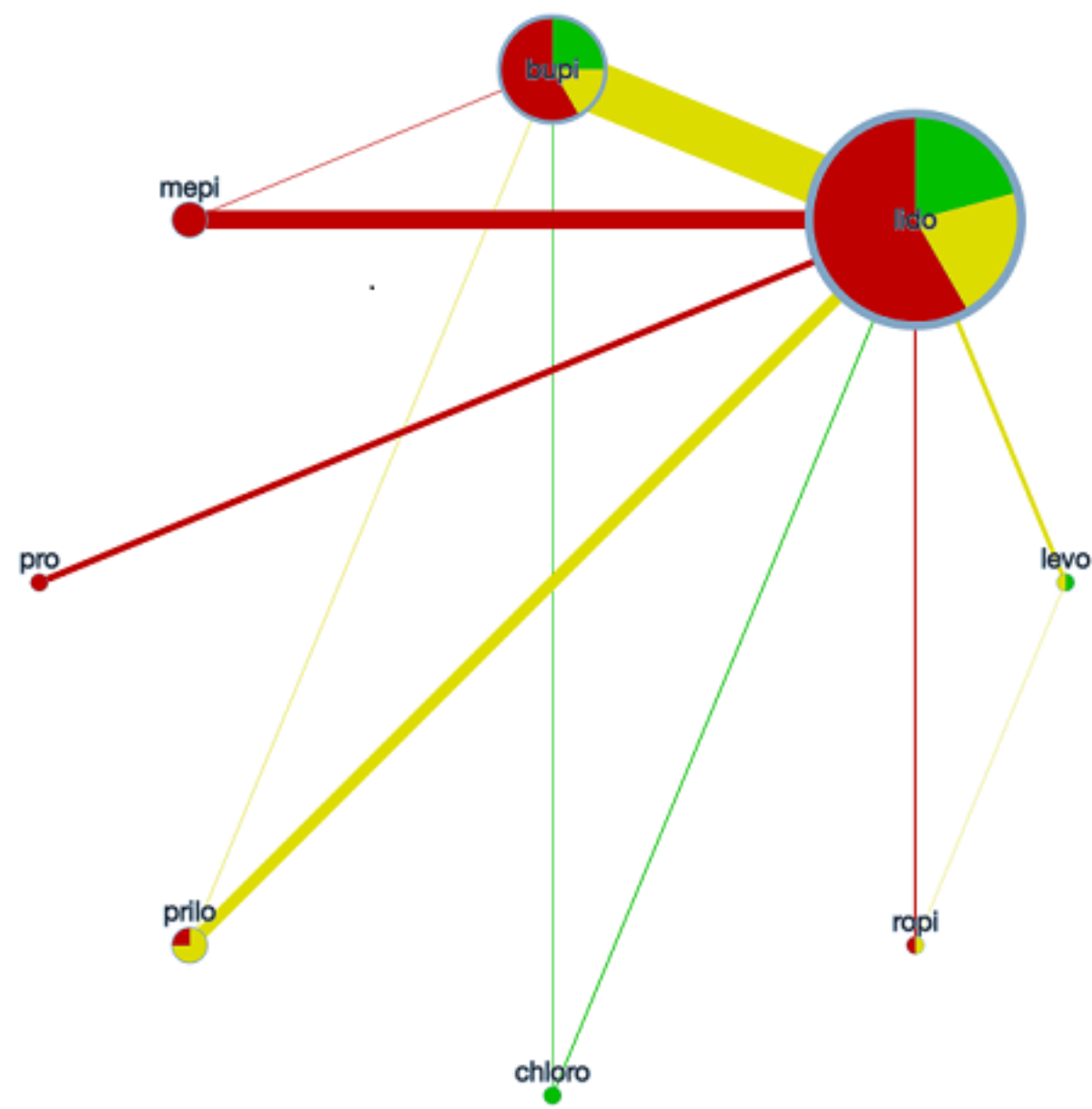




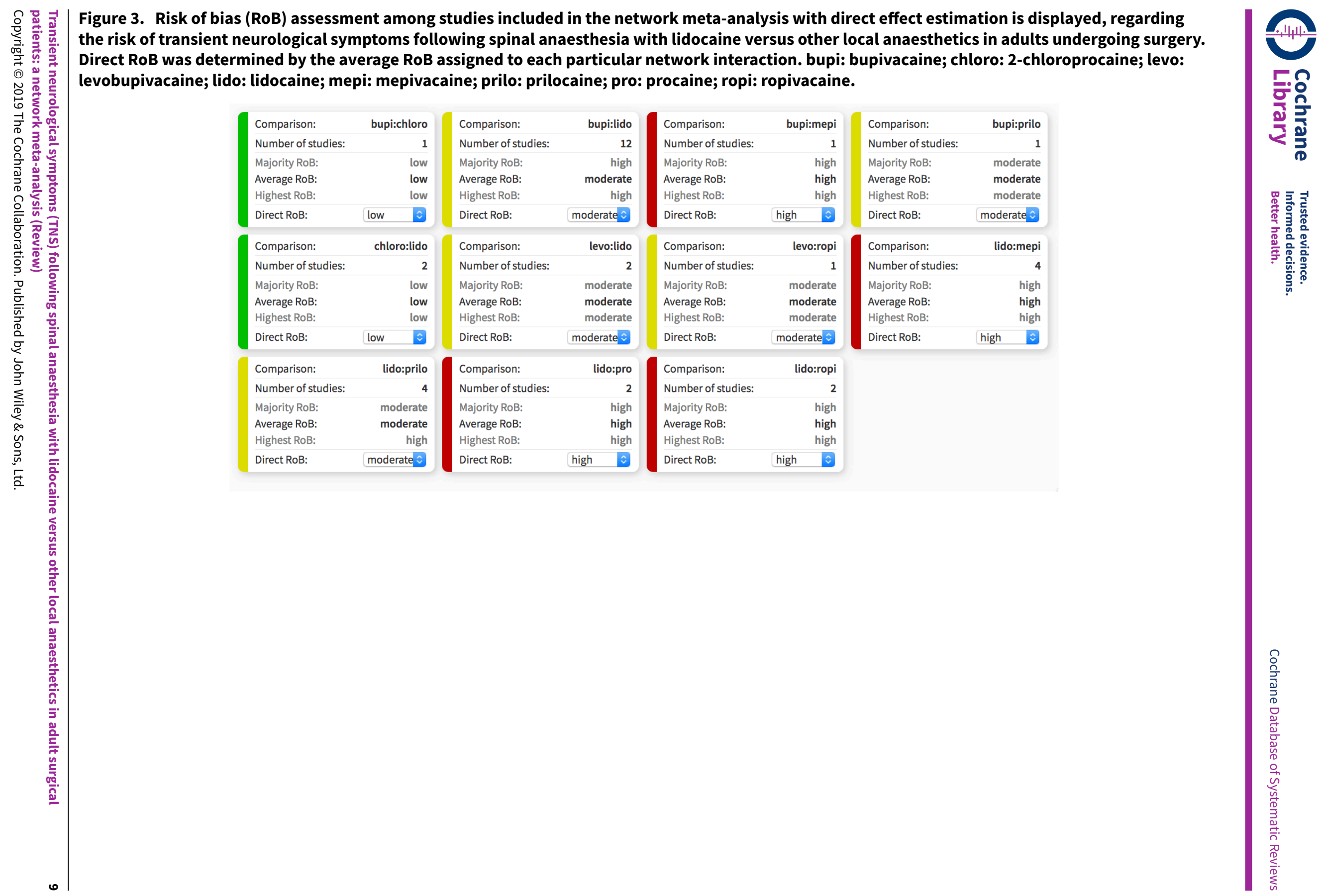




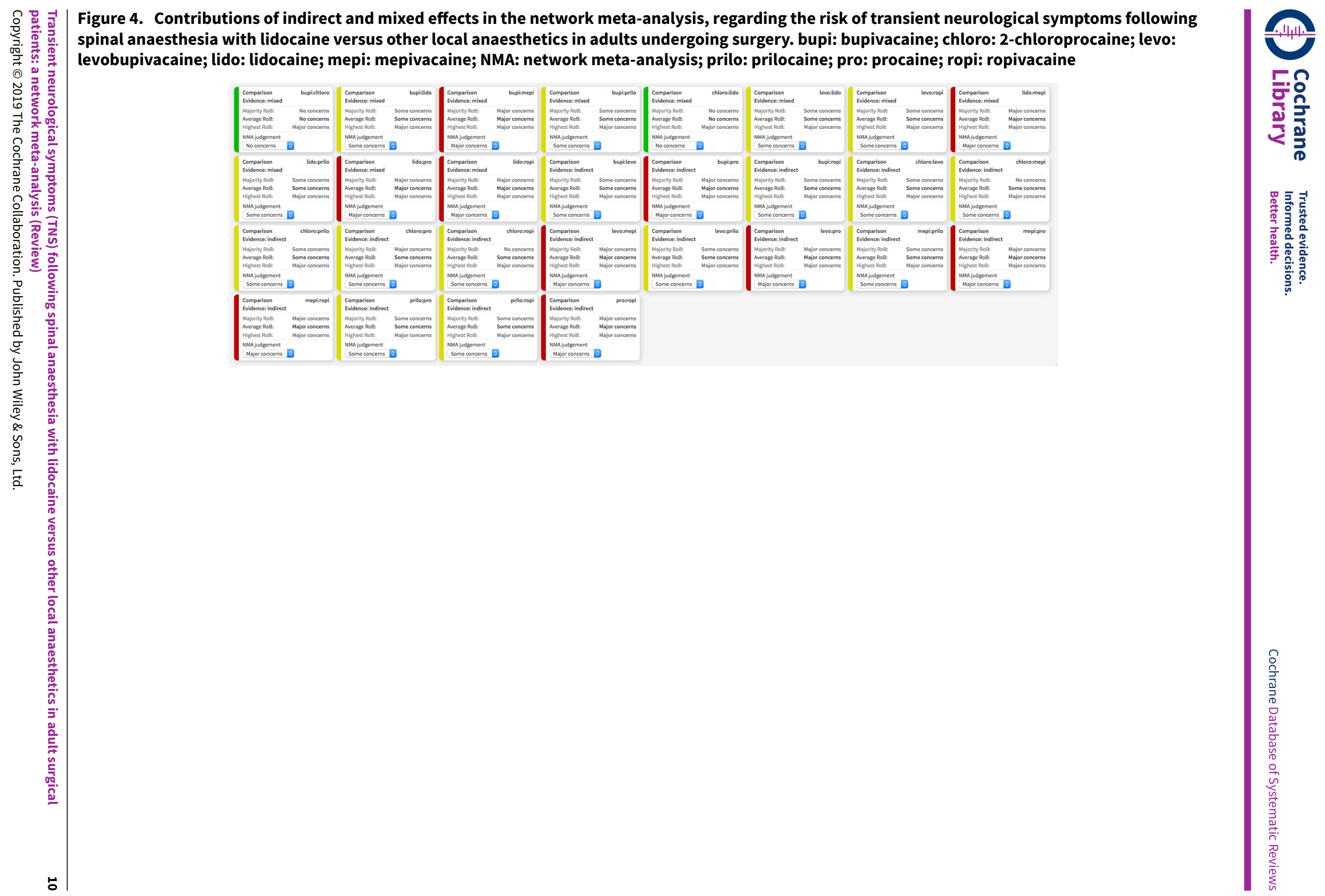




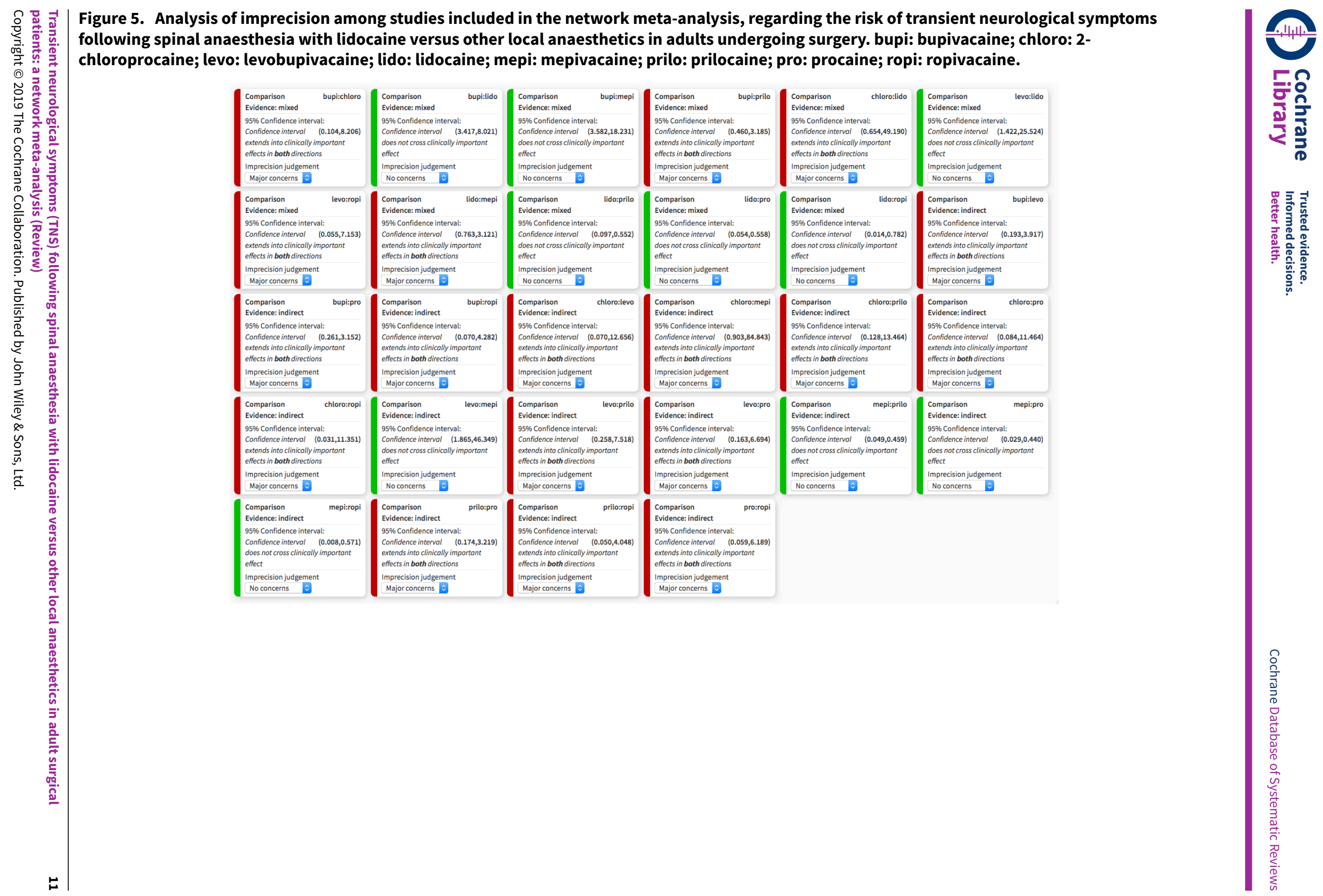




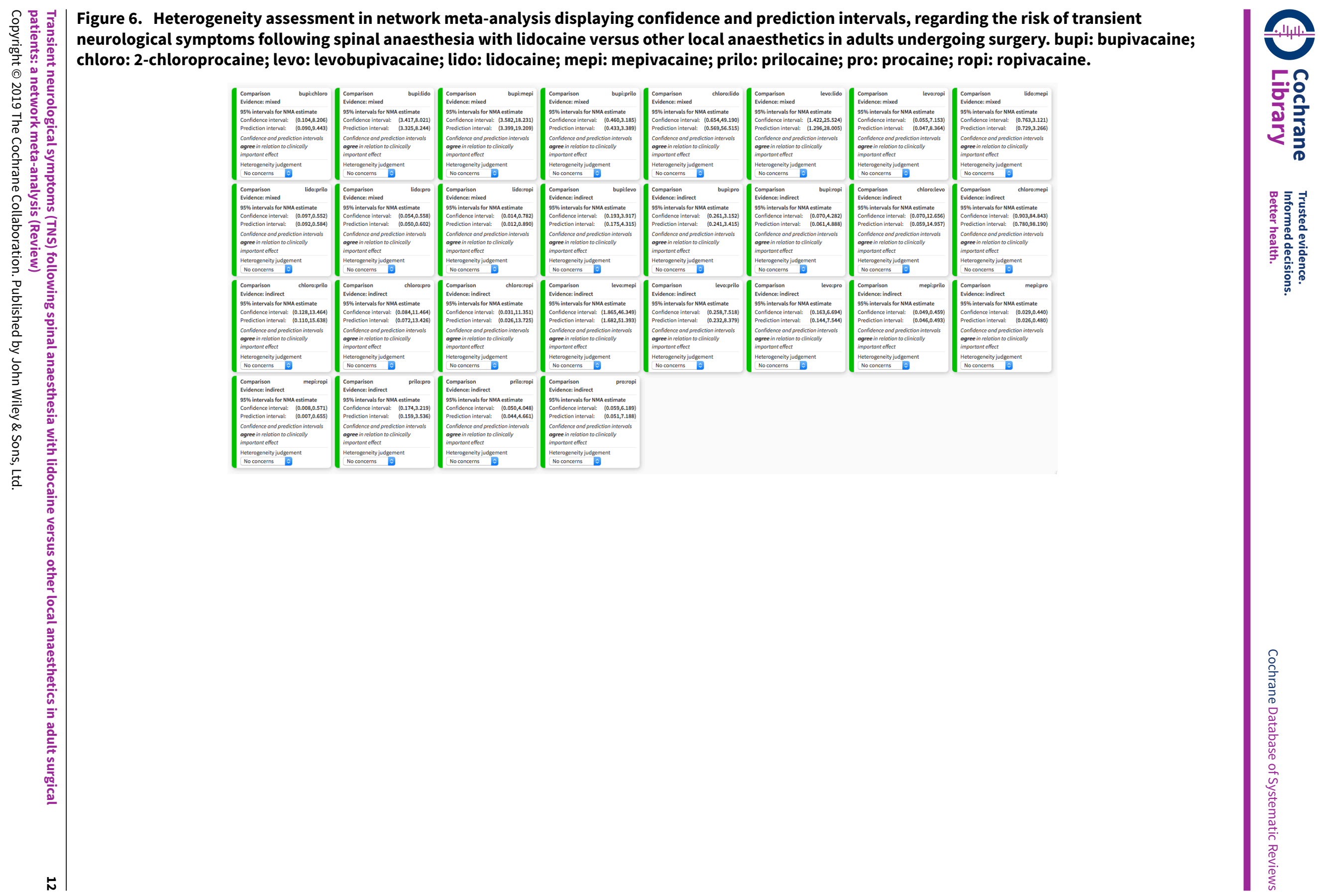


Figure 7. Summary of risk of bias assigned to studies included in the network meta-analysis across six domains: study limitations, imprecision, heterogeneity, incoherence, indirectness, publication bias, regarding the risk of transient neurological symptoms following spinal anaesthesia with lidocaine versus other local anaesthetics in adults undergoing surgery. Output was created with CINeMA software. bupi: bupivacaine; chloro: 2 chloroprocaine; levo: levobupivacaine; lido: lidocaine; mepi: mepivacaine; prilo: prilocaine; pro: procaine; ropi: ropivacaine.

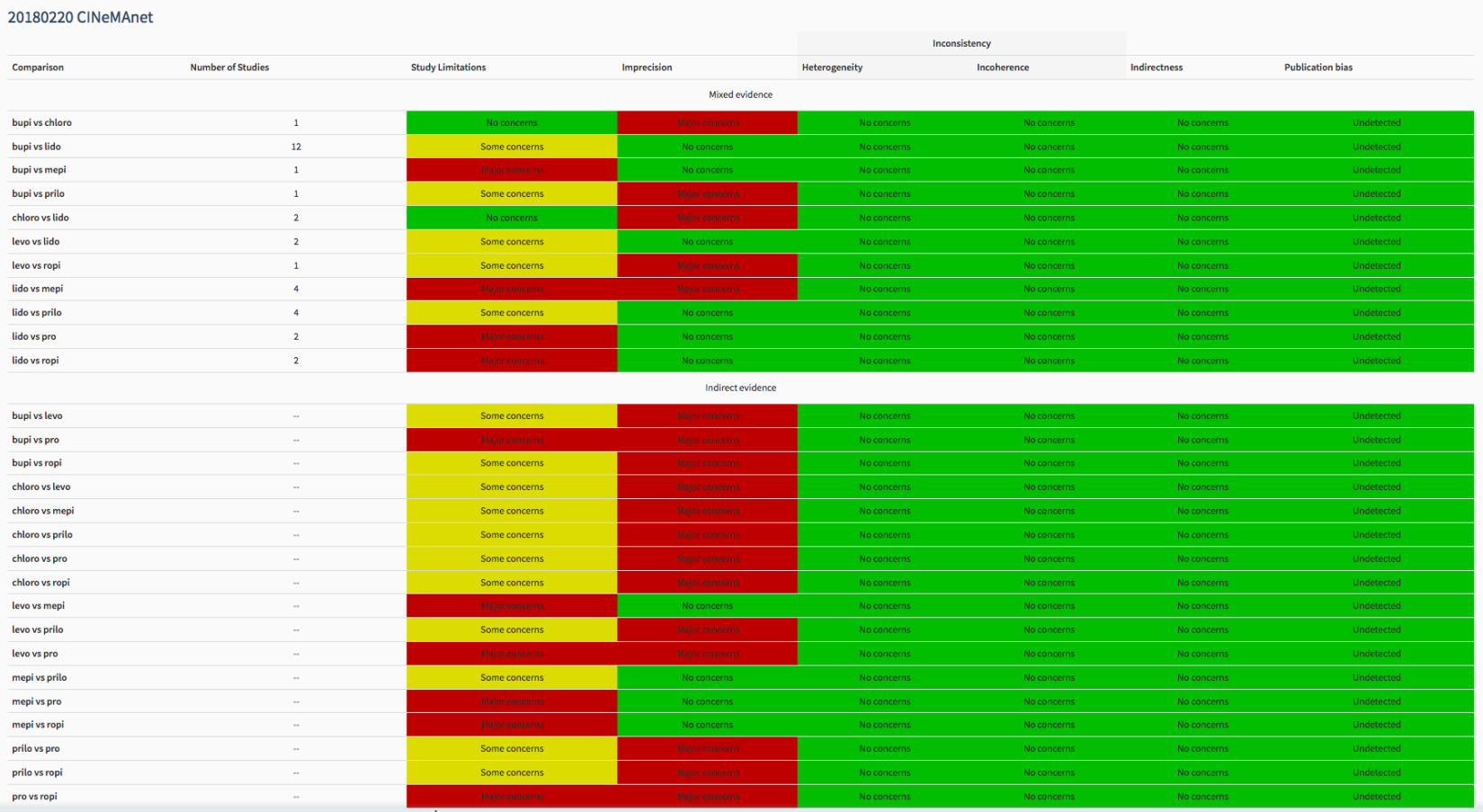




\section{B A C K G R O U N D}

\section{Description of the condition}

August Bier performed the first spinal anaesthesia in 1898 using cocaine, which was the first known local anaesthetic (Bier 1899). Cocaine was soon replaced by another less toxic local anaesthetic, amylocaine. Other local anaesthetics were gradually introduced: procaine, 2-chloroprocaine, dibucaine, lidocaine, tetracaine, mepivacaine, prilocaine, bupivacaine, and finally ropivacaine and levobupivacaine. Lidocaine, procaine, tetracaine, mepivacaine, dibucaine, and bupivacaine are still used for spinal anaesthesia (Axelrod 1998; Hiller 1997; Holmdahl 1998; IselinChaves 1996; Masuda 1998; Tagariello 1998). Spinal anaesthesia allows patients to avoid the undesirable effects of general anaesthetic drugs (Doleman 2018; Miller 2018), and may reduce the likelihood of patients having long-term pain after surgery (Weinstein 2018). However, spinal anaesthesia does have problems, including postdural puncture headache (Aravelo-Rodriguez 2017).

The increase in day-case surgery has generated a need for a local anaesthetic with a quick onset and short duration of action that allows for a speedy recovery and early discharge. So far, this profile is fulfilled only by lidocaine (Liu 1998).

Intrathecally (spinally) administered local anaesthetics cause reversible blockade of nerve impulse conduction in the affected nerve roots. Experiments on animals have shown that all tested local anaesthetics have potentially neurotoxic effects that are dependent on the dosage used and the duration of exposure ( $L$ 1985). All local anaesthetics can cause permanent nerve damage when administered in a high concentration or when applied over a long period of time.

However, retrospective and prospective surveys and databases dealing with postoperative outcomes have shown that serious and permanent neurological complications after spinal anaesthesia are rare events (Corbey 1998; Dahlgren 1995; Freedman 1998; Noble 1971; Phillips 1969; Renck 1995; Tarkkila 1991; Vandam 1955). Reported cases of such permanent neurological deficits involve all known local anaesthetics (Auroy 1997; Green 1961; Kane 1981; Sumi 1996; Vandam 1960). 2-Chloroprocaine is an example of a local anaesthetic that has been used for spinal anaesthesia since 1952 (Foldes 1952), especially for obstetric epidural anaesthesia because of its rapid onset of action, quick metabolism, and low toxicity (Winnie 2001). In the early 1980s reports about permanent neurological deficits in eight people who inadvertently received high doses of 2-chloroprocaine intrathecally were published (Moore 1982; Reisner 1980). Although these sequelae were probably due to the combination of low $\mathrm{pH}$ and the presence of the antioxidant bisulfite, the use of 2-chloroprocaine was then abandoned.

From the beginning of 1990, a number of cases were published reporting cauda equina syndrome that was related to the introduction of a microcatheter technique for continuous spinal anaesthesia with hyperbaric 5\% lidocaine (the drug of choice) (Rigler 1991; Schell 1991).

In 1993, a new adverse effect, transient neurological toxicity, was described in people recovering from single injection spinal anaesthesia with lidocaine (Schneider 1993). In the following years, new names for this condition appeared in the literature including transient radicular irritation (TRI) (Hampl 1995a) and transient neurological symptoms (TNS) (Hampl 1998).

The symptoms of TNS can appear in a few hours or within up to 24 hours; that is, well after full recovery (return of sensory and motor function) has been made from uneventful spinal anaesthesia. These symptoms consist of pain originating in the gluteal region and radiating to both lower extremities, in the absence of abnormal neurological examination or imaging (Gerancher 1997; Pollock 2000; Tarkkila 1995).

Lower back pain is different from pain experienced in the buttocks and lower extremities after recovery from spinal anaesthesia, which has been characterized as 'transient neurological symptoms'; this also shows no evidence of localized nerve damage. Studies with different concentrations and doses of lidocaine have shown that the risk of TNS was not dose- or concentration-dependent (Freedman 1998; Hampl 1996; Pollock 1999; Tong 2003). All forms of lidocaine have been associated with TNS: hyperbaric (Tong 2003); isobaric (Hampl 1996); and when diluted with cerebrospinal fluid (Pollock 1999). The cause of this painful condition is still unknown and none of the speculations on its origin have been substantiated. The term 'transient neurological symptoms' implies neurological pathology. Failing identification of the pathogenesis of TNS, there should be consideration given to choosing a neutral descriptive term which does not imply particular causation.

\section{Description of the intervention}

Spinal anaesthesia consists of using a fine needle to locate the fluid-filled subarachnoid space around the spinal cord and to inject local anaesthetics before surgery. In some circumstances, spinal anaesthesia is a valuable alternative to general anaesthesia. For short procedures and procedures conducted in ambulatory settings, a rapid, short-acting anaesthesia may be beneficial. The chosen medication and dose can affect the quality, duration and potential adverse effects of spinal anaesthesia. Consequently, all these factors are important when choosing a specific technique.

Lidocaine is an effective agent for inducing spinal anaesthesia but also known to be associated with TNS. There are many alternative agents that may be associated with a lower incidence of this adverse event.

\section{How the intervention might work}

TNS has been interpreted as a sign of possible neurotoxicity of local anaesthetics (Casati 1998; Douglas 1995; Hiller 1997; Lynch 1997). However, as the pathogenesis of TNS remains unknown, potential explanations as to why lidocaine may be associated with a higher incidence of TNS than other local anaesthetics remain speculative.

\section{Why it is important to do this review}

Previous versions of this review have suggested that lidocaine is more likely to cause TNS than many alternative agents. In this update, we sought further data published since 2009 to confirm or modify our previous findings. We also added a network metaanalysis (NMA), which allows us to perform direct and indirect comparisons between all types of interventions, which may help clarify which specific local anaesthetics present the lower risk of TNS, by ranking these in terms of risk of TNS. 


\section{O B JECTIVES}

To determine the frequency of TNS after spinal anaesthesia with lidocaine and compare it with other types of local anaesthetics by performing a meta-analysis for all pair-wise comparisons, and conducting network meta-analysis (NMA) to rank interventions.

\section{ME T HO D S}

\section{Criteria for considering studies for this review}

\section{Types of studies}

We considered randomized controlled trials (RCTs), and quasiRCTs (i.e. in which participants were allocated to treatment or control groups in a non-random way such as alternate allocation, allocation by day of the week, odd-even study numbers), that were published in full, regardless of blinding.

The included studies could have included any type of surgery, any spinal needle size, and any patient positioning after administration of the intrathecal local anaesthetics.

\section{Types of participants}

We included all adults who received spinal anaesthesia. The followup of these participants was at least 24 hours and longer for participants who developed TNS. We chose this time interval because the symptoms of TNS appear within 24 hours after spinal anaesthesia (Aouad 2001).

\section{Types of interventions}

The included studies had to have two or more arms that used a distinct local anaesthetic (irrespective of the dose, concentration, and baricity of the solution) for spinal anaesthesia in preparation for surgery.

We excluded studies dealing with meperidine as a sole intrathecal agent, or combinations of local anaesthetics and opioids. We also excluded studies in which spinal anaesthesia was combined with epidural analgesia to restrict our analysis to intrathecal injection of pure local anaesthetics. This approach was meant to support the clinical and methodological comparability across all direct comparisons in the whole network.

\section{Types of outcome measures}

\section{Primary outcomes}

- Presence of any transient neurological symptoms (TNS), defined as pain originating in the gluteal region and radiating to both lower extremities and appearing within up to 24 hours after full recovery (return of sensory and motor function) has been made from uneventful and non-complicated spinal anaesthesia.

\section{Secondary outcomes}

- Postoperative neurological symptoms (sensory deficits including numbness and weakness) which lasted longer than 24 hours after onset of spinal anaesthesia and which did not exist before the anaesthetic.

- Postoperative neurological signs (motor deficits including weakness in a radicular distribution) which lasted longer than 24 hours after onset of spinal anaesthesia and which did not exist before the anaesthetic.

\section{Search methods for identification of studies}

\section{Electronic searches}

We searched for studies with systematic and sensitive search strategies as outlined in Chapter 6.4 of the Cochrane Handbook of Systematic Reviews of Interventions (Higgins 2011). We applied no restrictions to language or publication status.

We searched the following databases:

- Cochrane Central Register of Controlled Trials Register (CENTRAL; the Cochrane Library, 2018, Issue 9);

- MEDLINE ALL, OvidSP (1966 to 25 November 2018);

- Elsevier Embase (1980 to 25 November 2018);

- LILACS (25 November 2018).

We developed a subject-specific search strategy in MEDLINE and modified it appropriately for the other databases. This search strategy allowed retrieval of trials of any two local anaesthetics for spinal anaesthesia. Where appropriate, we used the search strategy recommended in the Cochrane Handbook for Systematic Reviews of Interventions for identifying RCTs (Lefebvre 2011). See Appendix 1; Appendix 2; Appendix 3; Appendix 4 for the search strategies.

\section{Searching other resources}

We searched ClinicalTrials.gov Registry of Clinical Trials by National Institutes of Health $(\mathrm{NIH})$ and the World Health Organization International Clinical Trials Registry Platform (www.who.int/ictrp/ en/) on 25 November 2018.

We scanned the reference lists and citations of relevant studies and reviews for further references to trials. When necessary, we contacted trial authors for additional information.

\section{Data collection and analysis}

\section{Selection of studies}

Four review authors (PF, EMT, NLP, and JAB) assessed the search results, and excluded irrelevant reports. They independently examined studies for eligibility without blinding of study authors, institutions, journal of publication, and results. We retrieved and read the full text of potentially relevant studies and decided which studies to include. We listed excluded studies in the Characteristics of excluded studies table. We resolved disagreements by discussion.

\section{Data extraction and management}

Four review authors (PF, EMT, NLP, and JAB) recorded and documented the following information from the included studies in the Characteristics of included studies table: experimental design characteristics; number of participants; demographics; country of investigation; treatment groups; concentration and volume of the local anaesthetic used; duration of the follow-up period; and spinal needle size and shape. We regarded TNS, sensory deficits, or motor deficits as three separate outcomes.

We independently extracted data using a standard form and agreed on the data before entry into Review Manager 5 (Review Manager 2014). We resolved any discrepancies by discussion and internal correspondence. The data collection form very closely resembled the form used in the previous versions, already assessed for usability. 


\section{Assessment of risk of bias in included studies}

Four review authors (PF, EMT, NLP, and JAB) independently and without blinding assessed the risk of bias. We resolved disagreements by discussion and internal correspondence.

We assessed the risk of bias for the domains: random sequence generation, allocation concealment, blinding of participants, blinding of personnel, blinding of assessors, incomplete outcome data, and selective reporting. Study level judgements are presented in the 'Risk of bias' table of the Characteristics of included studies table (Appendix 6), and were made as described in the Cochrane Handbook for Systematic Reviews of Interventions, Section 8.5 (Higgins 2011).

We summarized the overall risk of bias for each study depending on the judgements for the domains:

- low risk of bias: low risk of bias for all key domains;

- unclear risk of bias: unclear risk of bias for one or more key domains;

- high risk of bias: high risk bias for one or more key domains.

\section{Measures of treatment effect}

We used the risk ratio (RR) as the effect estimate. We estimated the pair-wise relative treatment effects of the competing interventions in each included study using the RR with $95 \%$ confidence intervals $(95 \% \mathrm{Cl})$.

\section{Unit of analysis issues}

We included multi-arm studies in the data set as a series of two-arm comparisons. In the pair-wise direct comparison meta-analyses, no overall summary statistic was estimated across all interventions. In the NMA, the standard error of each two-arm comparison within a multi-arm study was adjusted by a method proposed by Rücker and Schwarzer (Rücker 2012; Rücker 2014), that uses back-calculated standard errors in the weighted least squares estimator to reflect the within-study correlation.

We did not find nor include cluster randomized trials. As each participant received a single surgical procedure, there were no trials with a crossover design.

\section{Dealing with missing data}

For the trials where dropouts were reported but without mention of their outcomes, we contacted the authors and included the missing data, where possible, to reduce the number of excluded participants.

\section{Assessment of heterogeneity}

Clinical and methodological diversity always occur between different studies, making heterogeneity inevitable (Higgins 2011). We performed meta-analysis only in the case of low- to moderateclinical heterogeneity, defined as similar positioning for the procedure (lithotomy versus supine), and shape and size of the spinal needle. This heterogeneity or diversity reflects differences in potential effect modifiers such as patient mix or agent dose. We assessed statistical heterogeneity as outlined below.

\section{Measures and tests for pair-wise meta-analysis heterogeneity}

We assessed statistical heterogeneity by the $\mathrm{Q}$ test, the $\mathrm{I}^{2}$ statistic, and a comparison of the between-trial variance $\left(\operatorname{tau}^{2}\right)$ of the effect estimates for each pair-wise comparison. We used a $\mathrm{Chi}^{2}$ test to examine the $\mathrm{Q}$ statistic for evidence of heterogeneity. The $\mathrm{I}^{2}$ statistic was interpreted following the guidelines suggested by Higgins 2011:

- $0 \%$ to $40 \%$ might not be important;

- $30 \%$ to $60 \%$ may represent moderate heterogeneity;

- $50 \%$ to $90 \%$ may represent substantial heterogeneity;

- $75 \%$ to $100 \%$ represents considerable heterogeneity.

\section{Assessment of statistical inconsistency}

Inconsistency is the statistical manifestation of intransitivity and occurs when the direct and indirect estimates in a network of treatments do not agree. This is analogous to the distinction between clinical/methodological heterogeneity and statistical heterogeneity in the pair-wise meta-analysis (Cipriani 2013). Consistency within, and between, designs were assessed by decomposition of Cochran's $Q$ statistic. The consistency of direct and indirect treatment comparisons used back-calculation methods (Dias 2010), as implemented in the netsplit function. If necessary, we examined net heat plots (Krahn 2013).

\section{Assessment of transitivity across treatment comparisons}

The main assumption underlying indirect and mixed comparison is that there are no important differences between trials comparing different local anaesthetics other than the agents given. As an example, consider the comparison of three agents $A, B$, and $C$ with the effect sizes labelled $A B, A C$, and $B C$ in studies reporting $A$ versus $C$ and $B$ versus $C$. Under the assumption of transitivity, then $A B_{\text {indirect }}=A C_{\text {direct }}-B C_{\text {direct }}$.

We assessed the assumption of transitivity by comparing the distribution of potential effect modifiers across the different pairwise comparisons. Variation in the spinal dose of local anaesthetic among studies was considered acceptable for combining. We also considered varied surgical procedures and varied populations as suitable for combining.

We assumed that participants who fulfilled the inclusion criteria and received these interventions would have been equally eligible to be randomized to any local anaesthetic in a hypothetical joint RCT of all local anaesthetics (Chaimani 2017). We assumed that this met the requirement of transitivity for an NMA (Caldwell 2005; Salanti 2012).

\section{Assessment of reporting biases}

Reporting bias occurs when the dissemination of research findings is influenced by the nature and direction of results. We constructed and examined funnel plots for asymmetry to detect reporting biases. We performed statistical tests of funnel plot asymmetry as necessary.

\section{Data synthesis}

We followed guidance on NMA in the PRISMA extension (Hutton 2015), and documents developed by the Cochrane Comparing 
Multiple Interventions Methods Group (methods.cochrane.org/ cmi/about-us).

\section{Methods for direct treatment comparisons}

We conducted pair-wise meta-analyses for all comparisons of local anaesthetics. We assumed a random-effects model for all data syntheses. We used an inverse variance weighting for summary statistics and random-effects models as we expected methodological and clinical heterogeneity across the included studies resulting in varying effect sizes between studies of pair-wise comparisons. We reported summary statistics as point estimates with $95 \% \mathrm{Cls}$; and determined summary statistics to indicate a difference if $95 \% \mathrm{Cls}$ did not cross the line of identity. We used Review Manager 5, for data synthesis, statistical analysis, and creation of forest plots (Review Manager 2014).

\section{Methods for indirect and mixed comparisons}

We performed a random-effects NMA for the primary outcome of TNS using all included studies based on a graph theoretical approach (Rücker 2012), within a frequentist framework in the $R$ statistical platform (R 2018), using the package netmeta (Rücker 2016). Spinal anaesthesia with lidocaine was the reference group due to its known association with TNS (see: Description of the intervention). The geometry of the network was displayed using graph theory as implemented in the netgraph function of netmeta.

For display of specific treatments in the NMA, abbreviations were used: bupi: bupivacaine; chloro: 2-chloroprocaine; levo: levobupivacaine; lido: lidocaine; mepi: mepivacaine; prilo: prilocaine; pro: procaine, and ropi: ropivacaine. Nodes in the network structure represented individual local anaesthetics.

\section{Relative treatment ranking}

For the primary outcome of TNS, we ranked the competing treatments by $\mathrm{P}$ scores using the netrank function in netmeta. $\mathrm{P}$ scores allow ranking of treatments on a continuous 0 (worst) to 1 (better) scale and are derived from the $P$ values of all pair-wise comparisons. P scores are a frequentist analogue and numerically similar to the Bayesian Surface Under the Cumulative Ranking curve (SUCRA) values (Rücker 2015). The P score of treatment is the mean certainty that it is better than another treatment.

\section{Subgroup analysis and investigation of heterogeneity}

We were unable to perform the preplanned subgroup analyses included participant positioning (lithotomy versus supine), the shape and size of the spinal needle, and pregnancy because of the available amount of data.

\section{Sensitivity analysis}

We performed no sensitivity analyses. Regarding the missing data, assuming that these data were missing at random, we intended to analyze only the available data (i.e. ignoring the missing data); and to evaluate how sensitive results were to reasonable changes in the assumptions that were made.

\section{'Summary of findings' table and GRADE}

Methods for evaluating the quality of evidence of a NMA have been proposed by Puhan and colleagues (Puhan 2014), and Salanti and colleagues (Salanti 2014). The quality of the body of evidence is assessed by the domains of study limitations, indirectness, inconsistency (heterogeneity, incoherence), imprecision, and risk of publication bias.

For the evaluation of the quality of evidence derived from NMA, we used a web app online tool denoted Confidence in Network Meta-Analysis (version 0.6) (CINeMA 2018; CINeMA). It implements proposals by Salanti 2014 and uses the netmeta 2013 package for calculations. According to the GRADE for NMA guidelines, we assessed the risk of bias for each treatment comparison separately.

\section{RES U L T S}

\section{Description of studies}

\section{Results of the search}

The results of the search are outlined in Figure 8. 
Figure 8. Study selection flow diagram corresponding to the last search update, up to November 2018.

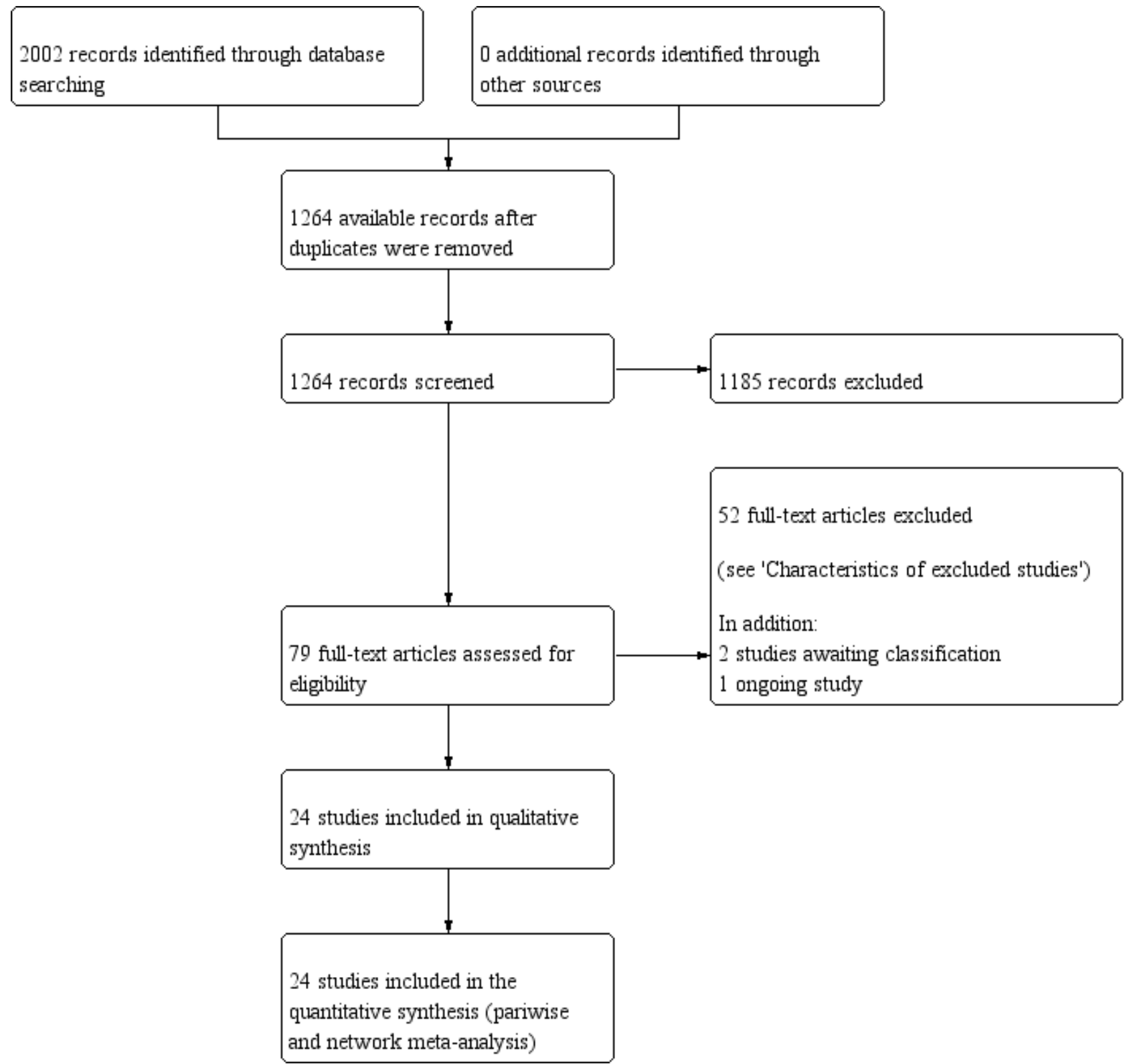

The electronic database searches yielded 2002 citations. No additional records were found through other sources. After we removed duplicates, 1264 unique citations remained. We excluded 1185 citations on the basis of title and abstract.

We considered 76 full-text studies dealing with neurological complications and spinal anaesthesia with lidocaine. Of these, we excluded 52 studies for the reasons cited in the Characteristics of excluded studies table. There are two studies awaiting classification (see Characteristics of studies awaiting classification table), and one ongoing study (see Characteristics of ongoing studies table).

\section{Included studies}

See Characteristics of included studies table.

\section{Interventions}

We included 24 RCTs in the final analysis and respective NMA. The characteristics of these studies can be found in Table 1. One RCT was identified in the first review update (Casati 2007). Eight were identified in the current update (Ali Hassan 2015; Etezadi 2013; Pradhan 2010; Teunkens 2016; de Santiago 2010; Imbelloni 2008a; Imbelloni 2008b; Yazicioglu 2013). Twenty-one studies satisfied the inclusion criterion of comparing lidocaine as one treatment arm with different local anaesthetics in the second treatment arm. The local anaesthetic in this second arm consisted of bupivacaine in 12 studies (Ali Hassan 2015; Aouad 2001; Etezadi 2013; Hampl 1995a; Hampl 1998; Keld 2000; Philip 2001; Pollock 1996; Pradhan 2010; Salmela 1998; de Santiago 2010; Yazicioglu 2013); prilocaine in four studies (de Weert 2000; Hampl 1998; Martinez-Bourio 1998; Salmela 1998); mepivacaine in three studies (Liguori 1998; Salazar 2001; Salmela 1998); procaine in two studies (Hodgson 2000; Le Truong

Transient neurological symptoms (TNS) following spinal anaesthesia with lidocaine versus other local anaesthetics in adult surgical 
2001); ropivacaine and levobupivacaine in one study (Breebaart 2003), and 2-chloroprocaine in one study (Casati 2007). There were five studies with more than two treatment arms (Breebaart 2003; Hampl 1998; Pollock 1996; Salmela 1998; Teunkens 2016). Hampl 1998 used two concentrations of lidocaine and, as the outcome of interest is not dependent on the concentration (Freedman 1998; Hampl 1996; Pollock 1999; Tong 2003), we pooled the results of the two groups. Four studies had three treatment groups: two alternative local anaesthetics in addition to lidocaine (Breebaart 2003; Pollock 1996; Salmela 1998; Teunkens 2016). In one study, a control group with participants receiving general anaesthesia was not taken into consideration for statistical analysis (Hampl 1995a).

\section{Countries and other differences between the studies}

Four studies were conducted in the USA; three each in Scandinavia and Spain; two each in Brazil, Switzerland, and Belgium; and one each in Canada, Egypt, Iran, Italy, Lebanon, Nepal, the Netherlands, and Turkey. Three studies differed from the rest because the participants were pregnant women (Aouad 2001; Philip 2001; Pradhan 2010). All studies investigated the frequency of TNS; two reported no events in any of the studied arms (Aouad 2001; Teunkens 2016). Seven studies had no events in the 'other treatment' arm (Breebaart 2003; Casati 2007; de Weert 2000; Hampl 1995a; Le Truong 2001; Liguori 1998; Pollock 1996). Six RCTs included subgroups of participants exposed to lithotomy or the supine position and pencil point or sharp spinal needles (Etezadi 2013; Le Truong 2001; Martinez-Bourio 1998; Pollock 1996; Salmela 1998; Østgaard 2000). In the remaining RCTs, most participants underwent surgery in the supine position, and each study used only one type of spinal needle (sharp or pencil point, $27 \mathrm{G}$ or larger).

\section{Outcomes}

All included studies investigated the risk of TNS, and no study was set up to investigate sensory and motor deficits after spinal anaesthesia. The follow-up period was at least 24 hours, and all participants with TNS were followed longer than 24 hours, until recovery. The interviewer who assessed the occurrence of TNS was blinded as to which treatment group the participant belonged to in all but one RCT (de Weert 2000; in which blinding was unclear). In nine of the studies the interview was done by telephone (Breebaart 2003; Casati 2007; Hodgson 2000; Keld 2000; Liguori 1998; MartinezBourio 1998; Pollock 1996; Imbelloni 2008a; Imbelloni 2008b), and in the remaining studies by direct contact with the participant, except for Le Truong 2001 (where it was unclear).

\section{Excluded studies}

We excluded 52 studies after full-text review. The reasons for exclusion included: a combination of local anaesthetics with other medications; no relevant comparison; and absence of lidocaine in any compared group or presence of lidocaine in all the groups.

Additional details are provided for 31 of these 52 studies. See Characteristics of excluded studies table for further details.

\section{Studies awaiting classification}

There are two studies awaiting classification (Frisch 2018; Gozdemir 2016); see: Characteristics of studies awaiting classification table.

\section{Ongoing studies}

We identified one ongoing study (NCT02818894); see: Characteristics of ongoing studies table. This ongoing study will compare lidocaine to bupivacaine spinal anaesthesia in people having a total hip arthroplasty. The objective of this study is to compare the effect of two spinal anaesthesia treatments on TNS.

\section{Risk of bias in included studies}

See the 'Risk of bias' graph (Figure 9), 'Risk of bias' summary Figure 10 , and 'Risk of bias' tables in the Characteristics of included studies table for more details.

\section{Figure 9. Risk of bias graph: review authors' judgements about each risk of bias item presented as percentages across all included studies.}

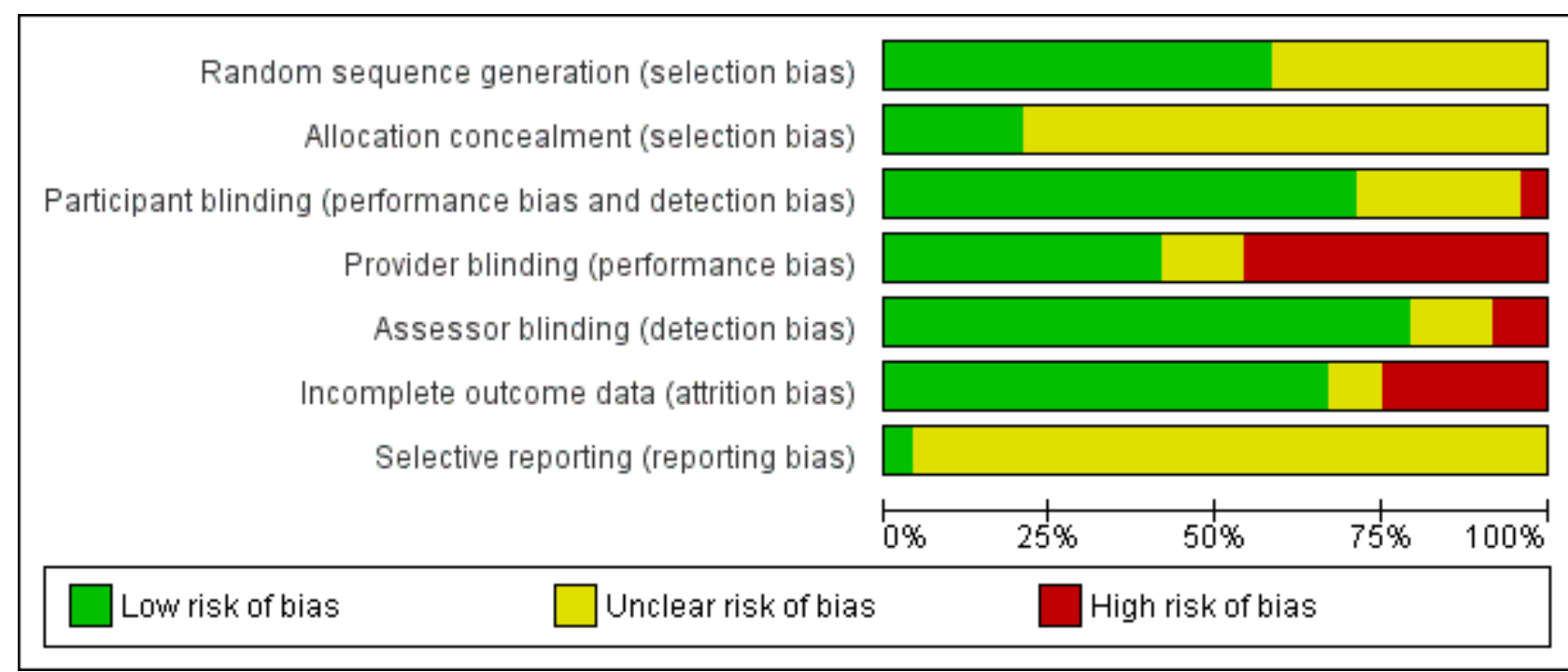

Transient neurological symptoms (TNS) following spinal anaesthesia with lidocaine versus other local anaesthetics in adult surgical 
Figure 10. Risk of bias summary: review authors' judgements about each risk of bias item for each included study.

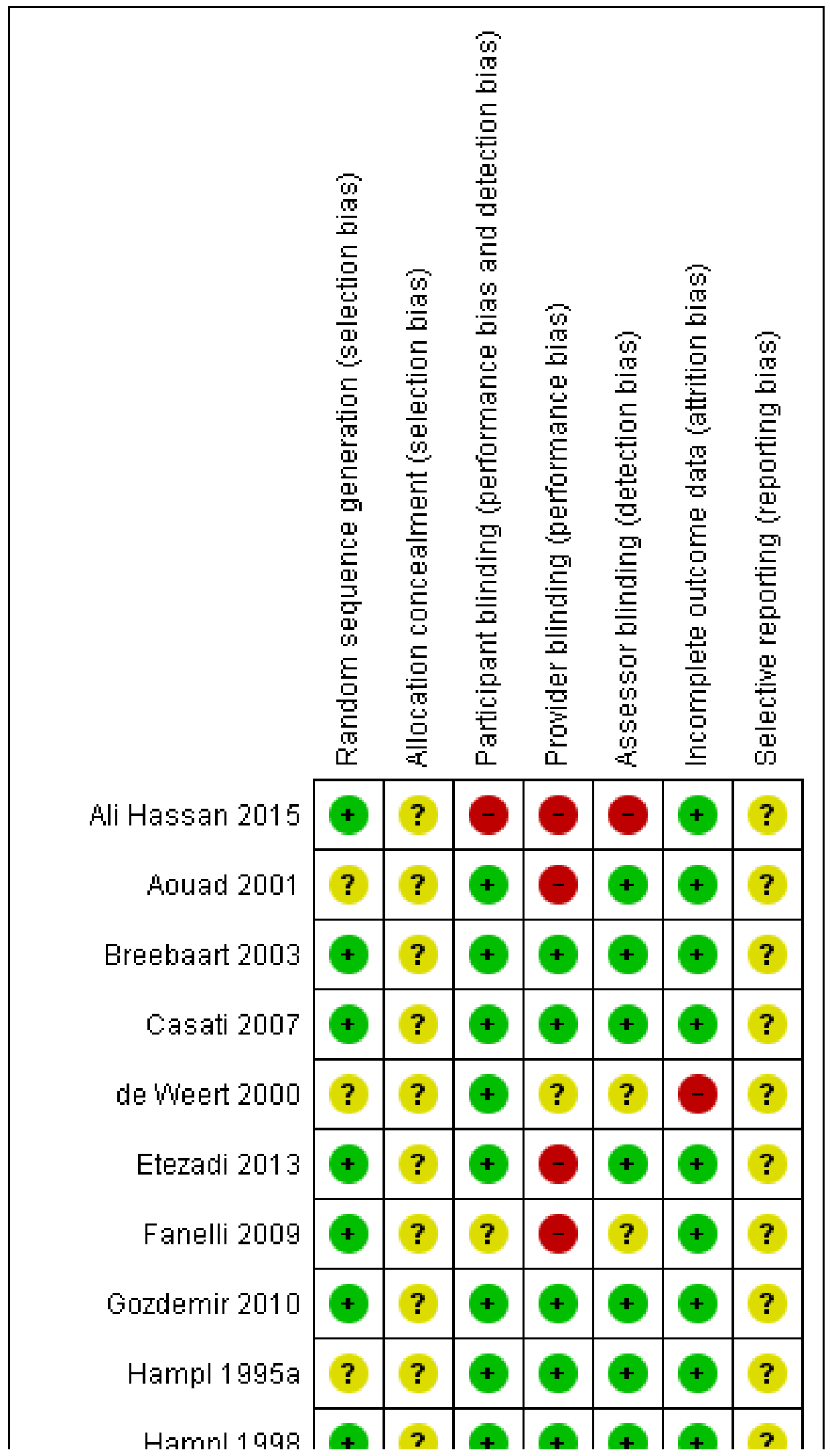

Transient neurological symptoms (TNS) following spinal anaesthesia with lidocaine versus other local anaesthetics in adult surgical 
Figure 10. (Continued)

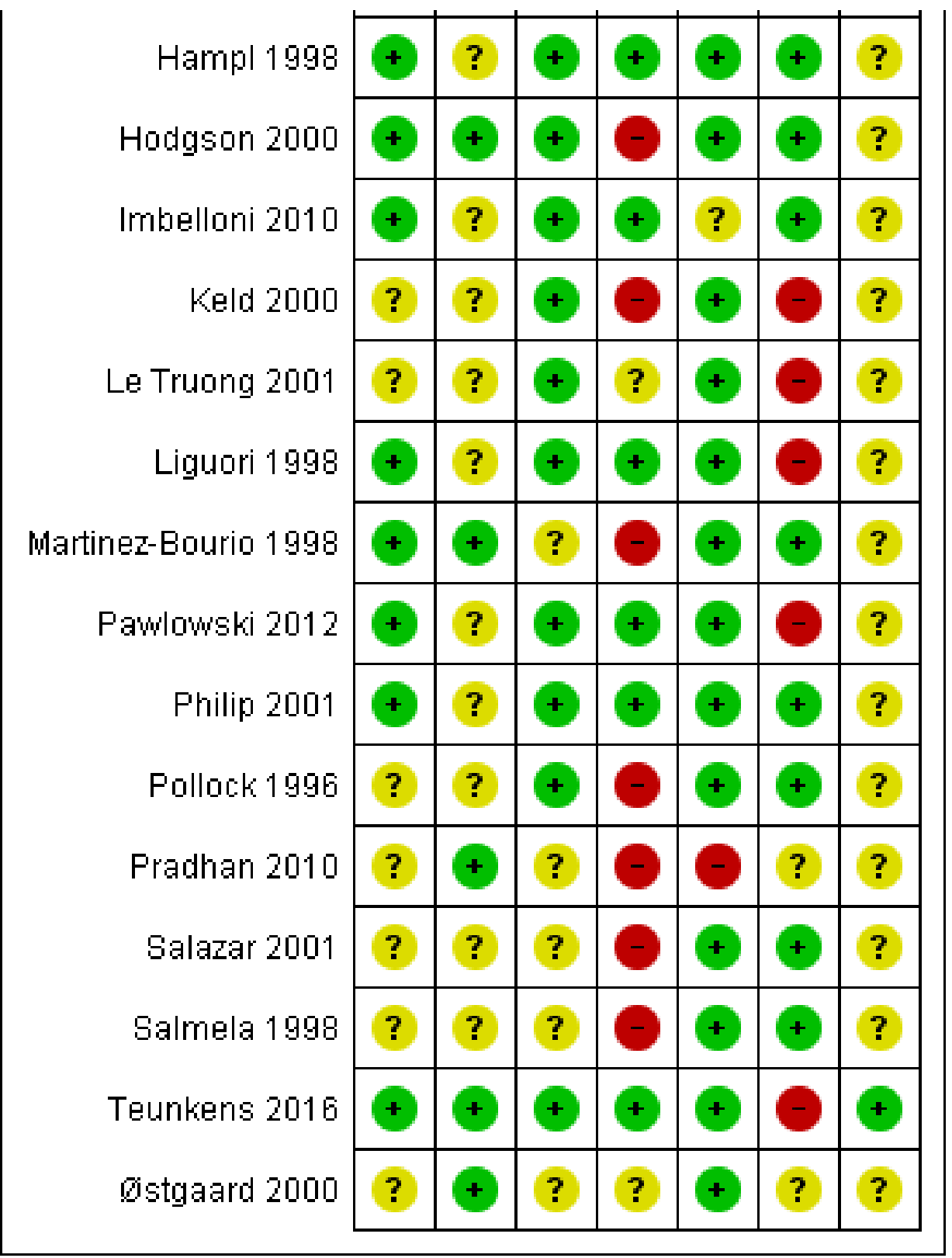

The overall quality of the included RCTs based on risk of bias assessment ranged from unclear to high. All of the studies were randomized; however, 10 studies did not specify the method of randomization (referring to a random number table, computergenerated random number sequence, tossing coin, etc.) and were thus considered to have an unclear risk of bias with regard to randomization of participants (Aouad 2001; de Weert 2000; Hampl 1995a; Keld 2000; Le Truong 2001; Pollock 1996; Pradhan 2010; Salazar 2001; Salmela 1998; Østgaard 2000).

\section{Allocation}

None of the included studies showed high risk of bias. Five studies specified adequate concealment of allocation (Hodgson 2000; Martinez-Bourio 1998; Pradhan 2010; Teunkens 2016; Østgaard 2000). Nine authors described allocation concealment consisting of participant assignment being determined by sealed envelopes or coded envelopes (Aouad 2001; Casati 2007; de Weert 2000; Etezadi 2013; Fanelli 2009; Gozdemir 2010; Imbelloni 2010; Pollock 1996; Salmela 1998). However, because these descriptions did not specify "sequentially numbered, sealed, opaque envelopes," the risk of bias was unclear. Ten studies did not describe allocation concealment, presenting an unclear risk of bias (Ali Hassan 2015; Breebaart 2003; Hampl 1995a; Hampl 1998; Keld 2000; Le Truong 2001; Liguori 1998; Pawlowski 2012; Philip 2001; Salazar 2001).

\section{Blinding}

Nine studies had a complete blinding procedure (participant, provider, and assessor) (Breebaart 2003; Casati 2007; Gozdemir 2010; Hampl 1995a; Hampl 1998; Liguori 1998; Pawlowski 2012; Philip 2001; Teunkens 2016). Six studies had blinding of participant and assessor (Aouad 2001; Etezadi 2013; Hodgson 2000; Keld 2000; Le Truong 2001; Pollock 1996). Blinding was unclear, inadequate, or

Transient neurological symptoms (TNS) following spinal anaesthesia with lidocaine versus other local anaesthetics in adult surgical 21 patients: a network meta-analysis (Review)

Copyright (c) 2019 The Cochrane Collaboration. Published by John Wiley \& Sons, Ltd. 
not performed in eight trials (Ali Hassan 2015; de Weert 2000; Fanelli 2009; Martinez-Bourio 1998; Pradhan 2010; Salazar 2001; Østgaard 2000; Salmela 1996).

\section{Incomplete outcome data}

Three studies reported outcomes for dropouts (Martinez-Bourio 1998; Philip 2001; Pollock 1996). Six RCTs with dropouts failed to report outcomes (de Weert 2000: one participant; Keld 2000: one participant; Le Truong 2001: six participants; Liguori 1998: three participants; Pawlowski 2012: seven participants; Teunkens 2016: seven participants). For two studies dropout information was unclear (Pradhan 2010; Østgaard 2000); see the Characteristics of included studies table for further details.

\section{Selective reporting}

Only one study stated whether all predefined or clinically relevant and reasonably expected outcomes were recorded and fully reported (Teunkens 2016). All of the other studies were reported in such a way that there was unclear risk of bias concerning selective reporting.

\section{Other potential sources of bias}

None noted.

\section{Effects of interventions}

See: Summary of findings for the main comparison Risk of transient neurological symptoms with spinal lidocaine compared to other local anaesthetic in adults undergoing surgery

We included 24 studies with 2253 enrolled participants in the NMA (Table 1; Table 2). Reported outcomes were available for 2226 participants. There were $27(1.65 \%)$ dropouts, or missing or not reported outcomes. Due to these numbers, we did not perform any related sensitivity analysis.

In 13 RCTs, we found no events of TNS in the comparator treatment group (Ali Hassan 2015; Aouad 2001; Breebaart 2003; Casati 2007; de Weert 2000; Hampl 1995a; Le Truong 2001; Liguori 1998; Pollock 1996; Pradhan 2010; Teunkens 2016; de Santiago 2010; Yazicioglu 2013). In six of these 13 RCTs, there were no cases of TNS (Ali Hassan 2015; Aouad 2001; Pradhan 2010; Teunkens 2016; de Santiago 2010; Yazicioglu 2013).

\section{Pair-wise meta-analysis of lidocaine versus alternative local anaesthetic agents}

\section{Rate of development of transient neurological symptoms}

Figure 1 summarizes our findings for all pair-wise comparisons between lidocaine and individual alternative agents. A summary RR comparing all alternative local anaesthetic agents to lidocaine was not estimated.

In total, 201/1097 (18\%) participants who received lidocaine developed TNS (occurrence of TNS by study is presented in Table 1 ).

The RR for the development of TNS was lower for bupivacaine (RR $0.16,95 \% \mathrm{Cl} 0.09$ to $0.28 ; 1^{2}=5 \%$; studies $=12$, participants $=$ 1220; moderate-quality evidence), levobupivacaine (RR 0.13 , 95\% $\mathrm{Cl} 0.02$ to $0.69 ; \mathrm{I}^{2}=0 \%$; studies $=2$, participants $=120$; low-quality evidence), prilocaine ( $\mathrm{RR} 0.18,95 \% \mathrm{Cl} 0.07$ to $0.49 ; \mathrm{I}^{2}=0 \%$; studies $=4$, participants $=429$; moderate-quality evidence), procaine (RR
$0.14,95 \% \mathrm{Cl} 0.04$ to $0.52 ; \mathrm{I}^{2}=0 \%$; studies = 2, participants = 130 ; moderate-quality evidence), and ropivacaine (RR $0.10,95 \% \mathrm{Cl} 0.01$ to $0.78 ; 1^{2}=0 \%$; studies $=2$, participants $=90$; low-quality evidence) (Analysis 1.1).

The RR was not different for 2-chloroprocaine (RR 0.09, 95\% Cl 0.01 to $1.51 ; 1^{2}=0 \%$; studies $=2$, participants $=94$; low-quality evidence), and mepivacaine (RR $1.01,95 \% \mathrm{Cl} 0.18$ to $5.82 ;\left.\right|^{2}=61 \%$; studies $=4$, participants $=274$; very low-quality evidence).

\section{Postoperative neurological symptoms (sensory deficits including numbness and weakness)}

There were no reports of ongoing sensory changes for the duration of follow-up in any of these trials.

\section{Postoperative neurological signs (motor deficits including weakness in a radicular distribution)}

There were no reports of ongoing motor changes for the duration of follow-up in any of these trials.

\section{Network meta-analysis}

See Table 3.

The NMA included 24 studies. These studies included eight different treatments. The total number of pair-wise comparisons was 32, which included 11 unique comparisons. Compared to lidocaine, the RR of TNS was lower for bupivacaine, levobupivacaine, prilocaine, procaine, and ropivacaine. The RRs were in the range of 0.10 to 0.23 (Table 2). The RR for 2-chloroprocaine was also small (0.18), but the $95 \% \mathrm{Cls}$ were wide (0.02 to 1.53 ). The RR for mepivacaine was greater than 1 suggesting an increased risk for TNS, but the $95 \% \mathrm{Cls}$ were wide ( 0.76 to 3.12 ). The tau 2 was 0 and the $\mathrm{I}^{2}$ statistic was $0 \%$; this is consistent with no heterogeneity and no inconsistency. The decomposition of Cochran's $Q$ statistic revealed no heterogeneity within or between designs. $P$ values were greater than 0.3 (Table 4). The splitting of the contribution of direct and indirect evidence did not demonstrate inconsistency; the $95 \% \mathrm{Cl}$ of the ratio of ratios (direct versus indirect) crossed the line of identity for all comparisons (Table 3).

A meta-analysis interaction plot for the 24 included studies showing the geometry of network was generated by using CINeMA tool (Figure 2).

Finally, we ranked the competing treatments by $\mathrm{P}$ scores, in terms of risk of developing TNS after spinal anaesthesia. There was a clear separation in the ranking of treatments (Table 5). The P scores of lidocaine and mepivacaine were low and very low. The P scores of the other treatments were 0.5 or above.

\section{Subgroup analysis}

We did not perform subgroup analysis based on participant position (lithotomy versus supine) or the shape and size of the spinal needle as we could not derive systematic data from the 24 included RCTs. Most participants were operated on in the supine position and most used pencil-point needles (in most cases $25 \mathrm{G}$ ). A subgroup analysis was not possible due to this lack of data.

A possible subgroup analysis concerned the effect of pregnancy on TNS. Three studies comparing bupivacaine versus lidocaine (caesarean delivery: Aouad 2001; Pradhan 2010; postpartum tubal 
ligation: Philip 2001), had only three events (lidocaine one, bupivacaine two) among the 310 participants. Considering the low event rate, we did not perform subgroup analysis.

\section{Missing data}

Only one study stated clearly that all predefined or clinically relevant and reasonably expected outcomes were recorded and fully reported (Teunkens 2016). The other studies were reported with an unclear risk of selective reporting, although none mentioned any missing data. After contacting the authors, we were left with 27 (1.65\%) dropouts.

\section{Sensitivity analysis}

An intention-to-treat analysis was possible for $14 / 20$ studies. Because of the small number of missing outcomes, we did not attempt to impute optimistic and pessimistic missing outcomes for the other five studies in a sensitivity analysis.

\section{Summary of findings and GRADE}

The CINeMA web app created a series of tables and plots for the quality of evidence of an NMA. Study limitations were determined by the average risk of bias after each investigator independently assigned their assessment of direct risk of bias (Figure 3). The NMAgenerated risk of bias assessment for indirect and mixed-effects included in the interaction analysis is available in Figure 4. A large proportion of studied interactions showed some or major concern in terms of study limitations.

To assess imprecision, an RR outside of the range of 0.909 to 1.1 was considered clinically important. Each component table within Figure 5 shows the imprecision judgement for each pair-wise comparison. In the 28 pair-wise comparisons with either mixed or indirect evidence, there were major concerns for imprecision in 18 .

Among included studies in the NMA, there were no concerns across studies in terms of heterogeneity (Figure 6), or incoherence $\left(\mathrm{Chi}^{2}=3.599\right.$, degrees of freedom $\left.=8, \mathrm{P}=0.891\right)$. All studies were considered to directly report TNS and thus indirectness was assigned a judgement of low concern. Similarly, publication bias was rated of low concern.

An aggregated chart summarizing all studies included in the NMA across the domains is available in Figure 7. For example, the mixed evidence for bupivacaine versus lidocaine has some concerns for study limitations, but no concerns for another domain.

\section{DISCUSSION}

\section{Summary of main results}

The main clinical question addressed by this review is whether local anaesthetics used for spinal anaesthesia caused symptoms of TNS less frequently than lidocaine.

We included 24 trials of mostly low- to moderate-quality evidence (GRADE), reporting on 2226 participants of whom 239 developed TNS, in the analysis. Included studies mostly had unclear to high risk of bias. Compared with lidocaine, most local anaesthetics were associated with a reduced risk of TNS development (with the exception of 2-chloroprocaine and mepivacaine) (bupivacaine: RR $0.16,95 \% \mathrm{Cl} 0.09$ to $0.28 ; 12$ studies; moderate-quality evidence; 2 chloroprocaine: RR $0.09,95 \% \mathrm{Cl} 0.01$ to 1.51 ; 2 studies; low-quality evidence; levobupivacaine: RR $0.13,95 \% \mathrm{Cl} 0.02$ to $0.69 ; 2$ studies; low-quality evidence; mepivacaine: RR $1.01,95 \% \mathrm{Cl} 0.18$ to 5.82 ; 4 studies; very low-quality evidence; prilocaine: RR $0.18,95 \% \mathrm{CI}$ 0.07 to 0.49 ; 4 studies; moderate-quality evidence; procaine: RR $0.14,95 \% \mathrm{Cl} 0.04$ to $0.52 ; 2$ studies; moderate-quality evidence; ropivacaine: RR $0.10,95 \% \mathrm{Cl} 0.01$ to $0.78 ; 2$ studies; low-quality evidence).

These data, with additional explanations, are found in the Summary of findings for the main comparison. Approximately one in five participants who received spinal anaesthesia with lidocaine developed TNS.

The NMA included 24 studies. These studies assessed eight different local anaesthetics. The number of pair-wise comparisons was 32 and the number of unique pair-wise comparisons was 11 . This analysis showed that, compared to lidocaine, the RRs of TNS development were lower for bupivacaine, levobupivacaine, prilocaine, procaine, and ropivacaine with RRs in the range of 0.10 to 0.23 while 2 -chloroprocaine and mepivacaine did not differ.

While Summary of findings for the main comparison for this review focused on the pair-wise meta-analysis results, results from the NMA can be found in Table 2 (results of NMA), Table 3, Table 4, and Table 5 (treatment ranking), as well as in Figure 2 (network structure), Figure 3 (risk of bias assessments), Figure 4, Figure 5, Figure 6, and Figure 7. Updates of this review will consider contemporary practices for presenting a 'Summary of findings' table for NMA results.

\section{Overall completeness and applicability of evidence}

How much does TNS influence patients' level of satisfaction and their rehabilitation? In one multicentre RCT, $20 \%$ of 453 participants who received spinal anaesthesia with lidocaine for short urological procedures developed TNS (Tong 2003). People with TNS had higher pain scores, used more analgesics postoperatively, and experienced higher degrees of functional impairment during the two postoperative days than those who did not develop TNS. Satisfaction was higher among people without TNS (96\%) than in people with TNS (89\%). However, the proportion of participants who stated they would accept future spinal anaesthesia was the same (95\%). It seems that the transitory pain and functional impairment are not of such degree that they have a negative influence on the patients' decisions to receive spinal anaesthesia in the future. In contrast, in one epidemiological study of 1863 participants, $30 \%$ of the 104 participants who developed TNS after intrathecal lidocaine rated their pain as severe (Freedman 1998).

\section{Quality of the evidence}

The present review showed that bupivacaine, prilocaine, and procaine are less likely to cause TNSs than lidocaine, but the quality of evidence was low to moderate based on GRADE assessments.

The quality of evidence comparing the risk of TNS following bupivacaine spinal anaesthesia compared with lidocaine was moderate, due to multiple studies in which blinding was inadequate and two studies that reported eight participants lost to follow-up (Ali Hassan 2015; Aouad 2001; Etezadi 2013; Keld 2000; Pollock 1996; Pradhan 2010; Salmela 1998; Teunkens 2016). Low-quality of evidence supported levobupivacaine as causing less TNS than lidocaine; the quality of evidence was downgraded for relatively small sample sizes, a rare event of interest, and wide $\mathrm{Cls}$ 
(Breebaart 2003; Gozdemir 2010). Moderate-quality evidence also supported prilocaine when compared with lidocaine; in this case, the quality of evidence was decreased for concerns about blinding, participants lost to follow-up, and pervasive unclear risk of bias.

The quality of evidence comparing 2-chloroprocaine, procaine, and ropivacaine with lidocaine was low. In the case of 2-chloroprocaine, only one study noted the event of interest (TNS), limiting the quality with small sample size and imprecision (Casati 2007; Teunkens 2016). The studies comparing procaine and ropivacaine with lidocaine were limited by relatively small sample sizes, a rare event of interest, wide $\mathrm{Cls}$, and inadequate blinding, as well as participants lost to follow-up (Breebaart 2003; Fanelli 2009; Hodgson 2000; Le Truong 2001).

The quality of evidence comparing mepivacaine with lidocaine presents an interesting problem. These studies had similar limitations in terms of inadequate blinding, participants lost to follow-up, and wide Cls (Liguori 1998; Pawlowski 2012; Salazar 2001; Salmela 1998). Furthermore, the studies demonstrated a small overlap in $\mathrm{Cls}$ and different directions of effect, with the $\mathrm{Cl}$ including the null hypothesis. These data may represent heterogeneity or no difference in effect. See Summary of findings for the main comparison for further details.

\section{Potential biases in the review process}

The consistent magnitude of the risk ratio reduction observed when local anaesthetics such as bupivacaine, levobupivacaine, prilocaine, procaine, and ropivacaine are used, compared to lidocaine, is a strength of the present review.

However, the limitations were numerous. The events were so rare that no randomized trial relating to this complication has been performed. In the patient population contained in this review, the total number of participants was only 2226. Only 239 developed TNS and no prolonged neurological sequelae were reported. Within the review, 13 of the included RCTs found no events of TNS in the treatment comparator arm, and six of these studies found no cases of TNS in either treatment arm. No specific corrections were made for studies with no events in either arm or for studies with no events in one or more arm, which may have introduced bias in the estimation of the treatment effect. The lack of responsiveness of many primary study authors to requests for information must be taken into account. These rare events can be found in the literature as case reports, retrospective and prospective surveys, or as reports from databases for registration of postoperative complications. Nevertheless, as the chosen primary outcome definitions were dichotomous (presence or absence of the complications), no study was excluded depending on alternative outcome definitions or clinical heterogeneity (or both), prioritization of data from multiple time points, the definition of subgroups, use of adjusted as opposed to unadjusted data, or outcome surrogacy.

Consequently, we did not detect any marginal decisions around the inclusion or exclusion of studies or use and analysis of data which could have impacted on the findings of the review.

There were no relevant departures from the protocol (Zaric 2003) (or last published version of the review, Zaric 2009) as a potential source of bias (see Differences between protocol and review).

Finally, we attempted to conduct a comprehensive search for studies, but the fact that two studies have not yet been incorporated (see Characteristics of studies awaiting classification) may be a source of potential bias. The results of these studies may impact the conclusions of this review in the future.

\section{Agreements and disagreements with other studies or reviews}

There have been no previous published systematic reviews including short-acting local anaesthetics (such as prilocaine or 2-chloroprocaine), rendering conclusions of other reports mostly speculative regarding the implications of these agents in the development of TNS.

\section{AUTHORS' CONCLUSIONS}

\section{Implications for practice}

There is low to moderate-quality evidence that transient neurological symptoms (TNS) are probably less frequent following spinal anaesthesia with bupivacaine, levobupivacaine, prilocaine, procaine, and ropivacaine than with lidocaine. Very-low to lowquality evidence suggests that TNS occurs after 2-chloroprocaine and mepivacaine is used for spinal anaesthesia at a similar frequency with lidocaine, but the evidence is very uncertain.

Among the studies included in this review, approximately one in five participants who received spinal anaesthesia with lidocaine developed TNS. This review showed that painful symptoms that are attributed to TNS ceased by the fifth postoperative day in all participants.

Finally, the risks of TNS should be weighed against the benefit of rapid, short-acting anaesthesia and the patient's viewpoint must be considered in the decision as to whether to use lidocaine for ambulatory anaesthesia.

Globally, the quality of evidence of reported studies is of very low to moderate quality and this should be taken into account when interpreting the results of this review. Finally, the results of one ongoing study (Characteristics of ongoing studies) and two studies in the Studies awaiting classification section may alter the conclusions of the review once assessed.

\section{Implications for research}

More data are necessary to accurately estimate the frequency of TNS following the use of mepivacaine and 2-chloroprocaine. 2-Chloroprocaine, in particular, may be a suitable replacement for lidocaine for spinal anaesthesia in ambulatory settings and high-quality, appropriately powered and blinded randomized controlled trials (RCT) are required to confirm these initial findings. Similarly, high-quality RCTs enrolling pregnant women are needed to generate conclusions about the frequency of TNS after spinal anaesthesia in this specific patient population.

We acknowledge such definitive RCTs may be difficult to perform regarding the risk of TNS for different local anaesthetic agents, and some useful comparisons may be made using alternative designs such as large prospective registries. A standardized definition of outcomes is of prime importance. A registry may be the best way to document the true risks of uncommon serious adverse events of local anaesthetic agents, such as permanent neurological deficits after regional anaesthesia. An international database for registration of such rare events could be the solution to this 
problem. Regional anaesthesia societies such as the European Society of Regional Anaesthesia and Pain Therapy (ESRA), the American Society of Regional Anesthesia (ASRA), and the Latin American Society of Regional Anaesthesia (LASRA) might be appropriate agents.

\section{ACKNOWLEDGEMENTS}

April 2019: we would like to thank Mike Bennett (Content Editor), Cathal Walsh (Statistical Editor), Joanne Guay (Peer Reviewer), Janet Wale (Consumer Editor), Janne Vendt (Information Specialist), Teo Quay (Managing Editor), and Andrew Smith (Coordinating Editor) for their help and editorial advice during the preparation of this systematic review. We also would like to thank Jane Cracknell (Managing Editor at the time of the review) for her help and advice. Finally, we thank Dimitris Mavridis who commented on an earlier draft.
November 2008: we would like to thank Prof Michael Bennett (Content Editor) and Dr Helen Worthington (Statistical and Coordinating Editor Cochrane Oral Health Group) for editing our updated review (Zaric 2009).

We would like to acknowledge the contribution of Yodying Punjasawadwong and Christian Christiansen to our original review (Zaric 2005). Dr Punjasawadwong helped with the literature search, evaluation, and construction of tables. Dr Christiansen helped with the evaluation of literature and revision of the text.

We would also like to thank Dr Peter Choi and Dr Helen Worthington for editing our original review (Zaric 2005), and acknowledge and thank Dr Janet Wale for her consumer synopsis. Her efforts greatly contributed to the editorial process of the review. 


\section{RE F E R E N C E S}

\section{References to studies included in this review}

\section{Ali Hassan 2015 \{published data only\}}

Ali Hassan HI. Comparison between two different selective spinal anesthesia techniques in ambulatory knee arthroscopy as fast-track anesthesia. Anesthesia, Essays and Researches 2015;9(1):21-7. [DOI: 10.4103/0259-1162.150157; PUBMED: 25886416]

\section{Aouad 2001 \{published data only\}}

Aouad MT, Siddik SS, Jalbout MI, Baraka AS. Does pregnancy protect against intrathecal lidocaine-induced transient neurological symptoms?. Anesthesia and Analgesia 2001;92(2):401-4. [PUBMED: 11159240]

\section{Breebaart 2003 \{published data only\}}

Breebaart MB, Vercauteren MP, Hoffmann VL, Adriaensen HA. Urinary bladder scanning after day-case arthroscopy under spinal anaesthesia: comparison between lidocaine, ropivacaine and levobupivacaine. British Journal of Anaesthesia 2003;90(3):309-13. [PUBMED: 12594142]

\section{Casati 2007 \{published data only\}}

Casati A, Fanelli G, Danelli G, Berti M, Ghisi D, Brivio M, et al. Spinal anesthesia with lidocaine or preservative-free 2chloroprocaine for outpatient knee arthroscopy: a prospective, randomized, double-blind comparison. Anesthesia and Analgesia 2007;104(4):959-64. [PUBMED: 17377114]

\section{de Weert 2000 \{published and unpublished data\}}

de Weert K, Traksel M, Gielen M, Slappendel R, Weber E, Dirksen $\mathrm{R}$. The incidence of transient neurological symptoms after spinal anaesthesia with lidocaine compared to prilocaine. Anaesthesia 2000;55(10):1020-4. [PUBMED: 11012500]

\section{Etezadi 2013 \{published data only\}}

Etezadi F, Karimi Yarandi K, Ahangary A, Shokri H, Imani F, Safari $S$, et al. The effect of needle type, duration of surgery and position of the patient on the risk of transient neurologic symptoms. Anesthesiology and Pain Medicine 2013;2(4):154-8. [PUBMED: 24223352]

\section{Fanelli 2009 \{published data only\}}

Fanelli G, Danelli G, Zasa M, Baciarello M, Di Cianni S, Leone S. Intrathecal ropivacaine $5 \mathrm{mg} / \mathrm{ml}$ for outpatient knee arthroscopy: a comparison with lidocaine $10 \mathrm{mg} / \mathrm{ml}$. Acta Anaesthesiologica Scandinavica 2009;53(1):109-15. [PUBMED: 19032560]

\section{Gozdemir 2010 \{published data only\}}

Gozdemir M, Muslu B, Sert H, Usta B, Demircioglu RI, Karatas OF, et al. Transient neurological symptoms after spinal anaesthesia with levobupivacaine $5 \mathrm{mg} / \mathrm{ml}$ or lidocaine $20 \mathrm{mg} / \mathrm{ml}$. Acta Anaesthesiologica Scandinavica 2010;54(1):59-64. [PUBMED: 19860749]

\section{Hampl 1995a \{published data only\}} Hampl KF, Schneider MC, Thorin D, Ummenhofer W, Drewe J. Hyperosmolarity does not contribute to transient radicular irritation after spinal anesthesia with hyperbaric 5\% lidocaine. Regional Anesthesia 1995;20(5):363-8. [PUBMED: 8519711]

\section{Hampl 1998 \{published data only\}}

Hampl KF, Heinzmann-Wiedmer S, Luginbuehl MC, Harms C, Seeberger M, Schneider MC, et al. Transient neurologic symptoms after spinal anesthesia: a lower incidence with prilocaine and bupivacaine than with lidocaine. Anesthesiology 1998;88(3):629-33. [PUBMED: 9523805]

\section{Hodgson 2000 \{published data only\}}

Hodgson PS, Liu SS, Barta MS, Gras TW, Pollock J, Neal JM. Procaine compared with lidocaine for incidence of transient neurologic symptoms. Regional Anesthesia and Pain Medicine 2000;25(3):218-22. [PUBMED: 10834773]

\section{Imbelloni 2010 \{published data only\}}

Imbelloni LE, Gouveia MA, Cordeiro JA. Hypobaric $0.15 \%$ bupivacaine versus hypobaric $0.6 \%$ lidocaine for posterior spinal anesthesia in outpatient anorectal surgery. Revista Brasileira de Anestesiologia 2010;60(2):113-20, 64-8. [PUBMED: 20485955]

\section{Keld 2000 \{published and unpublished data\}}

Keld KD, Hein L, Dalgaard M, Krogh L, Rodt SÅ. The incidence of transient neurologic symptoms (TNS) after spinal anaesthesia in patients undergoing surgery in the supine position. Hyperbaric lidocaine $5 \%$ versus hyperbaric bupivacaine $0,5 \%$. Acta Anaesthesiologica Scandinavica 2000;44(3):285-90. [PUBMED: 10714841]

Le Truong 2001 \{published and unpublished data\}

Le Truong HH, Girard M, Drolet P, Grenier Y, Boucher C, Bergeron L. Spinal anesthesia: a comparison of procaine and lidocaine. Canadian Journal of Anaesthesia 2001;48(5):470-3. [PUBMED: 11394516]

\section{Liguori 1998 \{published data only\}}

Liguori GA, Zayas VM, Chisholm MF. Transient neurologic symptoms after spinal anesthesia with mepivacaine and lidocaine. Anesthesiology 1998;88(3):619-23. [PUBMED: 9523803]

\section{Martinez-Bourio 1998 \{published data only\}}

Martinez-Bourio M, Arzuaga M, Quintana JM, Aguilera L, Aguirre J, Saez-Equilaz JL, et al. Incidence of transient neurologic symptoms after hyperbaric subarachnoid anesthesia with $5 \%$ lidocaine and $5 \%$ prilocaine. Anesthesiology 1998;88(3):624-8. [PUBMED: 9523804]

Pawlowski 2012 \{published data only\}

Pawlowski J, Orr K, Kim KM, Pappas AL, Sukhani R, Jellish WS. Anesthetic and recovery profiles of lidocaine versus mepivacaine for spinal anesthesia in patients undergoing outpatient orthopedic arthroscopic procedures. Journal of Clinical Anesthesia 2012;24(2):109-15. [PUBMED: 22342508] 
Philip 2001 \{published data only\}

Philip J, Sharma SK, Gottumukkala VN, Perez BJ, Slaymaker EA, Wiley J. Transient neurologic symptoms after spinal anesthesia with lidocaine in obstetric patients. Anesthesia and Analgesia 2001;92(2):405-9. [PUBMED: 11159241]

Pollock 1996 \{published data only\}

Pollock J, Neal JM, Stephensen CA, Wiley CE. Prospective study of the incidence of transient radicular irritation in patients undergoing spinal anesthesia. Anesthesiology 1996;84(6):1361-7. [PUBMED: 8669677]

Pradhan 2010 \{published data only\}

Pradhan B. Spinal anesthesia for cesarean section: comparison of 5.0\% lignocaine and $0.5 \%$ bupivacaine. Nepal Medical College Journal : NMCJ 2010;12(1):30-3. [PUBMED: 20677606]

Salazar 2001 \{published and unpublished data\}

Salazar F, Bogdanovich A, Adalia R, Chabas E, Gomar C. Transient neurologic symptoms after spinal anaesthesia using isobaric 2\% mepivacaine and isobaric 2\% lidocaine. Acta Anaesthesiologica Scandinavica 2001;45(2):240-5. [PUBMED: $11167171]$

\section{Salmela 1998 \{published data only\}}

Salmela L, Aromaa U. Transient radicular irritation after spinal anesthesia induced with hyperbaric solutions of cerebrospinal fluid-diluted lidocaine $50 \mathrm{mg} / \mathrm{ml}$ or mepivacaine $40 \mathrm{mg} / \mathrm{ml}$ or bupivacaine $5 \mathrm{mg} / \mathrm{ml}$. Acta Anaesthesiologica Scandinavica 1998;42(7):765-9. [PUBMED: 9698950]

\section{Teunkens 2016 \{published data only\}}

Teunkens A, Vermeulen K, van Gerven E, Fieuws S, van de Velde M, Rex S. Comparison of 2-chloroprocaine, bupivacaine, and lidocaine for spinal anesthesia in patients undergoing knee arthroscopy in an outpatient setting: a double-blind randomized controlled trial. Regional Anesthesia and Pain Medicine 2016;41(5):576-83. [DOI: 10.1097/ AAP.0000000000000420; PUBMED: 27281722]

\section{Østgaard 2000 \{published and unpublished data\}}

Østgaard G, Hallaråker O, Ulveseth OK, Flaatten H. A randomised study of lidocaine and prilocaine for spinal anaesthesia. Acta Anaesthesiologica Scandinavica 2000;44(4):436-40. [PUBMED: 10757577]

\section{References to studies excluded from this review}

\section{Ben-David 2000 \{published data only\}}

Ben-David B, Maryanovsky M, Gurevitch A, Lucyk C, Solosko D, Frankel $\mathrm{R}$, et al. A comparison of minidose lidocaine-fentanyl and conventional-dose lidocaine spinal anesthesia. Anesthesia and Analgesia 2000;91(4):865-70. [PUBMED: 11004039]

\section{Bergeron 1999 \{published data only\}}

Bergeron L, Girard M, Drolet P, Grenier Y, Truong HH, Boucher C. Spinal procaine with and without epinephrine and its relation to transient radicular irritation. Canadian Journal of Anaesthesia 1999;46(9):846-9. [PUBMED: 10490152]
Chan 1998 \{published data only\}

Chan VW, Garcia J, Al-Kaisy A, Drasner K. A comparative study of low-dose hyperbaric spinal lidocaine $0,5 \%$ versus $5 \%$ for continuous spinal anesthesia. Regional Anesthesia and Pain Medicine 1998;23(2):164-9. [PUBMED: 9570605]

\section{Chohedri 2015 \{published data only\}}

Chohedri A, Raeesi Estabragh R, Eghbal MH, Sahmeddini MA, Eftekharian $\mathrm{H}$, Shahabifar R. Comparing the duration of spinal anesthesia induced with bupivacaine and a bupivacainelidocaine combination in trans-urethral resection of the prostate (TURP). Anesthesiology and Pain Medicine 2015;5(4):e25675. [PUBMED: 26478863]

\section{de Santiago 2010 \{published data only\}}

de Santiago J, Santos-Yglesias J, Giron J, Jimenez A, Errando CL. Low-dose hypobaric spinal anesthesia for anorectal surgery in jackknife position: levobupivacaine-fentanyl compared to lidocaine-fentanyl [Anestesia subaracnoidea hipobarica a dosis bajas para cirugia anorrectal en posicion de navaja: comparacion entre levobupivacaina-fentanilo y lidocainafentanilo]. Revista Espanola de Anestesiologia y Reanimacion 2010;57(9):565-70. [PUBMED: 21155337]

\section{Frey 1998 \{published data only\}}

Frey K, Holman S, Mikat-Stevens M, Vazquez J, White L, Pedicini E, et al. The recovery profile of hyperbaric spinal anesthesia with lidocaine, tetracaine and bupivacaine. Regional Anesthesia and Pain Medicine 1998;23(2):159-63. [PUBMED: 9570604]

\section{Gentili 1997 \{published data only\}}

Gentili M, Senlis H, Houssel P, Monnier B, Bonnet F. Single-shot spinal anesthesia with small doses of bupivacaine. Regional Anesthesia 1997;22(6):511-4. [PUBMED: 9425965]

\section{Hampl 1995b \{published data only\}}

Hampl KF, Schneider MC, Ummenhofer W, Drewe J. Transient neurological symptoms after spinal anesthesia. Anesthesia and Analgesia 1995;81(6):1148-53. [PUBMED: 7486096]

\section{Hampl 1996 \{published data only\}}

Hampl KF, Schneider MC, Pargger H, Gut J, Drewe J, Drasner K. A similar incidence of transient neurologic symptoms after spinal anesthesia with $2 \%$ and $5 \%$ lidocaine. Anesthesia and Analgesia 1996;83(5):1051-4. [PUBMED: 8895284]

\section{Henderson 1998 \{published data only\}}

Henderson DJ, Faccenda KA, Morrison LM. Transient radicular irritation with intrathecal plain lignocaine. Acta Anaesthesiologica Scandinavica 1998;42(3):376-8. [PUBMED: 9542568]

\section{Hiller 1999 \{published data only\}}

Hiller A, Karjalainen K, Balk M, Rosenberg PH. Transient neurological symptoms after spinal anaesthesia with hyperbaric $5 \%$ lidocaine or general anaesthesia. British Journal of Anaesthesia 1999;82(4):575-9. [PUBMED: 10472226] 


\section{Imbelloni 2008a \{published data only\}}

Imbelloni LE, Gouveia MA, Cordeiro JA. Low dose of lidocaine: comparison of 15 with $20 \mathrm{mg} / \mathrm{ml}$ with dextrose for spinal anesthesia in lithotomy position and ambulatory surgery. Acta Anaesthesiologica Scandinavica 2008;52(6):856-61. [DOI: 10.1111/j.1399-6576.2007.01511.x; PUBMED: 18582308]

\section{Imbelloni 2008b \{published data only\}}

Imbelloni LE, Gouveia MA, Vieira EM, Cordeiro JA. Selective sensory spinal anaesthesia with hypobaric lidocaine for anorectal surgery. Acta Anaesthesiologica Scandinavica 2008;52(10):1327-30. [DOI: 10.1111/j.1399-6576.2008.01749.x; PUBMED: 19025522

\section{Jacobsen 2011 \{published data only\}}

Jacobsen J, Husum B, von Staffeldt H, Qvist TF, Jensen PE, Kledal $S$. The addition of lidocaine to bupivacaine does not shorten the duration of spinal anesthesia: a randomized, double-blinded study of patients undergoing knee arthroscopy. Anesthesia and Analgesia 2011;113(5):1272-5. [PUBMED: 21918168]

\section{Lee 2008 \{published data only\}}

Lee SJ, Bai SJ, Lee JS, Kim WO, Shin YS, Lee KY. The duration of intrathecal bupivacaine mixed with lidocaine. Anesthesia and Analgesia 2008;107(3):824-7. [PUBMED: 18713891]

\section{Liam 1998 \{published data only\}}

Liam BL, Yim CF, Chong JL. Dose response study of lidocaine $1 \%$ for spinal anaesthesia for lower limb and perineal surgery. Canadian Journal of Anaesthesia 1998;45(7):645-50. [PUBMED: 9717596]

\section{Loo 1999 \{published data only\}}

Loo CC, Irestedt L. Cauda equina syndrome after spinal anaesthesia with hyperbaric 5\% lignocaine: a review of six cases of cauda equina syndrome reported to the Swedish Pharmaceutical Insurance 1993-1997. Acta Anaesthesiologica Scandinavica 1999;43(4):371-9. [PUBMED: 10225068]

\section{Markey 1997 \{published data only\}}

Markey JR, Montiague R, Winnie AP. A comparative efficacy study of hyperbaric $5 \%$ lidocaine and $1.5 \%$ lidocaine for spinal anesthesia. Anesthesia and Analgesia 1997;85(5):1105-7. [PUBMED: 9356108]

\section{Mgbakor 2012 \{published data only\}}

Mgbakor AC, Adou BE. Plea for greater use of spinal anaesthesia in developing countries. Tropical Doctor 2012;42(1):49-51. [PUBMED: 22037518]

\section{Morisaki 1998 \{published data only\}}

Morisaki H, Masuda J, Kaneko S, Matsushima M, Takeda J. Transient neurologic syndrome in one thousand forty-five patients after $3 \%$ lidocaine spinal anesthesia. Anesthesia and Analgesia 1998;86(5):1023-6. [PUBMED: 9585290]

\section{Murto 1999 \{published data only\}}

Murto K, Lui AC, Cicutti N. Adding low dose meperidine to spinal lidocaine prolongs postoperative analgesia. Canadian Journal of Anaesthesia 1999;46(4):327-34. [PUBMED: 10232715]

\section{Pawlowski 2000 \{published data only\}}

Pawlowski J, Sukhani R, Pappas AL, Kim KM, Lurie J, Gunnerson $\mathrm{H}$, et al. The anesthetic and recovery profile of two doses ( 60 and $80 \mathrm{mg}$ ) of plain mepivacaine for ambulatory spinal anesthesia. Anesthesia and Analgesia 2000;91(3):580-4. [PUBMED: 10960380]

\section{Pollock 1999 \{published data only\}}

Pollock JE, Liu SS, Neal JM, Stephenson CA. Dilution of spinal lidocaine does not alter the incidence of transient neurologic symptoms. Anesthesiology 1999;90(2):445-50. [PUBMED: 9952151]

\section{Punj 2013 \{published data only\}}

Punj J, Khan RM. Spinal anaesthesia for pelvic surgery: low concentrations of lignocaine and bupivacaine are effective with less adverse events. Middle East Journal of Anaesthesiology 2013;22(1):71-7. [PUBMED: 23833854]

\section{Salmela 1996 \{published data only\}}

Salmela L, Aromaa U, Cozanitis DA. Leg and back pain after spinal anaesthesia involving hyperbaric $5 \%$ lignocaine. Anaesthesia 1996;51(4):391-3. [PUBMED: 8686832]

\section{Sia 1998 \{published data only\}}

Sia S, Pullano C. Transient radicular irritation after spinal anaesthesia with $2 \%$ isobaric mepivacaine. British Journal of Anaesthesia 1998;81(4):622-4. [PUBMED: 9924248]

\section{Tong 2003 \{published data only\}}

Tong D, Wong J, Chung F, Friedlander M, Bremang J, Mezei G, et al. Prospective study on incidence and functional impact of transient neurologic symptoms associated with $1 \%$ versus $5 \%$ hyperbaric lidocaine in short urologic procedures. Anesthesiology 2003;98(2):485-94. [PUBMED: 12552209]

\section{Vaghadia 2012 \{published data only\}}

Vaghadia H, Neilson G, Lennox PH. Selective spinal anesthesia for outpatient transurethral prostatectomy (TURP): randomized controlled comparison of chloroprocaine with lidocaine. Acta Anaesthesiologica Scandinavica 2012;56(2):217-23. [PUBMED: 22236346]

\section{Wong 1999 \{published data only\}}

Wong CA, Slavenas $\mathrm{P}$. The incidence of transient radicular irritation after spinal anesthesia in obstetric patients. Regional Anesthesia and Pain Medicine 1999;24(1):55-8. [PUBMED: 9952096]

\section{Yazicioglu 2013 \{published data only\}}

Yazicioglu D, Akkaya T, Kulacoglu H. Addition of lidocaine to bupivacaine for spinal anaesthesia compared with bupivacaine spinal anaesthesia and local infiltration anaesthesia. Acta Anaesthesiologica Scandinavica 2013;57(10):1313-20. [PUBMED: 23980580]

\section{Zayas 1999 \{published data only\}}

Zayas VM, Liguori GA, Chisholm MF, Susman MH, Gordon MA. Dose response relationships for isobaric spinal mepivacaine using the combined spinal epidural technique. Anesthesia and Analgesia 1999;89(5):1167-71. [PUBMED: 10553828]

Transient neurological symptoms (TNS) following spinal anaesthesia with lidocaine versus other local anaesthetics in adult surgical 


\section{References to studies awaiting assessment}

\section{Frisch 2018 \{published data only\}}

Frisch NB, Darrith B, Hansen DC, Wells A, Sanders S, Berger RA. Single-dose lidocaine spinal anesthesia in hip and knee arthroplasty. Arthroplasty Today 2018;4(2):236-9. [PUBMED: 29896560]

\section{Gozdemir 2016 \{published data only\}}

Gozdemir M, Muslu B, Sert H, Usta B, Demircioglu RI, Kasikara H. Transient neurological symptoms after spinal anesthesia. Clinical and Investigative Medicine. Medecine Clinique et Experimentale 2016;39(6):S106-10. [PUBMED: 27917802]

\section{References to ongoing studies}

NCT02818894 \{published data only\}

NCT02818894. Spinals in THA (total hip arthroplasty). clinicaltrials.gov/ct2/show/NCT02818894 (first received 30 June 2016).

\section{Additional references}

\section{Aravelo-Rodriguez 2017}

Arevalo-Rodriguez I, Muñoz L, Godoy-Casasbuenas N, Ciapponi A, Arevalo JJ, Boogaard S, et al. Needle gauge and tip designs for preventing post-dural puncture headache (PDPH). Cochrane Database of Systematic Reviews 2017, Issue 4. [DOI: 10.1002/14651858.CD010807.pub2]

\section{Auroy 1997}

Auroy Y, Narchi P, Messiah A, Litt L, Rouvier B, Samii K. Serious complications related to regional anesthesia - results of a prospective survey in France. Anesthesiology 1997;87(3):479-86. [PUBMED: 9316950]

\section{Axelrod 1998}

Axelrod EH, Alexander GD, Brown M, Schork MA. Procaine spinal anesthesia: a pilot study of the incidence of transient neurological symptoms. Journal of Clinical Anesthesia 1998;10(5):404-9. [PUBMED: 9702622]

\section{Bier 1899}

Bier AK, von Esmarch JF. Experiments with the cocainization of the spinal cord [Versuche uber Cocainisiring des Ruckenmarkes]. Deutsche Zeitschrift fur Chirurgie 1899;51:361-9.

\section{Caldwell 2005}

Caldwell, DM, Ades AE, Higgins JPT. Simultaneous comparison of multiple treatments: combining direct and indirect evidence. BMJ 2005;331(7521):897-900. [PUBMED: 16223826]

\section{Casati 1998}

Casati A, Fanelli G, Aldegheri G, Berti M, Leoni A, Torri G. A transient neurological deficit following intrathecal injection of $1 \%$ hyperbaric bupivacaine for unilateral spinal anaesthesia. European Journal of Anaesthesiology 1998;15(1):112-3. [PUBMED: 9522152]

\section{Chaimani 2017}

Chaimani A, Caldwell DM, Li T, Higgins JP, Salanti G. Additional considerations are required when preparing a protocol for a systematic review with multiple interventions. Journal of Clinical Epidemiology 2017;83:65-74. [PUBMED: 28088593]

\section{CINeMA 2018 [Computer program]}

Papakonstantinou T, Salanti G. CINeMA Confidence in Network Meta-Analysis. Version 0.6. Bern (Switzerland): Institute of Social and Preventive Medicine, 2018.

\section{Cipriani 2013}

Cipriani A, Higgins, JP, Geddes JR, Salanti G. Conceptual and technical challenges in network meta-analysis. Annals of Internal Medicine 2013;159(2):130-7. [PUBMED: 23856683]

\section{Corbey 1998}

Corbey MP, Bach AB. Transient radicular irritation (TRI) after spinal anaesthesia in day-case surgery. Acta Anaesthesiologica Scandinavica 1998;42(4):425-9. [PUBMED: 9563861]

\section{Dahlgren 1995}

Dahlgren N, Tornebrandt K. Neurological complications after anaesthesia. A follow-up of 18000 spinal and epidural anaesthetics performed over three years. Acta Anaesthesiologica Scandinavica 1995;39(7):872-80. [PUBMED: 8848884]

\section{Dias 2010}

Dias S, Welton NJ, Caldwell DM, Ades AE. Checking consistency in mixed treatment comparison meta-analysis. Statistics in Medicine 2010;29(7-8):932-44. [PUBMED: 20213715]

\section{Doleman 2018}

Doleman B, Leonardi-Bee J, Heinink TP, Bhattacharjee D, Lund JN, Williams JP. Pre-emptive and preventive opioids for postoperative pain in adults undergoing all types of surgery. Cochrane Database of Systematic Reviews 2018, Issue 12. [DOI: 10.1002/14651858.CD012624.pub2]

\section{Douglas 1995}

Douglas MJ. Neurotoxicity of lidocaine - does it exist?. Canadian Journal of Anaesthesia 1995;42(3):181-5. [PUBMED: 7743565]

\section{Foldes 1952}

Foldes FF, McNall PG. 2-Chloroprocaine: a new local anesthetic agent. Anesthesiology 1952;13(3):287-96. [PUBMED: 14933832]

\section{Freedman 1998}

Freedman JM, Li DK, Drasner K, Jaskela MC, Larsen B, Wi S. Transient neurologic symptoms after spinal anesthesia. Anesthesiology 1998;89(3):633-41. [PUBMED: 9743399]

\section{Gerancher 1997}

Gerancher JC. Cauda equina syndrome following a single spinal administration of $5 \%$ hyperbaric lidocaine through a 25 -gauge Whitacre needle. Anesthesiology 1997;87(3):687-9. [PUBMED: 9316976] 


\section{Green 1961}

Green NM. Neurological sequelae of spinal anesthesia. Anesthesiology 1961;22:682-98.

\section{Higgins 2011}

Higgins JP, Green S, editor(s). Cochrane Handbook for Systematic Reviews of Interventions Version 5.1.0 (updated March 2011). The Cochrane Collaboration, 2011. Available from handbook.cochrane.org.

\section{Hiller 1997}

Hiller A, Rosenberg PH. Transient neurological symptoms after spinal anaesthesia with $4 \%$ mepivacaine and $0.5 \%$ bupivacaine. British Journal of Anaesthesia 1997;79(3):301-5. [PUBMED: 9389845]

\section{Holmdahl 1998}

Holmdahl HM. Xylocain (lidocaine, lignocaine), its discovery and Gordh's contribution to its clinical use. Acta Anaesthesiologica Scandinavica. Supplementum 1998;42(113):8-12. [PUBMED: 9932112]

\section{Hutton 2015}

Hutton B, Salanti G, Caldwell DM, Chaimani A, Schmid CH, Cameron $\mathrm{C}$, et al. The PRISMA extension statement for reporting systematic reviews incorporating network meta-analyses of health care interventions: checklist and explanations. Annals of Internal Medicine 2015;162(11):777-84. [PUBMED: 26030634]

\section{Iselin-Chaves 1996}

Iselin-Chaves IA, Van Gessel EF, Donald FA, Forster A, Gamulin Z. The effects of solution concentration and epinephrine on lateral distribution of hyperbaric tetracaine spinal anesthesia. Anesthesia and Analgesia 1996;83(4):755-9. [PUBMED: 8831316]

\section{Kane 1981}

Kane RE. Neurologic deficits following epidural or spinal anesthesia. Anesthesia and Analgesia 1981;60(3):150-61. [PUBMED: 7011100]

\section{Kopacz 2005}

Kopacz DJ. Spinal 2-chloroprocaine: minimum effective dose. Regional Anesthesia and Pain Medicine 2005;30(1):36-42. [PUBMED: 15690266]

\section{Krahn 2013}

Krahn U, Binder $\mathrm{H}$, Konig J. A graphical tool for locating inconsistency in network meta-analyses. BMC Medical Research Methodology 2013;13:35. [PUBMED: 23496991]

\section{Lefebvre 2011}

Lefebvre C, Manheimer E, Glanville J. Chapter 6: Searching for studies. In: Higgins JP, Green S, editor(s). Cochrane Handbook for Systematic Reviews of Interventions Version 5.1.0 (updated March 2011). The Cochrane Collaboration, 2011. Available from handbook.cochrane.org.

\section{Li 1985}

Li DF, Bahar M, Cole G, Rosen M. Neurological toxicity of the subarachnoid infusion of bupivacaine, lignocaine or 2-chloroprocaine in the rat. British Journal of Anaesthesia 1985;57(4):424-9. [PUBMED: 3986072]

\section{Liu 1998}

Liu SS. Drugs for spinal anesthesia: past, present and future. Regional Anesthesia and Pain Medicine 1998;23(4):344-6. [PUBMED: 9690583]

\section{Lynch 1997}

Lynch J, zur Nieden M, Kasper SM, Radbruch L. Transient radicular irritation after spinal anesthesia with hyperbaric 4\% mepivacaine. Anesthesia and Analgesia 1997;85(4):872-3. [PUBMED: 9322473]

\section{Masuda 1998}

Masuda R, Yokoyama K, Inoue T. Spread of spinal anesthesia with 3 different hyperbaric solutions used in Japan. Masui 1998;47(12):1444-50. [PUBMED: 9990212]

\section{Miller 2018}

Miller D, Lewis SR, Pritchard MW, Schofield-Robinson OJ, Shelton CL, Alderson P, et al. Intravenous versus inhalational maintenance of anaesthesia for postoperative cognitive outcomes in elderly people undergoing non-cardiac surgery. Cochrane Database of Systematic Reviews 2018, Issue 8. [DOI: 10.1002/14651858.CD012317.pub2]

\section{Moore 1982}

Moore DC, Spierdijk J, vanKleef JD, Coleman RL, Love GF. Chloroprocaine neurotoxicity: four additional cases. Anesthesia and Analgesia 1982;61(2):155-9. [PUBMED: 7198876]

\section{netmeta 2013 [Computer program]}

Ruecker G, Schwarzer G. netmeta: network meta-analysis with R. Version 0.3-1. CRAN.R-project.org/package-netmeta, 2013.

\section{Noble 1971}

Noble AB, Murray JG. A review of the complications of spinal anaesthesia with experiences in Canadian teaching hospitals from 1959 to 1969. Canadian Anaesthetists' Society Journal 1971;18(1):5-17. [PUBMED: 4322858]

\section{Phillips 1969}

Phillips OC, Ebner H, Nelson AT, Black MH. Neurologic complications following spinal anesthesia with lidocaine: a prospective review of 10,440 cases. Anesthesiology 1969;30(3):284-9. [PUBMED: 4305091]

\section{Pollock 2000}

Pollock JE, Burkhead D, Neal JM, Liu SS, Friedman A, Stephenson C, et al. Spinal nerve function in five volunteers experiencing transient neurologic symptoms after lidocaine subarachnoid anesthesia. Anesthesia and Analgesia 2000;90(3):658-65. [PUBMED: 10702453]

\section{Puhan 2014}

Puhan MA, Schünemann HJ, Murad MH, Li T, BrignardelloPetersen R, Singh JA, et al. GRADE Working Group. A GRADE working group approach for rating the quality of treatment effect estimates from network meta-analysis. $B M J$ 2014;349:g5630. [PUBMED: 25252733] 


\section{R 2018 [Computer program]}

R Core Team. R: a Language and Environment for Statistical Computing. Version 3.4.4. Vienna (Austria): R Foundation for Statistical Computing, 2018.

\section{Reisner 1980}

Reisner LS, Hochman BN, Plumer MH. Persistent deficit and adhesive arachnoiditis following intrathecal 2-chloroprocaine injection. Anesthesia and Analgesia 1980;59(6):452-4. [PUBMED: 7189987]

\section{Renck 1995}

Renck H. Neurological complications of central nerve blocks. Acta Anaesthesiologica Scandinavica 1995;39(7):859-68. [PUBMED: 8848882]

\section{Review Manager 2014 [Computer program]}

Nordic Cochrane Centre, The Cochrane Collaboration. Review Manager 5 (RevMan 5). Version 5.3. Copenhagen: Nordic Cochrane Centre, The Cochrane Collaboration, 2014.

\section{Rigler 1991}

Rigler ML, Drasner K, Krejcie TC, Yelich SJ, Scholnick FT, DeFontes J, et al. Cauda equina syndrome after continuous spinal anesthesia. Anesthesia and Analgesia 1991;72(3):275-81. [PUBMED: 1994754]

\section{Rücker 2012}

Rucker G. Network meta-analysis, electrical networks and graph theory. Research Synthesis Methods 2012;3(4):312-24. [Pubmed: 26053424]

\section{Rücker 2014}

Rücker G, Schwarzer G. Reduce dimension or reduce weights? Comparing two approaches to multi-arm studies in network meta-analysis. Statistics in Medicine 2014;33(25):4353-69. [PUBMED: 24942211]

\section{Rücker 2015}

Rücker G, Schwarzer G. Ranking treatments in frequentist network meta-analysis works without resampling methods. BMC Medical Research Methodology 2015;15:58. [DOI: 10.1186/ s12874-015-0060-8; Pubmed: 26227148]

\section{Rücker 2016 [Computer program]}

Rucker G, Schwarzer G, Krahn U, Konig J. netmeta: network meta-analysis using frequentist methods. Version R package 0.9-2. Vienna (Austria): R Foundation for Statistical Computing, 2016.

\section{Salanti 2012}

Salanti G. Indirect and mixed-treatment comparison, network, or multiple-treatments meta-analysis: many names, many benefits, many concerns for the net generation evidence synthesis tool. Research Synthesis Methods 2012;3(2):80-97. [PUBMED: 26062083]

\section{Salanti 2014}

Salanti G, Del Giovane C, Chaimani A, Caldwell DM, Higgins JP. Evaluating the quality of evidence from a network metaanalysis. Plos One 2014;9(7):e99682. [PUBMED: 24992266]

\section{Schell 1991}

Schell RM, Brauer FS, Cole DJ, Applegate RL 2nd. Persistent sacral nerve root deficits after continuous spinal anaesthesia. Canadian Journal of Anaesthesia 1991;38(7):908-11. [PUBMED: 1742828]

\section{Schneider 1993}

Schneider M, Ettlin T, Kaufmann M, Schumacher P, Urwyler A, Hampl K, et al. Transient neurologic toxicity after hyperbaric subarachnoid anesthesia with 5\% lidocaine. Anesthesia and Analgesia 1993;76(5):1154-7. [PUBMED: 8141862]

\section{Sell 2008}

Sell A, Tein T, Pirkänen M. Spinal 2-chloroprocaine: effective dose for ambulatory surgery. Acta Anaesthesiological Scandinavica 2008;52(5):695-9. [PUBMED: 18419724]

\section{Smith 2004}

Smith KN, Kopacz DJ, McDonald SB. Spinal 2-chloroprocaine: a dose-ranging study and the effect of added epinephrine. Anesthesia and Analgesia 2004;98(1):81-8. [PUBMED: 14693591]

\section{Sumi 1996}

Sumi M, Sakura S, Kosaka Y. Intrathecal hyperbaric 0.5\% tetracaine as a possible cause of transient neurologic toxicity. Anesthesia and Analgesia 1996;82(5):1076-7. [PUBMED: 8610872]

\section{Tagariello 1998}

Tagariello V, Bertini L. Unusually prolonged duration of spinal anesthesia following 2\% mepivacaine. Regional Anesthesia and Pain Medicine 1998;23(4):424-6. [PUBMED: 9690597]

\section{Tarkkila 1991}

Tarkkila PJ, Kaukinen S. Complications during spinal anesthesia: a prospective study. Regional Anesthesia 1991;16(2):101-6. [PUBMED: 2043522]

\section{Tarkkila 1995}

Tarkkila P, Huhtala J, Tuominen M. Transient radicular irritation after spinal anaesthesia with hyperbaric 5\% lignocaine. British Journal of Anaesthesia 1995;74(3):328-9. [PUBMED: 7718381]

\section{Vandam 1955}

Vandam LD, Dripps RD. A long-term follow-up of 10,098 spinal anesthetics. II. Incidence and analysis of minor sensory neurological defects. Surgery 1955;38(3):463-9. [PUBMED: 13246935]

\section{Vandam 1960}

Vandam LD, Dripps RD. Long-term follow-up of patients who received 10,098 spinal anesthetics. Part IV. Neurological disease incident to traumatic lumbar puncture during spinal anesthesia. JAMA 1960;172:1483-7. [PUBMED: 13841201]

\section{Weinstein 2018}

Weinstein EJ, Levene JL, Cohen MS, Andreae DA, Chao JY, Johnson M, et al. Local anaesthetics and regional anaesthesia versus conventional analgesia for preventing persistent postoperative pain in adults and children. Cochrane

Transient neurological symptoms (TNS) following spinal anaesthesia with lidocaine versus other local anaesthetics in adult surgical 
Database of Systematic Reviews 2018, Issue 4. [DOI: 10.1002/14651858.CD007105.pub4]

\section{Winnie 2001}

Winnie AP, Nader AM. Santayana's prophecy fulfilled. Regional Anesthesia and Pain Medicine 2001;26(6):558-64. [PUBMED: 11707796]

\section{Yoos 2005}

Yoos JR, Kopacz DJ. Spinal 2-chloroprocaine for surgery: an initial 10-month experience. Anesthesia and Analgesia 2005;100(2):553-8. [PUBMED: 15673893]

\section{References to other published versions of this review}

\section{Zaric 2003}

Zaric D, Christiansen C, Pace NL, Punjasawadwong Y.

Transient neurologic symptoms (TNS) following spinal

\section{CHARACTERISTICS OF STUDIES}

Characteristics of included studies [ordered by study ID] anaesthesia with lidocaine versus other local anaesthetics. Cochrane Database of Systematic Reviews 2003, Issue 2. [DOI: 10.1002/14651858.CD003006]

\section{Zaric 2005}

Zaric D, Christiansen C, Pace NL, Punjasawadwong Y. Transient neurologic symptoms (TNS) following spinal anaesthesia with lidocaine versus other local anaesthetics. Cochrane Database of Systematic Reviews 2005, Issue 4. [DOI: 10.1002/14651858.CD003006.pub2]

\section{Zaric 2009}

Zaric D, Pace NL. Transient neurologic symptoms (TNS) following spinal anaesthesia with lidocaine versus other local anaesthetics. Cochrane Database of Systematic Reviews 2009, Issue 2. [DOI: 10.1002/14651858.CD003006.pub3]

\section{Ali Hassan 2015}

Rethods $\quad$ Randomization: yes
Participant blinding: no
Provider blinding: no
Assessor blinding: unclear
Dropouts: not reported

Country: Egypt
ASA: I and II
Gender: men and women
Mean age: 42 (SD 17) years
Procedures: various
Ambulatory surgery: yes
Surgical positioning: supine
Number of participants: 50

Interventions

Drug 1: $2 \%$ lido, isobaric, fixed dose $(1 \mathrm{~mL})$

Drug 2: $0.5 \%$ bupi, isobaric, fixed dose $(0.6 \mathrm{~mL})$

Needle: sharp-point

\begin{tabular}{ll}
\hline Outcomes & TNS at 1,3 , and 7 days \\
\hline Notes & Follow-up duration: 7 days \\
& Follow-up method: telephone contact
\end{tabular}

Transient neurological symptoms (TNS) following spinal anaesthesia with lidocaine versus other local anaesthetics in adult surgical 
Ali Hassan 2015 (Continued)

TNS therapy: not described

\section{Risk of bias}

Bias Authors' judgement Support for judgement

Random sequence genera- Low risk tion (selection bias)

Quote: "fifty patients were randomized by a computer generated random number table and by 1:1 ratio into two groups of 25 each."

Allocation concealment Unclear risk No mention of allocation concealment.

(selection bias)

Participant blinding (per-

High risk

Quote: "prospective, randomized, and open study was conducted (sic), includ-

formance bias and detecing 50 outpatients undergoing knee arthroscopy." tion bias)

\begin{tabular}{|c|c|c|}
\hline $\begin{array}{l}\text { Provider blinding (perfor- } \\
\text { mance bias) }\end{array}$ & High risk & $\begin{array}{l}\text { Quote: "prospective, randomized, and open study was conducted (sic), includ- } \\
\text { ing } 50 \text { outpatients undergoing knee arthroscopy." }\end{array}$ \\
\hline
\end{tabular}

\begin{tabular}{ll}
\hline $\begin{array}{l}\text { Assessor blinding (detec- } \\
\text { tion bias) }\end{array}$ & $\begin{array}{l}\text { Quote: "prospective, randomized, and open study was conducted (sic), includ- } \\
\text { ing } 50 \text { outpatients undergoing knee arthroscopy." }\end{array}$ \\
& Comment: the assessor was not identified. \\
\hline
\end{tabular}

Incomplete outcome data Low risk No dropouts.

(attrition bias)

All outcomes

Selective reporting (re- Unclear risk Study protocol not available.

porting bias)

Aouad 2001

\begin{tabular}{ll}
\hline Methods & Randomization: yes \\
Participant blinding: yes \\
Provider blinding: no \\
Assessor blinding: yes \\
Dropouts: 0 \\
\hline
\end{tabular}

Participants Country: Lebanon

ASA: I and II

Gender: women

Mean age: 31 (SD 5) years

Caesarean section

Surgical positioning: supine

Number of participants: 200 
Needle: $25 \mathrm{G}$, pencil-point

\begin{tabular}{ll}
\hline Outcomes & TNS at 1 day \\
& Back pain \\
\hline Notes & Follow-up duration: 1.3 days \\
& Follow-up method: telephone contact
\end{tabular}

\section{Risk of bias}

\begin{tabular}{lll}
\hline Bias & Authors' judgement & Support for judgement \\
\hline $\begin{array}{l}\text { Random sequence genera- } \\
\text { tion (selection bias) }\end{array}$ & Unclear risk & $\begin{array}{l}\text { Quote: "patients were allocated randomly by sealed envelope..." } \\
\text { Comment: did not specify the method of randomization (referring to a random } \\
\text { number table, computer-generated random number sequence, tossing coin, } \\
\text { etc.). }\end{array}$ \\
\hline $\begin{array}{l}\text { Allocation concealment } \\
\text { (selection bias) }\end{array}$ & Unclear risk & $\begin{array}{l}\text { Quote: "patients were allocated randomly by sealed envelope..." } \\
\text { Comment: did not specify allocation by sequentially numbered, sealed, } \\
\text { opaque envelopes. }\end{array}$ \\
\hline
\end{tabular}

Participant blinding (per- $\quad$ Low risk Quote: "patients were blinded as to the spinal anesthetic used."
formance bias and detec-

tion bias)

\begin{tabular}{|c|c|c|}
\hline $\begin{array}{l}\text { Provider blinding (perfor- } \\
\text { mance bias) }\end{array}$ & High risk & $\begin{array}{l}\text { Quote: "the anesthesiologist who administered the spinal anesthetic and } \\
\text { collected the data on sensory and motor blockade was not blinded as to the } \\
\text { study groups." }\end{array}$ \\
\hline
\end{tabular}

\begin{tabular}{|c|c|c|}
\hline $\begin{array}{l}\text { Assessor blinding (detec- } \\
\text { tion bias) }\end{array}$ & Low risk & $\begin{array}{l}\text { Quote: "all patients were interviewed... by an anesthesiologist who was un- } \\
\text { aware of the local anesthetic given." }\end{array}$ \\
\hline
\end{tabular}

Incomplete outcome data Low risk 200 participants enrolled. Results reported for 200 participants.
(attrition bias)
All outcomes

Selective reporting (re- Unclear risk Study protocol not available.

porting bias)

\section{Breebaart 2003}

Rethods
Randomization: yes
Provider blinding: yes
Assessor blinding: yes
Dropouts: 0

Participants Country: Belgium

Transient neurological symptoms (TNS) following spinal anaesthesia with lidocaine versus other local anaesthetics in adult surgical 
Breebaart 2003 (Continued)

\section{ASA: I}

Gender: men and women

Mean age (range): lido: 42 (20-57); levo: 39 (18-59); ropi: 39 (19-57) years

Ambulatory surgery

Surgical positioning: supine

Number of participants: 90

\begin{tabular}{ll}
\hline Interventions & Drug 1: $2 \%$ lido, isobaric, fixed dose $(3 \mathrm{~mL})$ \\
& Drug 2: $0.5 \%$ levo, isobaric, fixed dose $(3 \mathrm{~mL})$ \\
& Drug 3: $0.75 \%$ ropi, isobaric, fixed dose $(3 \mathrm{~mL})$ \\
& Needle: $27 \mathrm{G}$, pencil-point \\
\hline Outcomes & TNS at 2 days \\
& Urinary retention \\
\hline Notes & Follow-up duration: 2 days \\
& Follow-up method: telephone contact \\
& TNS therapy: none \\
& TNS resolution: 1 day
\end{tabular}

\section{Risk of bias}

\begin{tabular}{lll}
\hline Bias & Authors' judgement & Support for judgement \\
\hline $\begin{array}{l}\text { Random sequence genera- } \\
\text { tion (selection bias) }\end{array}$ & Low risk & Quote "...randomised (by a computer-generated randomisation sequence)..." \\
\hline $\begin{array}{l}\text { Allocation concealment } \\
\text { (selection bias) }\end{array}$ & Unclear risk & Not described. \\
\hline $\begin{array}{l}\text { Participant blinding (per- } \\
\text { formance bias and detec- } \\
\text { tion bias) }\end{array}$ & Low risk & Quote: "...double-blind study." \\
\hline
\end{tabular}

\section{Provider blinding (perfor- Low risk} mance bias)
Quote: "...double-blind study." "All 3-ml solutions were prepared in an adjacent space by a supervisor not involved in the subsequent evaluation of the study-patient."

Comment: we assume from this comment that the syringes were unlabelled.

\begin{tabular}{ll}
\hline $\begin{array}{l}\text { Assessor blinding (detec- } \\
\text { tion bias) }\end{array}$ & Low risk \\
\end{tabular}

Incomplete outcome data Low risk

Incomplete outcome data Low risk
(attrition bias)
All outcomes

Quote: "ninety patients...were included..." "Two days after discharge, all patients were contacted by phone..."

Comment: results reported for 90 participants.

\footnotetext{
Selective reporting (re- Unclear risk Study protocol not available.
porting bias)

Transient neurological symptoms (TNS) following spinal anaesthesia with lidocaine versus other local anaesthetics in adult surgical 


Rethods
Pandomization: yes
Provider blinding: yes
Assessor blinding: yes
Dropouts: 0

Country: Italy
ASA: I and II
Gender: men and women
Mean age (range): lido: 49 (20-69); 2-chlorprocaine: 46 (18-70) years
Ambulatory surgery
Surgical positioning: supine
Number of participants: 30

Interventions

Drug 1: 2\% lido, isobaric, fixed dose $(2.5 \mathrm{~mL})$

Drug 2: 2\% 2-chlorprocaine isobaric, fixed dose $(2.5 \mathrm{~mL})$

Needle: $25 \mathrm{G}$, pencil-point

\begin{tabular}{ll}
\hline Outcomes & TNS during first 7 days \\
\hline Notes & Follow-up duration: 7 days \\
& Follow-up method: telephone contact \\
& TNS therapy: NSAID \\
& TNS resolution: 7 days \\
\hline
\end{tabular}

\section{Risk of bias}

\begin{tabular}{|c|c|c|}
\hline Bias & Authors' judgement & Support for judgement \\
\hline $\begin{array}{l}\text { Random sequence genera- } \\
\text { tion (selection bias) }\end{array}$ & Low risk & $\begin{array}{l}\text { Quote: "using a computer-generated sequence of numbers, and sealed en- } \\
\text { velopes patients were randomly allocated to receive...(sic)." }\end{array}$ \\
\hline \multirow[t]{2}{*}{$\begin{array}{l}\text { Allocation concealment } \\
\text { (selection bias) }\end{array}$} & Unclear risk & $\begin{array}{l}\text { Quote. "using a computer-generated sequence of numbers, and sealed en- } \\
\text { velopes patients were randomly allocated to receive...(sic)." }\end{array}$ \\
\hline & & $\begin{array}{l}\text { Comment: did not specify allocation by sequentially numbered, sealed, } \\
\text { opaque envelopes. }\end{array}$ \\
\hline $\begin{array}{l}\text { Participant blinding (per- } \\
\text { formance bias and detec- } \\
\text { tion bias) }\end{array}$ & Low risk & Quote: "...prospective, randomized, double-blind study..." \\
\hline $\begin{array}{l}\text { Provider blinding (perfor- } \\
\text { mance bias) }\end{array}$ & Low risk & $\begin{array}{l}\text { Quote: "the anesthesiologist performing the spinal injection, as well as the ob- } \\
\text { servers making assessments were blinded to patient grouping (sic)." }\end{array}$ \\
\hline
\end{tabular}

Transient neurological symptoms (TNS) following spinal anaesthesia with lidocaine versus other local anaesthetics in adult surgical 
Casati 2007 (Continued)

$\begin{aligned} & \text { Assessor blinding (detec- } \quad \text { Low risk } \\ & \text { tion bias) }\end{aligned} \quad \begin{aligned} & \text { Quote: "the anesthesiologist performing the spinal injection, as well as the ob- } \\ & \text { servers making assessments were blinded to patient grouping (sic)." }\end{aligned}$
tion bias) servers making assessments were blinded to patient grouping (sic)."

Incomplete outcome data Low risk

No dropouts.

(attrition bias)

All outcomes

$\begin{aligned} & \text { Selective reporting (re- } \\ & \text { porting bias) }\end{aligned}$
Unclear risk Study protocol not available.

porting bias)

\section{de Weert 2000}

$\begin{array}{ll}\text { Methods } & \text { Randomization: yes } \\ \text { Participant blinding: yes } \\ \text { Provider blinding: unclear } \\ \text { Assessor blinding: unclear } \\ \text { Dropouts: } 1 \text {, outcome not reported }\end{array}$

Country: the Netherlands
ASA: I and II
Gender: men and women
Mean age: lido: 43 (SD 14); prilo: 37 (SD 11) years
Ambulatory surgery: unclear
Surgical positioning: supine
Number of participants: 70

\begin{tabular}{ll}
\hline Interventions & Drug 1: $2 \%$ lido, isobaric, fixed dose $(4 \mathrm{~mL})$ \\
& Drug $2: 2 \%$ prilo, isobaric, fixed dose $(4 \mathrm{~mL})$ \\
& Needle: 25 G, pencil-point \\
\hline Outcomes & TNS at 1 day \\
\hline Notes & Follow-up duration: $1-4$ days \\
& Follow-up method: direct contact, telephone contact \\
& TNS therapy: unclear \\
& TNS resolution: 2 -3 days
\end{tabular}

\section{Risk of bias}

\section{Bias}

Random sequence generation (selection bias)

\section{Authors' judgement Support for judgement}

Unclear risk Quote: "consecutive patients were randomly allocated using sealed envelopes..." 
de Weert 2000 (Continued)

Comment: did not specify the method of randomization (referring to a random number table, computer-generated random number sequence, tossing coin, etc.).

\begin{tabular}{ll}
\hline $\begin{array}{l}\text { Allocation concealment } \\
\text { (selection bias) }\end{array}$ & $\begin{array}{l}\text { Unclear risk } \\
\text { velopes..." }\end{array}$ \\
& $\begin{array}{l}\text { Comment: did not specify allocation by sequentially numbered, sealed, } \\
\text { opaque envelopes. }\end{array}$
\end{tabular}

\begin{tabular}{|c|c|c|}
\hline $\begin{array}{l}\text { Participant blinding (per- } \\
\text { formance bias and detec- } \\
\text { tion bias) }\end{array}$ & Low risk & $\begin{array}{l}\text { Quote: "the purpose of this double-blind study..." } \\
\text { Comment: participants likely blinded. }\end{array}$ \\
\hline
\end{tabular}

\begin{tabular}{|c|c|c|}
\hline $\begin{array}{l}\text { Provider blinding (perfor- } \\
\text { mance bias) }\end{array}$ & Unclear risk & $\begin{array}{l}\text { Quote: "the purpose of this double-blind study..." } \\
\text { Comment: volume of local anaesthetic was same in each group, and study } \\
\text { was described as double-blind. However, there was no description of who pre- } \\
\text { pared the study drug. }\end{array}$ \\
\hline $\begin{array}{l}\text { Assessor blinding (detec- } \\
\text { tion bias) }\end{array}$ & Unclear risk & $\begin{array}{l}\text { Quote: "the purpose of this double-blind study..." } \\
\text { Comment: assessor blinding not specified. }\end{array}$ \\
\hline $\begin{array}{l}\text { Incomplete outcome data } \\
\text { (attrition bias) } \\
\text { All outcomes }\end{array}$ & High risk & $\begin{array}{l}\text { Quote: "one patient in the prilocaine group could not be included because the } \\
\text { data were incomplete." } \\
\text { Comment: risk of bias was high because a single dropout may affect the esti- } \\
\text { mated risk of a rare event. }\end{array}$ \\
\hline $\begin{array}{l}\text { Selective reporting (re- } \\
\text { porting bias) }\end{array}$ & Unclear risk & Study protocol not available. \\
\hline
\end{tabular}

Etezadi 2013

\begin{tabular}{ll} 
Methods & Randomization: yes \\
Participant blinding: unclear & Provider blinding: no \\
& Assessor blinding: yes \\
& Dropouts: 0 \\
\hline Participants & Country: Iran \\
& ASA: I and II \\
& Gender: men and women \\
& Age range: $18-60$ years \\
& Ambulatory surgery: no \\
& Surgical positioning: supine, lithotomy \\
& Number of participants: 250 \\
\hline Drug $1: 5 \%$ lido, hyperbaric, variable dose $(1.5-2 \mathrm{~mL})$
\end{tabular}

Transient neurological symptoms (TNS) following spinal anaesthesia with lidocaine versus other local anaesthetics in adult surgical 
Needle: $25 \mathrm{~g}$ sharp and pencil point

\begin{tabular}{ll}
\hline Outcomes & TNS \\
\hline Notes & Follow-up duration: 5 days \\
& Follow-up method: in person, unclear after 48 hours ("visited") \\
& TNS therapy: NSAIDs \\
& TNS resolution: unclear
\end{tabular}

\section{Risk of bias}

\begin{tabular}{|c|c|c|}
\hline Bias & Authors' judgement & Support for judgement \\
\hline $\begin{array}{l}\text { Random sequence genera- } \\
\text { tion (selection bias) }\end{array}$ & Low risk & $\begin{array}{l}\text { Quote: "... randomization was achieved by a computer-generated block of } \\
\text { numbers and sealed envelope technique." }\end{array}$ \\
\hline \multirow[t]{2}{*}{$\begin{array}{l}\text { Allocation concealment } \\
\text { (selection bias) }\end{array}$} & Unclear risk & $\begin{array}{l}\text { Quote: "... randomization was achieved by a computer-generated block of } \\
\text { numbers and sealed envelope technique." }\end{array}$ \\
\hline & & $\begin{array}{l}\text { Comment: did not specify allocation by sequentially numbered, sealed, } \\
\text { opaque envelopes. }\end{array}$ \\
\hline $\begin{array}{l}\text { Participant blinding (per- } \\
\text { formance bias and detec- } \\
\text { tion bias) }\end{array}$ & Low risk & $\begin{array}{l}\text { Study was described as "double-blind" but otherwise participant blinding was } \\
\text { not addressed. }\end{array}$ \\
\hline $\begin{array}{l}\text { Provider blinding (perfor- } \\
\text { mance bias) }\end{array}$ & High risk & $\begin{array}{l}\text { Volumes of local anaesthetic were not the same for the } 2 \text { interventions, thus } \\
\text { provider not blinded. }\end{array}$ \\
\hline $\begin{array}{l}\text { Assessor blinding (detec- } \\
\text { tion bias) }\end{array}$ & Low risk & $\begin{array}{l}\text { Quote: "the symptoms of TNS... were observed by a neurosurgeon that was } \\
\text { blinded to... the type of drug... used for spinal anesthesia." }\end{array}$ \\
\hline $\begin{array}{l}\text { Incomplete outcome data } \\
\text { (attrition bias) } \\
\text { All outcomes }\end{array}$ & Low risk & 250 participants enrolled, data reported for 250 participants. \\
\hline $\begin{array}{l}\text { Selective reporting (re- } \\
\text { porting bias) }\end{array}$ & Unclear risk & Study protocol not available. \\
\hline
\end{tabular}

Fanelli 2009

\begin{tabular}{ll}
\hline Methods & Randomization: yes \\
& Allocation concealment: yes \\
& Participant blinding: unclear \\
& Provider blinding: no \\
& Assessor blinding: unclear \\
Dropouts: 0
\end{tabular}

Transient neurological symptoms (TNS) following spinal anaesthesia with lidocaine versus other local anaesthetics in adult surgical 
Fanelli 2009 (Continued)

ASA: I and II

Gender: unclear

Age range: $18-80$ years

Ambulatory surgery: yes

Surgical positioning: supine

Number of participants: 30

\begin{tabular}{ll}
\hline Interventions & Drug 1: $1 \%$ lido, isobaric, fixed dose $(5 \mathrm{~mL})$ \\
& Drug 2: $0.5 \%$ ropi, isobaric, fixed dose $(2 \mathrm{~mL})$ \\
& Needle: 25 g, pencil-point \\
\hline Outcomes & TNS at 1 and 7 days \\
\hline Notes & Follow-up: 7 days \\
& Follow-up method: telephone contact \\
& TNS therapy: ketoprofen, tramadol \\
& TNS resolution: by 7 days
\end{tabular}

\section{Risk of bias}

\begin{tabular}{|c|c|c|}
\hline Bias & Authors' judgement & Support for judgement \\
\hline $\begin{array}{l}\text { Random sequence genera- } \\
\text { tion (selection bias) }\end{array}$ & Low risk & $\begin{array}{l}\text { Quote: "using a computer-generated sequence of numbers for randomisation, } \\
\text { and sealed envelopes for allocation concealment, patients were allocated to } \\
\text { receive a spinal injection of either } 50 \mathrm{mg} \text { of plain lidocaine } 10 \mathrm{mg} / \mathrm{ml} \text { or } 10 \mathrm{mg} \\
\text { of plain ropivacaine } 5 \mathrm{mg} / \mathrm{ml} . "\end{array}$ \\
\hline \multirow[t]{2}{*}{$\begin{array}{l}\text { Allocation concealment } \\
\text { (selection bias) }\end{array}$} & Unclear risk & $\begin{array}{l}\text { Quote: "using a computer-generated sequence of numbers for randomisation, } \\
\text { and sealed envelopes for allocation concealment..." }\end{array}$ \\
\hline & & $\begin{array}{l}\text { Comment: did not specify allocation by sequentially numbered, sealed, } \\
\text { opaque envelopes. }\end{array}$ \\
\hline $\begin{array}{l}\text { Participant blinding (per- } \\
\text { formance bias and detec- } \\
\text { tion bias) }\end{array}$ & Unclear risk & $\begin{array}{l}\text { Quote: "we therefore conducted a prospective, randomised, blind study..." } \\
\text { Comment: no description of participant blinding provided. }\end{array}$ \\
\hline $\begin{array}{l}\text { Provider blinding (perfor- } \\
\text { mance bias) }\end{array}$ & High risk & $\begin{array}{l}\text { Quote: "the anaesthesiologist performing the spinal block, who was aware of } \\
\text { patient's group allocation, was not involved in patient's follow-up." }\end{array}$ \\
\hline \multirow[t]{2}{*}{$\begin{array}{l}\text { Assessor blinding (detec- } \\
\text { tion bias) }\end{array}$} & Unclear risk & $\begin{array}{l}\text { Quote: "after spinal injection, a blinded observer recorded progression and re- } \\
\text { covery from the spinal block, until home discharge criteria were achieved." }\end{array}$ \\
\hline & & $\begin{array}{l}\text { Comment: no statement regarding the blinding status of the person perform- } \\
\text { ing the telephone interview assessing TNS symptoms. }\end{array}$ \\
\hline $\begin{array}{l}\text { Incomplete outcome data } \\
\text { (attrition bias) } \\
\text { All outcomes }\end{array}$ & Low risk & No dropouts. \\
\hline
\end{tabular}


Fanelli 2009 (Continued)
Selective reporting (re-
Unclear risk
No study protocol available. porting bias)

Gozdemir 2010

Rethods
Randomization: yes
Participant blinding: yes
Provider blinding: yes
Assessor blinding: yes
Dropouts: 0

\begin{tabular}{ll}
\hline Participants & Country: Turkey \\
ASA: I and II \\
Gender: men and women \\
Age range: $20-81$ years \\
Ambulatory surgery: no \\
Surgical positioning: supine \\
Number of participants: 60
\end{tabular}

\begin{tabular}{ll}
\hline Interventions & Drug 1: $2 \%$ lido, isobaric, fixed dose $(4 \mathrm{~mL})$ \\
& Drug 2: $0.5 \%$ levo, isobaric, fixed dose $(4 \mathrm{~mL})$ \\
& Needle: sharp \\
\hline Outcomes & TNS at 3 days \\
\hline Notes & Follow-up duration: 7 days \\
& Follow-up method: telephone contact \\
& TNS therapy: NSAID \\
& TNS resolution: 7 days
\end{tabular}

\section{Risk of bias}

\section{Bias}

Random sequence genera- Low risk tion (selection bias)

\section{Authors' judgement Support for judgement}

Quote: "patients were assigned randomly by the authors..."

Comment: did not state method of randomization (flipping a coin, random number table, etc.)

$\begin{array}{ll}\begin{array}{l}\text { Allocation concealment } \\ \text { (selection bias) }\end{array} & \text { Unclear risk }\end{array} \quad \begin{aligned} & \text { Quote: "patients were assigned randomly by the authors via a sealed envelope } \\ & \text { method to receive either isobaric levobupivacaine } \mathrm{HCl} \text { or isobaric lidocaine." }\end{aligned}$


Comment: did not specify allocation by sequentially numbered, sealed, opaque envelopes.

\begin{tabular}{|c|c|c|}
\hline $\begin{array}{l}\text { Participant blinding (per- } \\
\text { formance bias and detec- } \\
\text { tion bias) }\end{array}$ & Low risk & $\begin{array}{l}\text { Quote: "we enrolled } 60 \text { patients ( } 47 \text { male, } 13 \text { female, overall mean age } 30 \text { years } \\
\text { [range } 20-81 \text { years]) in this prospective, randomised, double-blind study." }\end{array}$ \\
\hline $\begin{array}{l}\text { Provider blinding (perfor- } \\
\text { mance bias) }\end{array}$ & Low risk & $\begin{array}{l}\text { Quote: "both drugs were prepared at } 4 \mathrm{ml} \text { doses and were drawn into syringes } \\
\text { by an independent anaesthesia resident so that the anaesthetist performing } \\
\text { the injection was unaware of which drug was being given." }\end{array}$ \\
\hline $\begin{array}{l}\text { Assessor blinding (detec- } \\
\text { tion bias) }\end{array}$ & Low risk & $\begin{array}{l}\text { Quote: "the investigators performing the interviews were unaware of which } \\
\text { anaesthetic had been used." }\end{array}$ \\
\hline $\begin{array}{l}\text { Incomplete outcome data } \\
\text { (attrition bias) } \\
\text { All outcomes }\end{array}$ & Low risk & No dropouts. \\
\hline $\begin{array}{l}\text { Selective reporting (re- } \\
\text { porting bias) }\end{array}$ & Unclear risk & Study protocol not available. \\
\hline
\end{tabular}

\section{Hampl 1995a}

Rethods
Randomization: yes
Provider blinding: yes
Assessor blinding: yes
Dropouts: 0

Country: Switzerland
ASA: I and II
Gender: women
Age range: $19-81$ years
Procedures: gynaecological
Ambulatory surgery: no
Surgical positioning: lithotomy
Number of participants: 44

Interventions $\quad$ Drug 1: $5 \%$ lido, hyperbaric, fixed dose $(1.5 \mathrm{~mL})$

Drug 2: $0.5 \%$ bupi, hyperbaric, fixed dose $(1.5 \mathrm{~mL})$

Needle: 25 G, pencil-point

\begin{tabular}{|c|c|}
\hline Outcomes & $\begin{array}{l}\text { TNS at } 1 \text { day } \\
\text { Back pain }\end{array}$ \\
\hline Notes & Follow-up duration: $1-4$ days \\
\hline
\end{tabular}


Hampl 1995a (Continued)

Follow-up method: direct contact

TNS therapy: unclear

TNS resolution: all recovered

\section{Risk of bias}

Bias Authors' judgement Support for judgement

Random sequence genera- Unclear risk tion (selection bias)

Quote: "patients were randomly assigned to receive one of the following three local anesthetic solutions..."

Comment: did not specify the method of randomization (referring to a random number table, computer-generated random number sequence, tossing coin, etc.).

\begin{tabular}{|c|c|c|}
\hline $\begin{array}{l}\text { Allocation concealment } \\
\text { (selection bias) }\end{array}$ & Unclear risk & $\begin{array}{l}\text { No mention of the method of allocation concealment (central allocation, se- } \\
\text { quentially numbered, sealed, opaque envelopes, or sequentially numbered } \\
\text { drug containers of identical appearance). }\end{array}$ \\
\hline
\end{tabular}

Participant blinding (per- Low risk Quote: "...the aim of this prospective double-blinded study was..."
formance bias and detection bias)

\begin{tabular}{lll}
\hline $\begin{array}{l}\text { Provider blinding (perfor- } \\
\text { mance bias) }\end{array}$ & Low risk & $\begin{array}{l}\text { Quote: "the drugs were delivered by the pharmacy in blinded vials each con- } \\
\text { taining } 2 \text { ml local anesthetic solution." }\end{array}$ \\
\hline $\begin{array}{l}\text { Assessor blinding (detec- } \\
\text { tion bias) }\end{array}$ & Low risk & $\begin{array}{l}\text { Quote: "on post-operative day 1, all patients were evaluated for TRI by oral in- } \\
\text { terrogation by one anesthesiologist who was unaware of details of the anes- } \\
\text { thesia procedure." }\end{array}$ \\
\hline $\begin{array}{l}\text { Incomplete outcome data } \\
\begin{array}{l}\text { (attrition bias) } \\
\text { All outcomes }\end{array}\end{array}$ & Low risk & Quote "... we studied 44 ASA class I and II patients..." \\
\hline
\end{tabular}

Selective reporting (re- Unclear risk Study protocol not available.

porting bias)

\section{Hampl 1998}

\begin{tabular}{ll}
\hline Methods & Randomization: yes \\
Participant blinding: yes \\
Provider blinding: yes \\
Assessor blinding: yes \\
Dropouts: 0 \\
\hline
\end{tabular}

Country: Switzerland
ASA: I and II
Gender: women
Mean age: lido: 39 (SD 17); prilo 39 (SD 13); bupi 36 (SD 14) years


Hampl 1998 (Continued)

Procedures: gynaecological

Ambulatory surgery: unclear

Surgical positioning: lithotomy

Number of participants: 90

\begin{tabular}{ll}
\hline Interventions & Drug 1: $2 \%$ lido, hyperbaric, fixed do \\
& Drug 2: $2 \%$ prilo, hyperbaric, fixed dose \\
& Drug 3: $0.5 \%$ bupi, hyperbaric, fixed \\
& Needle: $25 \mathrm{G}$, pencil-point \\
\hline Outcomes & TNS at 1 day \\
\hline Notes & Follow-up duration: $1-5$ days \\
& Follow-up methods: direct contact \\
& TNS therapy: unclear \\
& TNS resolution: $2-4$ days
\end{tabular}

\section{Risk of bias}

\begin{tabular}{lll}
\hline Bias & Authors' judgement & Support for judgement \\
\hline $\begin{array}{l}\text { Random sequence genera- } \\
\text { tion (selection bias) }\end{array}$ & Low risk & $\begin{array}{l}\text { Quote: "patients were assigned using a computer-generated randomization } \\
\text { scheme..." }\end{array}$ \\
\hline
\end{tabular}

\begin{tabular}{lll}
\hline $\begin{array}{l}\text { Allocation concealment } \\
\text { (selection bias) }\end{array}$ & Unclear risk mention of method of allocation concealment.
\end{tabular}

\begin{tabular}{lll}
\hline $\begin{array}{l}\text { Participant blinding (per- } \\
\text { formance bias and detec- } \\
\text { tion bias) }\end{array}$ & Low risk & $\begin{array}{l}\text { Quote: "the study solutions were provided by the hospital pharmacy... and } \\
\text { were provided in blinded vials." }\end{array}$ \\
\hline $\begin{array}{l}\text { Provider blinding (perfor- } \\
\text { mance bias) }\end{array}$ & Low risk & $\begin{array}{l}\text { Quote: "the study solutions were provided by the hospital pharmacy... and } \\
\text { were provided in blinded vials." }\end{array}$ \\
\hline $\begin{array}{l}\text { Assessor blinding (detec- } \\
\text { tion bias) }\end{array}$ & Low risk & $\begin{array}{l}\text { Quote: "...patients were evaluated for TNSs by a physician unaware of the } \\
\text { drug administered and the details of the anaesthetic procedure." (stated in ab- } \\
\text { stract, not in methods). }\end{array}$ \\
\hline $\begin{array}{l}\text { Incomplete outcome data } \\
\text { (attrition bias) }\end{array}$ & Low risk & Enrolled 90 participants, reported data for 90 participants. \\
$\begin{array}{l}\text { All outcomes } \\
\begin{array}{l}\text { Selective reporting (re- } \\
\text { porting bias) }\end{array}\end{array}$ & Unclear risk & Study protocol not available. \\
\hline
\end{tabular}

Hodgson 2000

$\begin{array}{ll}\text { Methods } & \text { Randomization: yes } \\ & \text { Participant blinding: yes }\end{array}$

Transient neurological symptoms (TNS) following spinal anaesthesia with lidocaine versus other local anaesthetics in adult surgical 
Hodgson 2000 (Continued)

Provider blinding: no

Assessor blinding: yes

Dropouts: 0

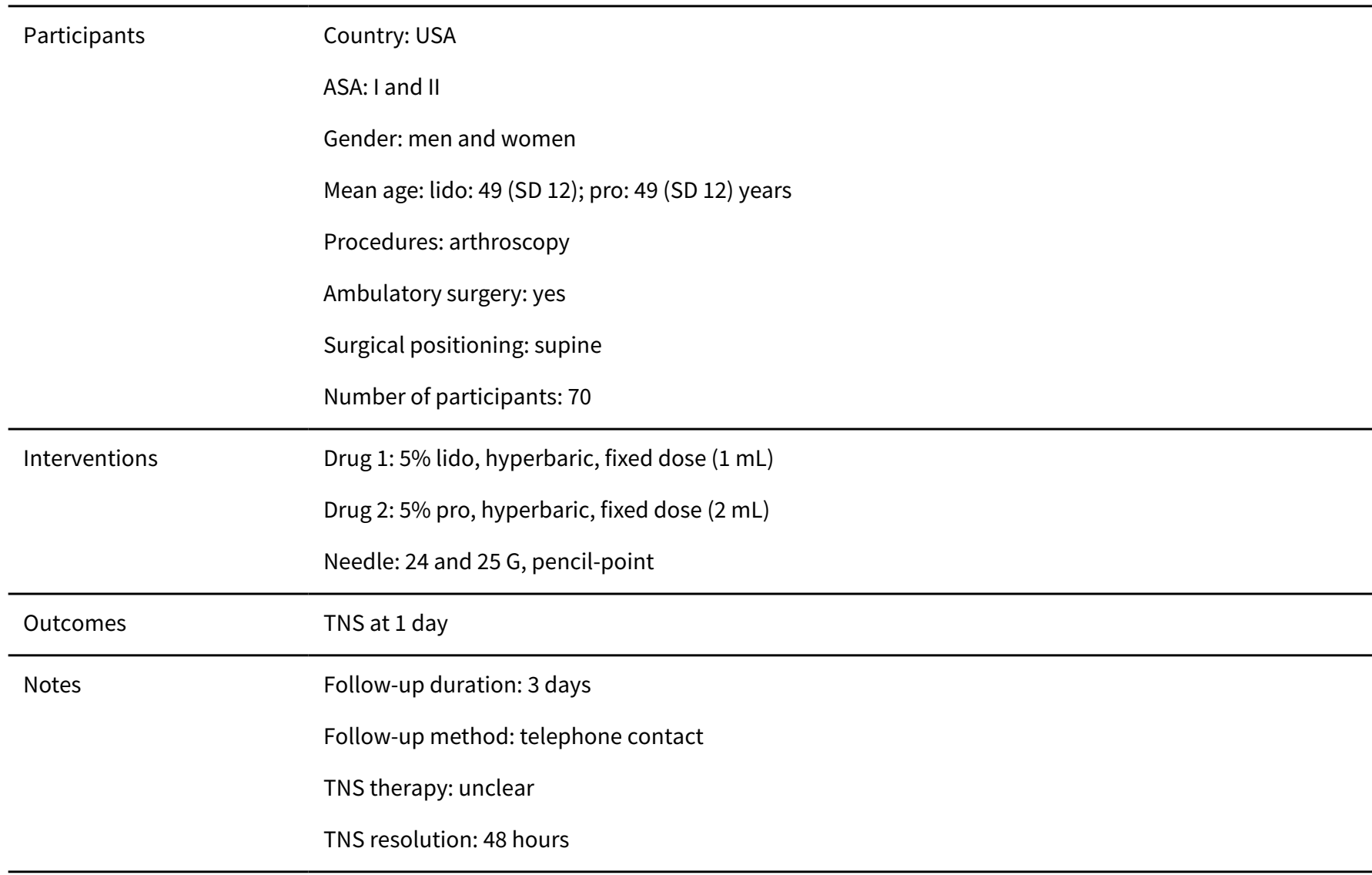

\section{Risk of bias}

Bias Authors' judgement Support for judgement

Random sequence genera- Low risk tion (selection bias)

Quote: "randomization was accomplished by random selection of blank, closed envelopes assigned by a computer-generated scheme to lidocaine or procaine by a numerical code which remained unbroken until data collection and assessment of all patients was complete."

\begin{tabular}{ll}
\hline $\begin{array}{l}\text { Allocation concealment } \\
\text { (selection bias) }\end{array}$ & Low risk \\
& $\begin{array}{l}\text { Quote: "randomization was accomplished by random selection of blank, } \\
\text { closed envelopes assigned by a computer-generated scheme to lidocaine or } \\
\text { procaine by numerical code which remained unbroken until data collection } \\
\text { and assessment of all patients was complete." }\end{array}$ \\
\hline
\end{tabular}

\begin{tabular}{lll}
$\begin{array}{l}\text { Participant blinding (per- } \\
\text { formance bias and detec- } \\
\text { tion bias) }\end{array}$ & Quote: "the patient remained blinded to the study drug." \\
\hline $\begin{array}{l}\text { Provider blinding (perfor- } \\
\text { mance bias) }\end{array}$ & High risk & $\begin{array}{l}\text { Quote: "...side effects...were managed intraoperatively by the managing anes- } \\
\text { thesia team, which was not blinded to the spinal drug." }\end{array}$ \\
$\begin{array}{l}\text { Assessor blinding (detec- } \\
\text { tion bias) }\end{array}$ & Low risk & $\begin{array}{l}\text { Quote: "patients were contacted...by a single anesthesiologist blinded to the } \\
\text { agent that the patient had received." }\end{array}$ \\
\hline
\end{tabular}

Transient neurological symptoms (TNS) following spinal anaesthesia with lidocaine versus other local anaesthetics in adult surgical 
Hodgson 2000 (Continued)

Incomplete outcome data Low risk Randomized 70 participants, results reported on 70 participants.

(attrition bias)

All outcomes

Selective reporting (re- $\quad$ Unclear risk $\quad$ Study protocol not available.
porting bias)

porting bias)

Imbelloni 2010

Rethods
Randomization: yes
Participant blinding: yes
Provider blinding: yes
Assessor blinding: unclear
Dropouts: 0

\begin{tabular}{ll}
\hline Participants & Country: Brazil \\
ASA: I and II & Gender: men and women \\
& Age range: $20-60$ years \\
& Ambulatory surgery: yes \\
& Surgical positioning: prone jack-knife \\
& Number of participants: 150 \\
\hline Interventions & Drug 1: $0.6 \%$ lido, hypobaric, fixed dose $(3 \mathrm{~mL})$ \\
& Drug 2: $0.15 \%$ bupi, hypobaric, fixed dose $(3 \mathrm{~mL})$ \\
& Needle: $27 \mathrm{G}$, sharp \\
\hline Outcomes & TNS \\
\hline Notes & Follow-up duration: 30 days \\
Follow-up method: telephone contact & TNS therapy: not available \\
\hline
\end{tabular}

\section{Risk of bias}

\section{Bias}

Random sequence genera- Low risk tion (selection bias)

\section{Allocation concealment} (selection bias)

\section{Authors' judgement Support for judgement}

Quote: "the randomized sequence was generated by a computer..."

Unclear risk

Quote: "the randomized sequence was generated by a computer, which was followed by the preparation of coded envelopes."

Transient neurological symptoms (TNS) following spinal anaesthesia with lidocaine versus other local anaesthetics in adult surgical 
Imbelloni 2010 (Continued)

Comment: did not specify allocation by sequentially numbered, sealed, opaque envelopes.

\begin{tabular}{ll}
\hline Participant blinding (per- & Low risk \\
formance bias and detec- & Quote: "...patients... were recruited for this prospective, randomized, dou- \\
tion bias) & ble-blind study."
\end{tabular}

\begin{tabular}{|c|c|c|}
\hline $\begin{array}{l}\text { Provider blinding (perfor- } \\
\text { mance bias) }\end{array}$ & Low risk & $\begin{array}{l}\text { Quote: "both solutions were prepared by an anesthesiologist who did not par- } \\
\text { ticipate in the study." }\end{array}$ \\
\hline \multirow[t]{2}{*}{$\begin{array}{l}\text { Assessor blinding (detec- } \\
\text { tion bias) }\end{array}$} & Unclear risk & $\begin{array}{l}\text { Quote: "proprioception and sensorial blockade were assessed by another } \\
\text { anesthesiologist, who was not aware of the groups..." }\end{array}$ \\
\hline & & $\begin{array}{l}\text { Comment: although the person assessing block characteristics was blinded, } \\
\text { there were no details about the follow-up assessor. }\end{array}$ \\
\hline $\begin{array}{l}\text { Incomplete outcome data } \\
\text { (attrition bias) } \\
\text { All outcomes }\end{array}$ & Low risk & No dropouts. \\
\hline $\begin{array}{l}\text { Selective reporting (re- } \\
\text { porting bias) }\end{array}$ & Unclear risk & Study protocol not available. \\
\hline
\end{tabular}

\section{Keld 2000}

\begin{tabular}{l} 
Rethods \\
Participant blinding: yes \\
Provider blinding: no \\
Assessor blinding: yes \\
Dropouts: 1 outcome reported \\
\hline
\end{tabular}

Participants $\quad$ Country: Denmark
ASA: I and II
Gender: men and women
Mean age: lido: 43; bupi: 46 years
Procedures: orthopaedic, general surgery
Ambulatory surgery: unclear
Surgical positioning: supine
Number of participants: 70

Interventions

Drug 1: 5\% lido, hyperbaric, fixed dose $(2 \mathrm{~mL})$

Drug 2: $0.5 \%$ bupi, hyperbaric, fixed dose $(2.5 \mathrm{~mL})$

Needle: $25 \mathrm{G}$, pencil-point

TNS at 1 day
Back pain

Transient neurological symptoms (TNS) following spinal anaesthesia with lidocaine versus other local anaesthetics in adult surgical patients: a network meta-analysis (Review)

Copyright $\odot 2019$ The Cochrane Collaboration. Published by John Wiley \& Sons, Ltd. 
Keld 2000 (Continued)

Follow-up duration: $1-3$ days
Follow-up methods: telephone contact
TNS therapy: unclear
TNS resolution: 41 hours

\section{Risk of bias}

\begin{tabular}{|c|c|c|}
\hline Bias & Authors' judgement & Support for judgement \\
\hline $\begin{array}{l}\text { Random sequence genera- } \\
\text { tion (selection bias) }\end{array}$ & Unclear risk & $\begin{array}{l}\text { Quote: "the patients were randomised to receive..." did not specify the } \\
\text { method of randomisation (referring to a random number table, computer-gen- } \\
\text { erated random number sequence, tossing coin, etc.). }\end{array}$ \\
\hline $\begin{array}{l}\text { Allocation concealment } \\
\text { (selection bias) }\end{array}$ & Unclear risk & No mention of allocation concealment. \\
\hline $\begin{array}{l}\text { Participant blinding (per- } \\
\text { formance bias and detec- } \\
\text { tion bias) }\end{array}$ & Low risk & Quote: "the study was performed as a prospective double-blinded study..." \\
\hline $\begin{array}{l}\text { Provider blinding (perfor- } \\
\text { mance bias) }\end{array}$ & High risk & $\begin{array}{l}\text { Quote: "this anaesthesiologist used the local anaesthetic according to the ran- } \\
\text { dom patient number and was therefore not blinded to the anaesthetic used." }\end{array}$ \\
\hline $\begin{array}{l}\text { Assessor blinding (detec- } \\
\text { tion bias) }\end{array}$ & Low risk & $\begin{array}{l}\text { Quote: "the patient was contacted... by a different anaesthesiologist, who was } \\
\text { blinded to the anaesthetic used..." }\end{array}$ \\
\hline \multirow{2}{*}{$\begin{array}{l}\text { Incomplete outcome data } \\
\text { (attrition bias) } \\
\text { All outcomes }\end{array}$} & High risk & $\begin{array}{l}\text { Quote: "one patient in the bupivacaine group received general anaesthesia } \\
\text { due to insufficient spinal anaesthesia and was excluded from the study." }\end{array}$ \\
\hline & & Comment: outcome from dropout not reported. \\
\hline $\begin{array}{l}\text { Selective reporting (re- } \\
\text { porting bias) }\end{array}$ & Unclear risk & Study protocol not available. \\
\hline
\end{tabular}

\section{Le Truong 2001}

\begin{tabular}{ll} 
Methods & Randomization: yes \\
Participant blinding: yes \\
Provider blinding: no \\
Assessor blinding: yes \\
Dropouts: 6 outcomes not reported \\
\hline
\end{tabular}

Participants Country: Canada

ASA: I and II

Gender: men and women

Mean age: lido: 38 (SD 9); pro: 41 (SD 11) years

Procedures: general surgery, gynaecological 
Le Truong 2001 (Continued)

Ambulatory surgery: unclear

Surgical positioning: supine, lithotomy

Number of participants: 66

\begin{tabular}{ll}
\hline Interventions & Drug 1: $5 \%$ lido, hyperbaric, fixed dose $(2 \mathrm{~mL})$ \\
& Drug 2: $10 \%$ pro, baricity unclear, fixed dose $(1 \mathrm{~mL})$ \\
& Needle: $27 \mathrm{G}$, pencil point \\
\hline Outcomes & TNS at 2 days \\
\hline Notes & Follow-up duration: 2 days \\
& Follow-up method: unclear \\
& TNS therapy: unclear \\
& TNS resolution: unclear \\
\hline
\end{tabular}

\section{Risk of bias}

\begin{tabular}{lll}
\hline Bias & Authors' judgement & Support for judgement \\
\hline $\begin{array}{l}\text { Random sequence genera- } \\
\text { tion (selection bias) }\end{array}$ & Unclear risk & $\begin{array}{l}\text { Quote: "patients were randomized to receive..." } \\
\text { Comment: did not specify the method of randomization (referring to a random } \\
\text { number table, computer-generated random number sequence, tossing coin, } \\
\text { etc.). }\end{array}$
\end{tabular}

\begin{tabular}{lll}
\hline $\begin{array}{l}\text { Allocation concealment } \\
\text { (selection bias) }\end{array}$ & Unclear risk & No mention of allocation concealment. \\
\hline $\begin{array}{l}\text { Participant blinding (per- } \\
\text { formance bias and detec- } \\
\text { tion bias) }\end{array}$ & Low risk & Quote: "this randomized, double-blind, prospective study..." \\
\end{tabular}

\begin{tabular}{lll}
\hline $\begin{array}{l}\text { Provider blinding (perfor- } \\
\text { mance bias) }\end{array}$ & Unclear risk & $\begin{array}{l}\text { Quote: "this randomized, double-blind, prospective study..." } \\
\text { Comment: no mention of provider blinding or preparation of study drug. As- } \\
\text { sessor was blinded. }\end{array}$ \\
\hline $\begin{array}{l}\text { Assessor blinding (detec- } \\
\text { tion bias) }\end{array}$ & Low risk & $\begin{array}{l}\text { Quote: "a blinded observer noted..." "...a blinded observer contacted the pa- } \\
\text { tients } 48 \text { h after surgery." }\end{array}$ \\
\hline $\begin{array}{l}\text { Incomplete outcome data } \\
\begin{array}{l}\text { (attrition bias) } \\
\text { All outcomes }\end{array}\end{array}$ & High risk & $\begin{array}{l}\text { Quote: "five patients had inadequate surgical anesthesia in group P... and one } \\
\text { in group L. All required general anesthesia and were excluded from the final } \\
\text { data analysis." }\end{array}$ \\
& $\begin{array}{l}\text { Comment: outcomes not reported from dropouts. } \\
\end{array}$
\end{tabular}

Selective reporting (re- Unclear risk $\quad$ Study protocol not available.
porting bias)

porting bias)

Methods Randomization: yes

Transient neurological symptoms (TNS) following spinal anaesthesia with lidocaine versus other local anaesthetics in adult surgical patients: a network meta-analysis (Review)

Copyright @ 2019 The Cochrane Collaboration. Published by John Wiley \& Sons, Ltd. 
Liguori 1998 (Continued)

Participant blinding: yes

Provider blinding: no

Assessor blinding: yes

Dropouts: 3 outcomes not reported

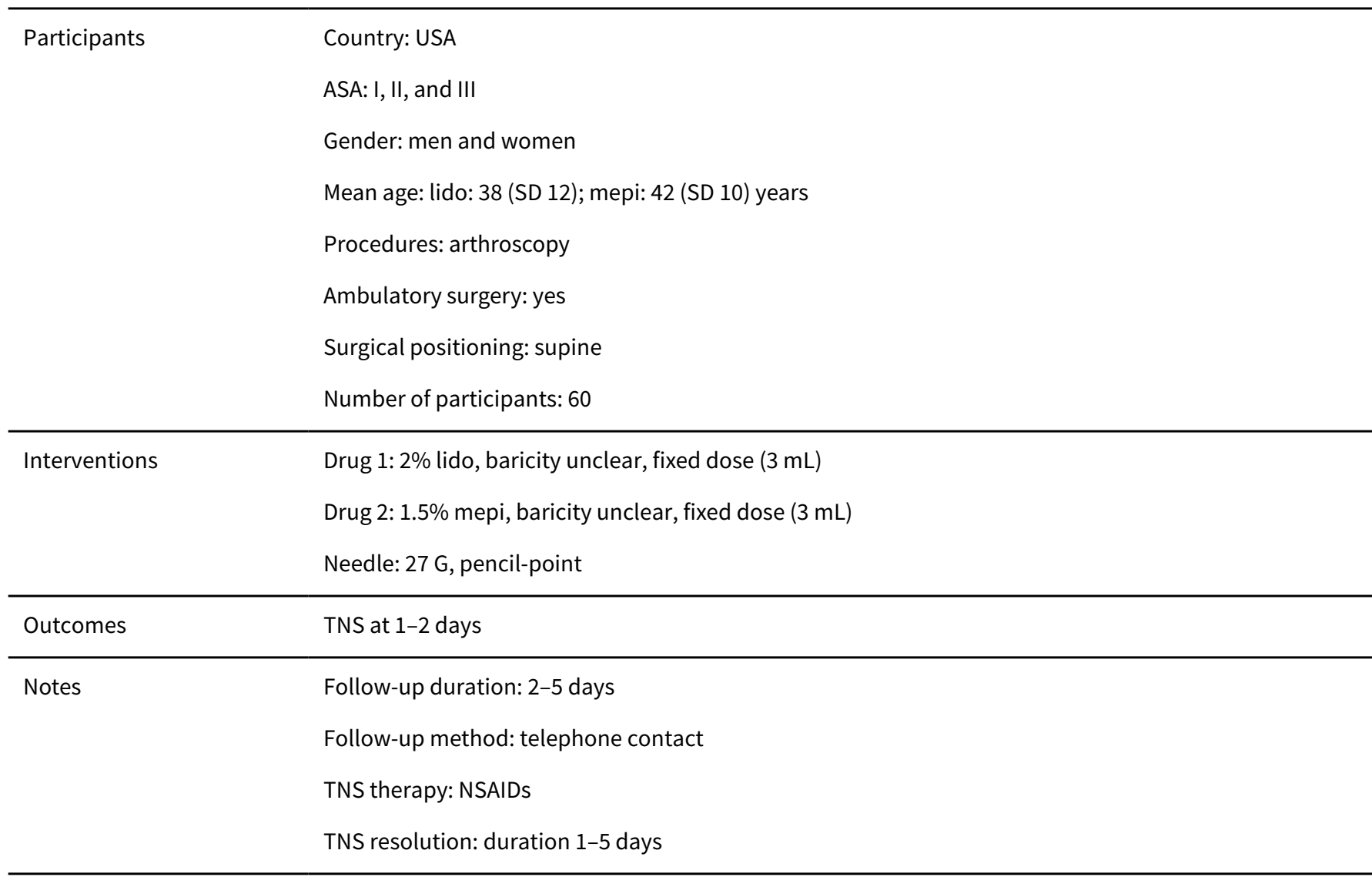

\section{Risk of bias}

Bias Authors' judgement Support for judgement

Random sequence genera- Low risk tion (selection bias)

Quote: "the patients were assigned using a random-number table to receive either $2 \% 3 \mathrm{ml}(60 \mathrm{mg})$ lidocaine... or $1.5 \% 3 \mathrm{ml}(45 \mathrm{mg}$ ) mepivacaine..."

Allocation concealment Unclear risk No mention of allocation concealment.

(selection bias)

Participant blinding (per- Low risk

formance bias and detec-

Low risk Quote: "...we decided to re-evaluate mepivacaine... in a randomized, doution bias) ble-blind comparison with isobaric $2 \%$ lidocaine..."

\begin{tabular}{|c|c|c|}
\hline $\begin{array}{l}\text { Provider blinding (perfor- } \\
\text { mance bias) }\end{array}$ & Low risk & $\begin{array}{l}\text { Quote: "...we decided to re-evaluate mepivacaine... in a randomized, dou } \\
\text { ble-blind comparison with isobaric } 2 \% \text { lidocaine..." }\end{array}$ \\
\hline
\end{tabular}

\begin{tabular}{ll}
\hline $\begin{array}{l}\text { Assessor blinding (detec- } \\
\text { tion bias) }\end{array}$ & Low risk \\
\end{tabular}

Incomplete outcome data High risk 3 participants in lido group lost to follow-up. Dropout outcomes not reported.
(attrition bias)


Liguori 1998 (Continued)

All outcomes

Selective reporting (re- $\quad$ Unclear risk $\quad$ Study protocol not available.
porting bias)

porting bias)

\section{Martinez-Bourio 1998}

Rethods
Pandomization: yes
Provider blinding: no
Assessor blinding: yes
Dropouts: 2 outcomes reported

Country: Spain
ASA: I, II, and III
Gender: men and women
Age range: $18-80$ years
Procedures: orthopaedic, urological, gynaecological, vascular, general surgery
Ambulatory surgery: unclear
Surgical positioning: supine, prone, lithotomy
Number of participants: 200

Interventions

Drug 1: 5\% lido, hyperbaric, variable dose

Drug 2: 5\% prilo, hyperbaric, variable dose

Needle: $25 \mathrm{G}$, pencil-point

\begin{tabular}{|c|c|c|}
\hline Outcomes & \multicolumn{2}{|l|}{$\begin{array}{l}\text { TNS at } 1-2 \text { days } \\
\text { Back pain }\end{array}$} \\
\hline \multirow[t]{4}{*}{ Notes } & \multicolumn{2}{|c|}{ Follow-up duration: $3-5$ days } \\
\hline & \multicolumn{2}{|c|}{ Follow-up method: direct contact, telephone contact } \\
\hline & \multicolumn{2}{|l|}{ TNS therapy: NSAIDs } \\
\hline & \multicolumn{2}{|c|}{ TNS resolution: maximum duration 10 days } \\
\hline \multicolumn{3}{|l|}{ Risk of bias } \\
\hline Bias & Authors' judgement & Support for judgement \\
\hline $\begin{array}{l}\text { Random sequence genera- } \\
\text { tion (selection bias) }\end{array}$ & Low risk & $\begin{array}{l}\text { Quote: "the patients were assigned... according to a computer-generated list } \\
\text { by simple random sampling." }\end{array}$ \\
\hline $\begin{array}{l}\text { Allocation concealment } \\
\text { (selection bias) }\end{array}$ & Low risk & $\begin{array}{l}\text { Quote: "patients were numbered consecutively by a blinded observer and allo- } \\
\text { cated to one of the anaesthetic solutions." }\end{array}$ \\
\hline
\end{tabular}

Transient neurological symptoms (TNS) following spinal anaesthesia with lidocaine versus other local anaesthetics in adult surgical 
Martinez-Bourio 1998 (Continued)
Participant blinding (per-
Unclear risk
Quote: "this prospective, masked, randomized study..." formance bias and detec-
Comment: participant blinding not mentioned. tion bias)

Quote: "the anesthetist who administered the spinal anesthesia (and collected

Provider blinding (perfor- High risk mance bias) the data on sensory and motor block) was not blinded to the study groups."

Assessor blinding (detec- Low risk tion bias)

Quote: "all patients were contacted by telephone 3-5 days after spinal anesthesia by an anaesthesiologist who was unaware of the drug given or details of the anaesthetic technique."

Incomplete outcome data Low risk (attrition bias)

Quote: "two blocks in the prilocaine group provided inadequate surgical anesAll outcomes thesia, and general anesthesia was required. None of the two patients with inadequate spinal anesthesia reported TNSs, but these patients were excluded from the final analysis..."

Comment: although these participants were excluded from the final analysis, the authors reported the outcome of interest. Therefore, risk of bias was low.

Selective reporting (re- Unclear risk Study protocol not available.

porting bias)

Pawlowski 2012

Rethods
Allocation concealment: unclear
Participant blinding: yes
Provider blinding: yes
Assessor blinding: yes
Dropouts: 7 dropouts, outcomes not reported

\section{Participants}

Country: USA

ASA I, II, and III

Gender: unclear

Age range: $19-70$ years

Ambulatory surgery: yes

Surgical positioning: supine

Number of participants: 84

Drug 2: $2 \%$ mepi, isobaric, fixed dose $(4 \mathrm{~mL})$

Needle: $27 \mathrm{G}$, pencil-point

\begin{tabular}{ll}
\hline Outcomes & TNS \\
\hline Notes & Follow-up duration: 3 days
\end{tabular}

Transient neurological symptoms (TNS) following spinal anaesthesia with lidocaine versus other local anaesthetics in adult surgical 
Pawlowski 2012 (Continued)

Follow-up method: telephone contact

TNS therapy: not available

TNS resolution: not available

\section{Risk of bias}

\begin{tabular}{|c|c|c|}
\hline Bias & Authors' judgement & Support for judgement \\
\hline $\begin{array}{l}\text { Random sequence genera- } \\
\text { tion (selection bias) }\end{array}$ & Low risk & $\begin{array}{l}\text { Quote: "patients were randomized to each group via computer-generated ran- } \\
\text { dom sequence..." }\end{array}$ \\
\hline $\begin{array}{l}\text { Allocation concealment } \\
\text { (selection bias) }\end{array}$ & Unclear risk & Did not discuss allocation concealment. \\
\hline $\begin{array}{l}\text { Participant blinding (per- } \\
\text { formance bias and detec- } \\
\text { tion bias) }\end{array}$ & Low risk & Quote: "the purpose of this prospective, randomized, double-blinded study..." \\
\hline $\begin{array}{l}\text { Provider blinding (perfor- } \\
\text { mance bias) }\end{array}$ & Low risk & $\begin{array}{l}\text { Quote: "the lidocaine and mepivacaine solutions for subarachnoid injection } \\
\text { were prepared by an investigator who did not participate in the patients' anes- } \\
\text { thetic care or data collection." }\end{array}$ \\
\hline $\begin{array}{l}\text { Assessor blinding (detec- } \\
\text { tion bias) }\end{array}$ & Low risk & $\begin{array}{l}\text { Quote: "a study-blinded observer assessed level of sensory block bilaterally } \\
\text { using a plastic pencil-point needle along the lumbar and thoracic dermatomes } \\
\text { in the midaxillary line." "Information on delayed variables, including fatigue, } \\
\text { nausea, vomiting, difficulty urinating, pain at the spinal needle site, pain at the } \\
\text { surgical site, back pain, back pain with radiating pain to the buttocks and/or } \\
\text { lower extremities (TNS), and numbness and tingling sensations, were obtained } \\
\text { by telephone call from a research nurse who was blinded to the study groups." }\end{array}$ \\
\hline $\begin{array}{l}\text { Incomplete outcome data } \\
\text { (attrition bias) } \\
\text { All outcomes }\end{array}$ & High risk & Dropout outcomes not reported. \\
\hline $\begin{array}{l}\text { Selective reporting (re- } \\
\text { porting bias) }\end{array}$ & Unclear risk & Study protocol not available. \\
\hline
\end{tabular}

Philip 2001

\begin{tabular}{ll}
\hline Methods & Randomization: yes \\
Participant blinding: yes \\
Provider blinding: yes \\
Assessor blinding: yes \\
Dropouts: 1 outcome reported \\
\hline
\end{tabular}

Participants

Country: USA

ASA: I

Gender: women

Mean age: lido: 27 (SD 5); bupi: 25 (SD 4) years

Transient neurological symptoms (TNS) following spinal anaesthesia with lidocaine versus other local anaesthetics in adult surgical 
Philip 2001 (Continued)

Procedures: postpartum tubal ligation

Ambulatory surgery: no

Surgical positioning: supine

Number of participants: 58

\begin{tabular}{ll} 
Interventions & Drug 1: $5 \%$ lido, hyperbaric, variable dose \\
& Drug 2: $0.75 \%$ bupi, hyperbaric, variable dose \\
& Needle: $25 \mathrm{G}$, pencil-point \\
\hline Outcomes & TNS at 1 day \\
& Back pain \\
\hline Notes & Follow-up duration: 3 weeks \\
& Follow-up method: direct contact \\
& TNS therapy: unclear \\
& TNS resolution: complete recovery at 2 days
\end{tabular}

\section{Risk of bias}

\begin{tabular}{|c|c|c|}
\hline Bias & Authors' judgement & Support for judgement \\
\hline $\begin{array}{l}\text { Random sequence genera- } \\
\text { tion (selection bias) }\end{array}$ & Low risk & $\begin{array}{l}\text { Quote: "they were assigned to receive either... lidocaine or ... bupivacaine in a } \\
\text { double-blinded manner using a computer-generated randomisation scheme." }\end{array}$ \\
\hline $\begin{array}{l}\text { Allocation concealment } \\
\text { (selection bias) }\end{array}$ & Unclear risk & No mention of the method of allocation concealment. \\
\hline $\begin{array}{l}\text { Participant blinding (per- } \\
\text { formance bias and detec- } \\
\text { tion bias) }\end{array}$ & Low risk & $\begin{array}{l}\text { Quote: "they were assigned to receive either... lidocaine or ... bupivacaine in a } \\
\text { double-blinded manner using a computer-generated randomisation scheme." }\end{array}$ \\
\hline $\begin{array}{l}\text { Provider blinding (perfor- } \\
\text { mance bias) }\end{array}$ & Low risk & $\begin{array}{l}\text { Quote: "they were assigned to receive either... lidocaine or ... bupivacaine in a } \\
\text { double-blinded manner using a computer-generated randomisation scheme." } \\
\text { "The local anaesthetic solutions were prepared by the hospital pharmacy... } \\
\text { and delivered in blinded vials." }\end{array}$ \\
\hline $\begin{array}{l}\text { Assessor blinding (detec- } \\
\text { tion bias) }\end{array}$ & Low risk & $\begin{array}{l}\text { Quote: "...the patients were then interviewed... at } 24 \text { and } 48 \mathrm{~h} \text { [hours] postop- } \\
\text { eratively by a research nurse who was blinded to the entire anaesthetic." }\end{array}$ \\
\hline \multirow[t]{2}{*}{$\begin{array}{l}\text { Incomplete outcome data } \\
\text { (attrition bias) } \\
\text { All outcomes }\end{array}$} & Low risk & $\begin{array}{l}\text { Quote: "one patient who received lidocaine was excluded from our analysis } \\
\text { because of an inadequate block that required general anesthesia. This patient } \\
\text { did not develop any postoperative symptoms." }\end{array}$ \\
\hline & & $\begin{array}{l}\text { Comment: although these participants were excluded from the final analysis, } \\
\text { the authors reported the outcome of interest. Therefore, the risk of bias was } \\
\text { low. }\end{array}$ \\
\hline $\begin{array}{l}\text { Selective reporting (re- } \\
\text { porting bias) }\end{array}$ & Unclear risk & Study protocol not available. \\
\hline
\end{tabular}


Pollock 1996

\begin{tabular}{ll}
\hline Methods & Randomization: yes \\
Participant blinding: yes \\
Provider blinding: yes \\
Assessor blinding: yes \\
Dropouts: 7 outcomes reported \\
\hline
\end{tabular}

Country: USA
ASA: I and II
Gender: men and women
Mean age: lido $1.2 \mathrm{~mL}: 52$ (SD 16); lido $3.0 \mathrm{~mL}: 51$ (SD 13); lido $1.5 \mathrm{~mL}: 53$ (SD 12); lido $3.75 \mathrm{~mL}: 59$ (SD
17); bupi $1.0 \mathrm{~mL}: 50$ (SD 16); bupi $1.2 \mathrm{~mL}: 62$ (SD 14) years
Procedures: arthroscopy, herniorrhaphy
Ambulatory surgery: yes
Surgical positioning: supine
Number of participants: 159

\begin{tabular}{ll}
\hline Interventions & Drug 1: $2 \%, 5 \%$ lido; hyperbaric, isobaric; fixed dose $(1.2,3.0,1.5,3.75 \mathrm{~mL})$ \\
& Drug 2: $0.75 \%$ bupi, hyperbaric, fixed dose $(1.0,1.2 \mathrm{~mL})$ \\
& Needle: 22 and $25 \mathrm{G}$, cutting and pencil-point \\
\hline Outcomes & TNS at 3 days \\
& Back pain \\
\hline Notes & Follow-up duration: $3-14$ days \\
& Follow-up method: telephone contact \\
& TNS therapy: NSAIDs, opioids \\
& TNS resolution: no symptoms at 14 days
\end{tabular}

\section{Risk of bias}

Bias Authors' judgement Support for judgement

Random sequence genera- Unclear risk Quote: "patients were... randomized by sealed envelope." tion (selection bias)

Comment: Cochrane criteria for low risk of bias requires allocation by "sequentially numbered, sealed, opaque envelopes."

\begin{tabular}{ll}
\hline $\begin{array}{l}\text { Allocation concealment } \\
\text { (selection bias) }\end{array}$ & Unclear risk
\end{tabular}$\quad \begin{aligned} & \text { Quote: "patients were... randomized by sealed envelope." } \\
& \text { Comment: did not specify allocation by sequentially numbered, sealed, } \\
& \text { opaque envelopes. }\end{aligned}$


Pollock 1996 (Continued)

Participant blinding (per- Low risk Quote: "...patients...were randomized and stratified in a double-blinded fashformance bias and detecion..." tion bias)

\section{Provider blinding (perfor- High risk} mance bias)
Quote. "...patients...were randomized and stratified in a double-blinded fashion..."

Comment: the volume of local anaesthetic was different between the 2 groups, and no mention was made of blinding the anaesthesiologist to the local anaesthetic used.
Assessor blinding (detec- Low risk tion bias)
Quote: "time to block resolution was defined as the time that a blinded PACU nurse could no longer detect presence of anesthesia by pinprick or alcohol swab." "...patients completed a telephone interview with a blinded investigator..."

Quote: "none of the seven subjects with inadequate spinal anesthesia reported TRI, but these patients were excluded from final data analysis because of the possibility that local anaesthetic was not placed intrathecally."

Comment: 5 from the lido groups, 2 from the bupi group. Although these participants were excluded from the final analysis, the authors reported the outcome of interest. Therefore, the risk of bias was low.

Selective reporting (re- Unclear risk Study protocol not available.

porting bias)

Pradhan 2010

Rethods
Participant blinding: no
Provider blinding: no
Assessor blinding: no
Dropouts: 0 reported

Participants

Country: Nepal

ASA: not specified

Gender: women

Mean age: 25 (SD 8) years

Procedures: caesarean section

Ambulatory surgery: no

Surgical positioning: supine

Number of participants: 52

Interventions

Drug 1: 5\% lido, hyperbaric, fixed dose $(1.5 \mathrm{~mL})$

Drug 2: $0.5 \%$ bupi, hyperbaric, fixed dose $(2.2 \mathrm{~mL})$ 
Pradhan 2010 (Continued)

Needle: $26 \mathrm{G}$, sharp-point

\begin{tabular}{ll}
\hline Outcomes & TNS at 1 day \\
\hline Notes & Follow-up duration: 1 days \\
& Follow-up method: direct contact \\
& TNS therapy: not described \\
\hline
\end{tabular}

\section{Risk of bias}

\begin{tabular}{lll}
\hline Bias & Authors' judgement & Support for judgement \\
\hline $\begin{array}{l}\text { Random sequence genera- } \\
\text { tion (selection bias) }\end{array}$ & Unclear risk & $\begin{array}{l}\text { Quote. "the patients were randomly divided into two groups... according to } \\
\text { the group in closed envelope upon arrival in operation (sic) theatre." } \\
\text { Comment: did not describe method of randomization. }\end{array}$ \\
\hline $\begin{array}{l}\text { Allocation concealment } \\
\text { (selection bias) }\end{array}$ & Low risk & $\begin{array}{l}\text { Quote. "the patients were randomly divided into two groups... according to } \\
\text { the group in closed envelope upon arrival in operation (sic) theatre." }\end{array}$ \\
& $\begin{array}{l}\text { Comment: although allocation concealment was not mentioned, the implied } \\
\text { sequence of enrolment in the study and then allocated to a group in the oper- } \\
\text { ating room suggested allocation concealment. }\end{array}$
\end{tabular}

Participant blinding (per- Unclear risk No mention of blinding participants to group assignment.

formance bias and detec-

nclear risk

No mention of blinding participants to group assignment.

tion bias)

$\begin{array}{ll}\begin{array}{l}\text { Provider blinding (perfor- } \\ \text { mance bias) }\end{array} & \text { High risk } \\ \text { No mention of blinding anaesthesiologists to group assignment and volume of } \\ \text { drug administered intrathecally was different according to group assignment. }\end{array}$

\begin{tabular}{|c|c|c|}
\hline $\begin{array}{l}\text { Assessor blinding (detec- } \\
\text { tion bias) }\end{array}$ & High risk & $\begin{array}{l}\text { No mention of blinding assessor to group assignment and no mention of the } \\
\text { participants being assessed by anyone other than the anaesthesiologist. }\end{array}$ \\
\hline
\end{tabular}

\begin{tabular}{ll}
\hline $\begin{array}{l}\text { Incomplete outcome data } \\
\text { (attrition bias) }\end{array}$ & Unclear risk
\end{tabular} $\begin{aligned} & 52 \text { participants enrolled. Dropouts not mentioned; unclear for how many par- } \\
& \text { ticipant results were reported. }\end{aligned}$

All outcomes

Selective reporting (re- Unclear risk Study protocol not available.

porting bias)

\section{Salazar 2001}

$\begin{array}{ll}\text { Methods } & \text { Randomization: yes } \\ \text { Participant blinding: unclear } & \text { Provider blinding: no } \\ \text { Assessor blinding: yes } & \text { Dropouts: } 1 \text { outcome not reported }\end{array}$

Participants Country: Spain

ASA: I and II

Transient neurological symptoms (TNS) following spinal anaesthesia with lidocaine versus other local anaesthetics in adult surgical 
Salazar 2001 (Continued)

Gender: men and women

Mean age: lido: 48 (SD 16); mepi: 42 (SD 16) years

Procedures: orthopaedic

Ambulatory surgery: no

Surgical positioning: supine

Number of participants: 81

\begin{tabular}{ll}
\hline Interventions & Drug $1: 2 \%$ lido, isobaric, variable dose \\
& Drug 2: $2 \%$ mepi, isobaric, variable dose \\
& Needle: 26 and $27 \mathrm{G}$, cutting \\
\hline Outcomes & TNS at 1 day \\
\hline Notes & Follow-up duration: $1+$ days \\
& Follow-up method: direct contact \\
& TNS therapy: NSAIDs \\
TNS resolution: 1 day
\end{tabular}

\section{Risk of bias}

\begin{tabular}{lll}
\hline Bias & Authors' judgement & Support for judgement \\
\hline $\begin{array}{l}\text { Random sequence genera- } \\
\text { tion (selection bias) }\end{array}$ & Unclear risk & $\begin{array}{l}\text { Quote: "they were randomized in two groups of } 40 \text { patients each..." } \\
\text { Comment: did not specify the method of randomization (referring to a random } \\
\text { number table, computer-generated random number sequence, tossing coin, } \\
\text { etc.). }\end{array}$ \\
\hline $\begin{array}{l}\text { Allocation concealment } \\
\text { (selection bias) }\end{array}$ & Unclear risk & $\begin{array}{l}\text { Quote: "eighty consecutive patients..." } \\
\text { Comment: no mention was made regarding allocation concealment. Noting } \\
\text { that the investigators enrolled eighty consecutive participants, the risk of bias } \\
\text { may have been low. }\end{array}$ \\
\hline
\end{tabular}

Participant blinding (per- Unclear risk No mention made of participant blinding.
formance bias and detection bias)

\begin{tabular}{|c|c|c|}
\hline $\begin{array}{l}\text { Provider blinding (perfor- } \\
\text { mance bias) }\end{array}$ & High risk & $\begin{array}{l}\text { Quote: "the anaesthesiologist who administered the spinal anaesthesia and } \\
\text { recorded all the anaesthetic and intraoperative data was not blinded to the } \\
\text { study groups." }\end{array}$ \\
\hline $\begin{array}{l}\text { Assessor blinding (detec- } \\
\text { tion bias) }\end{array}$ & Low risk & $\begin{array}{l}\text { Quote: "...the anaesthesiologist assessing the postoperative incidence of TNS } \\
\text { was blinded to the group allocation of the patient." }\end{array}$ \\
\hline $\begin{array}{l}\text { Incomplete outcome data } \\
\text { (attrition bias) } \\
\text { All outcomes }\end{array}$ & Low risk & 80 participants enrolled, results reported for 80 participants. \\
\hline $\begin{array}{l}\text { Selective reporting (re- } \\
\text { porting bias) }\end{array}$ & Unclear risk & Study protocol not available. \\
\hline
\end{tabular}

Transient neurological symptoms (TNS) following spinal anaesthesia with lidocaine versus other local anaesthetics in adult surgical 
Salmela 1998

Rethods
Participant blinding: no
Provider blinding: no
Assessor blinding: yes
Dropouts: 0

\begin{tabular}{ll}
\hline Participants & Country: Finland \\
ASA: I, II, III, and IV \\
Gender: 74 men, 16 women \\
Age range: $29-91$ years \\
Procedures: urological \\
Ambulatory surgery: unclear \\
Surgical positioning: supine, lithotomy \\
Number of participants: 90
\end{tabular}

\begin{tabular}{ll}
\hline Interventions & Drug 1: $5 \%$ lido, hyperbaric, variable dose \\
& Drug 2: $0.5 \%$ bupi, hyperbaric, variable dose \\
& Drug 3: $4 \%$ mepi, hyperbaric, variable dose \\
& Needle: 25 and 27 G, cutting and pencil-point \\
\hline Outcomes & TNS at 1 day \\
\hline Notes & Follow-up duration: 1 day \\
& Follow-up method: direct contact \\
& TNS therapy: NSAIDs, opioids \\
TNS resolution: $1-2$ days
\end{tabular}

\section{Risk of bias}

\begin{tabular}{lll}
\hline Bias & Authors' judgement & Support for judgement \\
\hline $\begin{array}{l}\text { Random sequence genera- } \\
\text { tion (selection bias) }\end{array}$ & Unclear risk & Quote: "...consecutive patients were randomized using sealed envelopes..." \\
& & Comment: no mention of randomization scheme. \\
\hline $\begin{array}{l}\text { Allocation concealment } \\
\text { (selection bias) }\end{array}$ & Unclear risk & Quote. "...consecutive patients were randomized using sealed envelopes..." \\
& $\begin{array}{l}\text { Comment: did not specify allocation by sequentially numbered, sealed, } \\
\text { opaque envelopes. }\end{array}$
\end{tabular}

\begin{tabular}{|c|c|c|}
\hline $\begin{array}{l}\text { Participant blinding (per- } \\
\text { formance bias and detec- } \\
\text { tion bias) }\end{array}$ & Unclear risk & $\begin{array}{l}\text { No mention of participant blinding or characterization of the study as "dou- } \\
\text { ble-blind." }\end{array}$ \\
\hline
\end{tabular}
tion bias)

Transient neurological symptoms (TNS) following spinal anaesthesia with lidocaine versus other local anaesthetics in adult surgical patients: a network meta-analysis (Review)

Copyright (c) 2019 The Cochrane Collaboration. Published by John Wiley \& Sons, Ltd. 
Salmela 1998 (Continued)

Provider blinding (perfor- High risk The anaesthesiologist performing the subarachnoid block varied the dose of mance bias)

local anaesthetic depending on the anticipated duration of the surgery. There was no mention of the anaesthesiologist being blinded to the participants' assigned group.

\begin{tabular}{|c|c|c|}
\hline $\begin{array}{l}\text { Assessor blinding (detec- } \\
\text { tion bias) }\end{array}$ & Low risk & $\begin{array}{l}\text { Quote: "the patients were interviewed using a standardized questionnaire on } \\
\text { the first postoperative day by an anesthesiologist who did not know which } \\
\text { spinal anesthetic agent had been used." }\end{array}$ \\
\hline
\end{tabular}

Incomplete outcome data Low risk $\quad$ Outcomes reported for all participants.
(attrition bias)

All outcomes

Selective reporting (re- Unclear risk $\quad$ Study protocol not available.
porting bias)

porting bias)

Teunkens 2016

Randomization: yes
Participant blinding: yes
Provider blinding: yes
Assessor blinding: yes
Dropouts: 7 reported (2 in 2-chloroprocaine group, 4 in lido group, 1 in bupi group)

\begin{tabular}{|c|c|}
\hline \multirow[t]{8}{*}{ Participants } & Country: Belgium \\
\hline & ASA: I, II, and III \\
\hline & Gender: men, women \\
\hline & Age range: $19-76$ years \\
\hline & Procedures: knee arthroscopy \\
\hline & Ambulatory surgery: yes \\
\hline & Surgical positioning: supine \\
\hline & Number of participants: 99 \\
\hline \multirow[t]{4}{*}{ Interventions } & Drug 1: $1 \%$ lido $40 \mathrm{mg}$ \\
\hline & Drug 2: $1 \%$ preservative-free 2-chloroprocaine $40 \mathrm{mg}$ \\
\hline & Drug 3: $0.5 \%$ bupi $7.5 \mathrm{mg}$ \\
\hline & Needle: $27 \mathrm{G}, 103 \mathrm{~mm}$ Whitacre needle \\
\hline \multirow[t]{2}{*}{ Outcomes } & TNS at day 1 \\
\hline & Time until complete recovery of the sensory block \\
\hline Notes & $\begin{array}{l}\text { All dosages in every intervention arm were diluted with saline to a total volume of } 4.5 \mathrm{~mL} \text { in an unla- } \\
\text { belled syringe. }\end{array}$ \\
\hline
\end{tabular}

Transient neurological symptoms (TNS) following spinal anaesthesia with lidocaine versus other local anaesthetics in adult surgical 
Teunkens 2016 (Continued)

Risk of bias

\begin{tabular}{|c|c|c|}
\hline Bias & Authors' judgement & Support for judgement \\
\hline $\begin{array}{l}\text { Random sequence genera- } \\
\text { tion (selection bias) }\end{array}$ & Low risk & $\begin{array}{l}\text { Quote: "...patients were randomly allocated...using a computer-generated } \\
\text { random table." }\end{array}$ \\
\hline $\begin{array}{l}\text { Allocation concealment } \\
\text { (selection bias) }\end{array}$ & Low risk & $\begin{array}{l}\text { Quote. "allocation concealment was ensured by enclosing assignments in } \\
\text { sealed, opaque, sequentially numbered envelopes, which were opened only } \\
\text { after arrival of the patient in the operating room." }\end{array}$ \\
\hline $\begin{array}{l}\text { Participant blinding (per- } \\
\text { formance bias and detec- } \\
\text { tion bias) }\end{array}$ & Low risk & Quote: "this prospective, double-blind, randomized, controlled clinical trial..." \\
\hline $\begin{array}{l}\text { Provider blinding (perfor- } \\
\text { mance bias) }\end{array}$ & Low risk & $\begin{array}{l}\text { Quote: "all dosages [of study medication] were diluted with saline to a total } \\
\text { volume of } 4.5 \mathrm{ml} \text { in an unlabeled syringe. The study medication was prepared } \\
\text { by a consultant staff member of the Department of Anesthesiology who was } \\
\text { not further involved in the perioperative care of the respective patients or in } \\
\text { data gathering and study visits." }\end{array}$ \\
\hline $\begin{array}{l}\text { Assessor blinding (detec- } \\
\text { tion bias) }\end{array}$ & Low risk & $\begin{array}{l}\text { Quote: "all data were collected by the study nurse of the department who was } \\
\text { blinded to the treatment." }\end{array}$ \\
\hline $\begin{array}{l}\text { Incomplete outcome data } \\
\text { (attrition bias) } \\
\text { All outcomes }\end{array}$ & High risk & Outcomes not reported for 7 participants. \\
\hline $\begin{array}{l}\text { Selective reporting (re- } \\
\text { porting bias) }\end{array}$ & Low risk & $\begin{array}{l}\text { Primary and secondary outcomes consistent with study protocol 2011-003675 } \\
\text { registered with the European Union Clinical Trials Register. }\end{array}$ \\
\hline
\end{tabular}

\title{
Østgaard 2000
}

$\begin{array}{ll}\text { Methods } & \text { Randomization: yes } \\ \text { Participant blinding: yes } \\ \text { Provider blinding: unclear } \\ \text { Assessor blinding: yes } \\ \text { Dropouts: } 4 \text { GA, outcomes reported }\end{array}$

\section{Participants}

\author{
Country: Norway \\ ASA: unclear \\ Gender: men and women \\ Mean ages: lido: 65 (SD 17); prilo: 69 (SD 12) years \\ Procedures: urological \\ Ambulatory surgery: unclear \\ Surgical positioning: supine, lithotomy \\ Number of participants: 100
}

Transient neurological symptoms (TNS) following spinal anaesthesia with lidocaine versus other local anaesthetics in adult surgical patients: a network meta-analysis (Review)

Copyright $\odot 2019$ The Cochrane Collaboration. Published by John Wiley \& Sons, Ltd. 
Østgaard 2000 (Continued)

Interventions

Drug 1: 2\% lido, isobaric, fixed dose (4 mL)

Drug 2: $2 \%$ prilo, isobaric, fixed dose $(4 \mathrm{~mL})$

Needle: 25, 26, 27, and 29 G, cutting

\begin{tabular}{ll}
\hline Outcomes & TNS at 1 day \\
& Other pain \\
\hline Notes & Follow-up duration: 1 day \\
& Follow-up method: direct contact \\
& TNS therapy: unclear \\
& TNS resolution: unclear
\end{tabular}

\section{Risk of bias}

\begin{tabular}{lll}
\hline Bias & Authors' judgement & Support for judgement \\
\hline $\begin{array}{l}\text { Random sequence genera- } \\
\text { tion (selection bias) }\end{array}$ & Unclear risk & $\begin{array}{l}\text { Quote: "patients were randomised in the morning using sealed envelopes..." } \\
\text { Comment: did not specify the method of randomization (referring to a random } \\
\text { number table, computer-generated random number sequence, tossing coin, } \\
\text { etc.). }\end{array}$ \\
\hline $\begin{array}{l}\text { Allocation concealment } \\
\text { (selection bias) }\end{array}$ & Low risk & $\begin{array}{l}\text { Quote: "patients were randomized in the morning using sealed envelopes..." } \\
\text { Comment: although this description was less detailed than the Cochrane stan- } \\
\text { dard for low risk of bias (sequentially numbered, opaque, sealed envelopes), } \\
\text { the sequent of enrolling participants the day before surgery and randomizing } \\
\text { on the day of surgery suggests allocation concealment probably happened. }\end{array}$
\end{tabular}

Participant blinding (per- $\quad$ Unclear risk $\quad$ Did not specify participant blinding.
formance bias and detec-

formance bias and detec-

tion bias)

\begin{tabular}{lll}
\hline $\begin{array}{l}\text { Provider blinding (perfor- } \\
\text { mance bias) }\end{array}$ & Unclear risk & No mention made of blinding, study drug, or double-blind study construction. \\
\hline $\begin{array}{l}\text { Assessor blinding (detec- } \\
\text { tion bias) }\end{array}$ & Low risk & $\begin{array}{l}\text { Quote: "the following day the patients were interviewed by an anesthesiolo- } \\
\text { gist unaware of the local anaesthetic given..." }\end{array}$ \\
\hline $\begin{array}{l}\text { Incomplete outcome data } \\
\text { (attrition bias) } \\
\text { All outcomes }\end{array}$ & Unclear risk & $\begin{array}{l}\text { Description of number of participants enrolled and participant data reported } \\
\text { were inconsistent. (Abstract stated } 100 \text { participants enrolled, methods section } \\
\text { of the text stated } 90 \text { participants enrolled, data for } 99 \text { participants were report- } \\
\text { ed.) } 4 \text { participants received GA and their results were reported. }\end{array}$ \\
\hline
\end{tabular}

Selective reporting (re- Unclear risk Study protocol not available.

porting bias)

All the study were randomized controlled trials.

ASA: American Society of Anesthesiologist Physical Status Score (I, II, III, and IV); bupi: bupivacaine; G: gauge; GA: general anaesthesia; levo: levobupivacaine; lido: lidocaine; mepi: mepivacaine; NSAID: non-steroidal anti-inflammatory drug; PACU: postanaesthesia care unit; prilo: prilocaine; pro: procaine; ropi: ropivacaine; SD: standard deviation; TNS: transient neurological symptoms.

None of the studies mentioned any financial support of pharmaceutical companies or other competing interests. In the case of unclear biases, attempts were made to obtain more information from the authors. 
Characteristics of excluded studies [ordered by study ID]

\begin{tabular}{|c|c|}
\hline Study & Reason for exclusion \\
\hline Ben-David 2000 & Fentanyl plus lidocaine. No arm with another local anaesthetic. \\
\hline Bergeron 1999 & No lidocaine, only 1 arm with procaine, risk of TNS: $1 / 62$ participants, but high risk of nausea. \\
\hline Chan 1998 & Continuous spinal anaesthesia with lidocaine $5 \%$. No follow-up, no mention of TNS. \\
\hline Chohedri 2015 & Combined 2 local anaesthetics. \\
\hline de Santiago 2010 & Combined local anaesthetic and fentanyl. \\
\hline \multirow[t]{3}{*}{ Frey 1998} & Volunteers and no surgery. \\
\hline & $\begin{array}{l}12 \text { participants. Crossover: lidocaine } 5 \% \text { (100 mg), tetracaine } 1 \%(30 \mathrm{mg}) \text { and bupivacaine } 0.75 \% \\
(15 \mathrm{mg})\end{array}$ \\
\hline & 3/12 participants had TNS, it was quite unpleasant, unable to sit and needed NSAID. \\
\hline Gentili 1997 & No lidocaine. Bupivacaine $0.1 \%, 0.15 \%$, and $0.2 \%$. Volume: $4 \mathrm{~mL} .90$ participants, 0 cases of TNS. \\
\hline Hampl 1995b & Non-randomized study \\
\hline Hampl 1996 & $\begin{array}{l}\text { Lidocaine in } 2 \text { different concentrations: } 5 \% \text { vs } 2 \% \text {. No difference in the risk of TNS ( } 8 / 25 \text { with } 5 \% \text { li- } \\
\text { docaine vs } 10 / 25 \text { with } 2 \% \text { lidocaine). Reduction in concentration did not reduce the risk of TNS. }\end{array}$ \\
\hline Henderson 1998 & Case history: 1 participant with TNS after $1 \%$ lidocaine $40 \mathrm{mg}$. Full recovery. \\
\hline Hiller 1999 & $\begin{array}{l}\text { Only } 1 \text { arm with lidocaine: second arm with general anaesthesia. Even participants who receive on- } \\
\text { ly general anaesthesia can develop TNS. }\end{array}$ \\
\hline Imbelloni 2008a & Only hyperbaric lidocaine: 2 arms with $2 \mathrm{~mL} 1.5 \%$ vs $1.5 \mathrm{~mL} 2 \%$. \\
\hline Imbelloni 2008b & Only hypobaric lidocaine: 3 arms with $3 \mathrm{~mL} 0.6 \%$ vs $4 \mathrm{~mL} 0.6 \%$ vs $5 \mathrm{ml} 0.6 \%$. \\
\hline Jacobsen 2011 & Combination of local anaesthetics. \\
\hline Lee 2008 & Combination of local anaesthetics. \\
\hline Liam 1998 & $\begin{array}{l}\text { Only lidocaine: } 3 \text { arms with } 1 \% \text { lidocaine in different volumes: } 4 \mathrm{~mL}, 6 \mathrm{~mL} \text {, and } 8 \mathrm{~mL} \text {. No cases of } \\
\text { TNS. }\end{array}$ \\
\hline Loo 1999 & $\begin{array}{l}\text { Swedish Pharmacological Insurance reported } 6 \text { cases of cauda equina syndrome between } 1993 \\
\text { and } 1997.5 \text { cases after single spinal injection of lidocaine } 5 \% \text { and } 1 \text { case after repeated injection. } \\
\text { Lidocaine doses was } 60-100 \mathrm{mg} \text {. All cases sustained permanent neurological deficits. Recommen- } \\
\text { dation: use } 2 \% \text { lidocaine and no more than } 60 \mathrm{mg} \text {. }\end{array}$ \\
\hline Markey 1997 & $\begin{array}{l}1.5 \% \text { lidocaine was as effective an anaesthetic as } 5 \% \text { for participants undergoing hernia operation. } \\
\text { No mention of TNS. }\end{array}$ \\
\hline Mgbakor 2012 & Non-randomized study, did not report TNS. \\
\hline Morisaki 1998 & $\begin{array}{l}\text { Non-randomized study: } 4 / 1045 \text { participants who received lidocaine } 3 \% 45 \mathrm{mg} \text { (for anorectal } \\
\text { surgery) had TNS. }\end{array}$ \\
\hline
\end{tabular}




\begin{tabular}{|c|c|}
\hline Study & Reason for exclusion \\
\hline Murto 1999 & $\begin{array}{l}\text { Intrathecal meperidine } 0.3 \mathrm{mg} / \mathrm{kg} \text { was added to lidocaine to prolong postoperative analgesia. No } \\
\text { mention of TNS. }\end{array}$ \\
\hline Pawlowski 2000 & $\begin{array}{l}\text { No lidocaine. Mepivacaine } 1.5 \%(60 \mathrm{mg}) \text { and } 2 \%(80 \mathrm{mg}) \text { was used in } 60 \text { participants. Follow-up at } \\
24 \text { hours: } 0 \text { cases of TNS. }\end{array}$ \\
\hline Pollock 1999 & $\begin{array}{l}\text { Only lidocaine was used: } 3 \text { arms with } 0.5 \%, 1 \% \text {, and } 2 \% \text { lidocaine: risk of TNS was not concentra- } \\
\text { tion-dependant ( } 20 / 109 \text { participants). }\end{array}$ \\
\hline Punj 2013 & Authors contacted several times to request unavailable data, without any response. \\
\hline Salmela 1996 & Only 1 arm with lidocaine 5\%. 13/44 urological participants had signs of TNS. \\
\hline Sia 1998 & 3 cases of TNS after spinal mepivacaine. \\
\hline Tong 2003 & $\begin{array}{l}\text { Only lidocaine was used, } 2 \text { arms with lidocaine } 80 \mathrm{mg}: 1 \% \text { ( } 218 \text { participants) and } 5 \% \text { hyperbaric li- } \\
\text { docaine ( } 235 \text { participants); risk of TNS was not concentration-dependant ( } 21 \% \text { with } 1 \% \text { lidocaine } \\
\text { vs } 18 \% \text { with } 5 \% \text { lidocaine). }\end{array}$ \\
\hline Vaghadia 2012 & Local anaesthetic combined with opioid. \\
\hline Wong 1999 & Non-randomized study. \\
\hline Yazicioglu 2013 & Combination of local anaesthetics. \\
\hline Zayas 1999 & $\begin{array}{l}\text { No lidocaine. Dose-response study for spinal mepivacaine } 1.5 \%, 25 \text { participants. } 40 \mathrm{mg}, 45 \mathrm{mg} \text {, and } \\
60 \mathrm{mg} \text { : } 5 \text { cases of TNS out of } 75 \text { participants; irrespective of mepivacaine doses. }\end{array}$ \\
\hline
\end{tabular}

NSAIDs: non-steroidal anti-inflammatory drugs; TNS: transient neurological symptoms.

Characteristics of studies awaiting assessment [ordered by study ID]

Frisch 2018

\begin{tabular}{ll}
\hline Methods & Not yet assessed \\
\hline Participants & Not yet assessed \\
\hline Interventions & Not yet assessed \\
\hline Outcomes & Not yet assessed \\
\hline Notes & Not yet assessed \\
\hline
\end{tabular}

Gozdemir 2016

\begin{tabular}{ll}
\hline Methods & Not yet assessed \\
\hline Participants & Not yet assessed \\
\hline Interventions & Not yet assessed \\
\hline Outcomes & Not yet assessed \\
\hline
\end{tabular}

Transient neurological symptoms (TNS) following spinal anaesthesia with lidocaine versus other local anaesthetics in adult surgical 
Gozdemir 2016 (Continued)
Notes
Not yet assessed

\section{Characteristics of ongoing studies [ordered by year of study]}

\section{NCT02818894}

Trial name or title

Methods

Methods

Intervention model: parallel assignment

Blinding: triple (participant, investigator, outcomes assessor)

\begin{tabular}{ll}
\hline Participants & $\begin{array}{l}186 \text { participants receiving total hip arthroplasty through anterior approach with lidocaine spinal } \\
\text { anaesthesia and completing telephone questionnaires to see how they are feeling postoperation. }\end{array}$ \\
\hline Interventions & Drug 1: lidocaine \\
& Drug 2: bupivacaine
\end{tabular}

\begin{tabular}{ll}
\hline Outcomes & Transient neurological symptoms at 1-3 days postoperation \\
Transient neurological symptoms at $1-7$ days postoperation \\
Transient neurological symptoms at $7-14$ days postoperation
\end{tabular}

\begin{tabular}{ll}
\hline Starting date & September 2016 \\
\hline Contact information & Ashley Freeman \\
& asroka@emory.edu \\
\hline
\end{tabular}

Notes Recruiting

Estimated study completion date: November 2019

DATA AND ANALYSES

\section{Comparison 1. One local anaesthetic versus a different local anaesthetic}

\begin{tabular}{lllll}
\hline Outcome or subgroup title & $\begin{array}{l}\text { No. of } \\
\text { studies }\end{array}$ & $\begin{array}{l}\text { No. of } \\
\text { partici- } \\
\text { pants }\end{array}$ & Statistical method & Effect size \\
\hline $\begin{array}{l}1 \text { Presence of any transient } \\
\text { neurological symptoms }\end{array}$ & 24 & & Risk Ratio (IV, Random, 95\% CI) & Subtotals only \\
\hline $\begin{array}{l}1.1 \text { Bupivacaine vs lidocaine } \\
1.2 \text { 2-Chlorprocaine vs lido- } \\
\text { caine }\end{array}$ & 2 & 1220 & Risk Ratio (IV, Random, 95\% CI) & $0.16[0.09,0.28]$ \\
\hline \hline
\end{tabular}

Transient neurological symptoms (TNS) following spinal anaesthesia with lidocaine versus other local anaesthetics in adult surgical 


\begin{tabular}{|c|c|c|c|c|}
\hline Outcome or subgroup title & $\begin{array}{l}\text { No. of } \\
\text { studies }\end{array}$ & $\begin{array}{l}\text { No. of } \\
\text { partici- } \\
\text { pants }\end{array}$ & Statistical method & Effect size \\
\hline $\begin{array}{l}1.3 \text { Levobupivacaine vs lido- } \\
\text { caine }\end{array}$ & 2 & 120 & Risk Ratio (IV, Random, 95\% CI) & $0.13[0.02,0.69]$ \\
\hline 1.4 Mepivacaine vs lidocaine & 4 & 274 & Risk Ratio (IV, Random, 95\% CI) & $1.01[0.18,5.82]$ \\
\hline 1.5 Prilocaine vs lidocaine & 4 & 429 & Risk Ratio (IV, Random, 95\% CI) & $0.18[0.07,0.49]$ \\
\hline 1.6 Procaine vs lidocaine & 2 & 130 & Risk Ratio (IV, Random, 95\% CI) & $0.14[0.04,0.52]$ \\
\hline 1.7 Ropivacaine vs lidocaine & 2 & 90 & Risk Ratio (IV, Random, 95\% CI) & $0.10[0.01,0.78]$ \\
\hline $\begin{array}{l}1.8 \text { Bupivacaine vs mepiva- } \\
\text { caine }\end{array}$ & 1 & 60 & Risk Ratio (IV, Random, 95\% CI) & $0.04[0.00,0.71]$ \\
\hline 1.9 Bupivacaine vs prilocaine & 1 & 60 & Risk Ratio (IV, Random, 95\% CI) & $0.33[0.01,7.87]$ \\
\hline $\begin{array}{l}1.10 \text { Levobupivacaine vs ropi- } \\
\text { vacaine }\end{array}$ & 1 & 60 & Risk Ratio (IV, Random, 95\% Cl) & $0.0[0.0,0.0]$ \\
\hline $\begin{array}{l}1.11 \text { Bupivacaine vs } 2 \text {-chlorp- } \\
\text { rocaine }\end{array}$ & 1 & 67 & Risk Ratio (IV, Random, 95\% CI) & $0.0[0.0,0.0]$ \\
\hline
\end{tabular}

Analysis 1.1. Comparison 1 One local anaesthetic versus a different local anaesthetic, Outcome 1 Presence of any transient neurological symptoms.

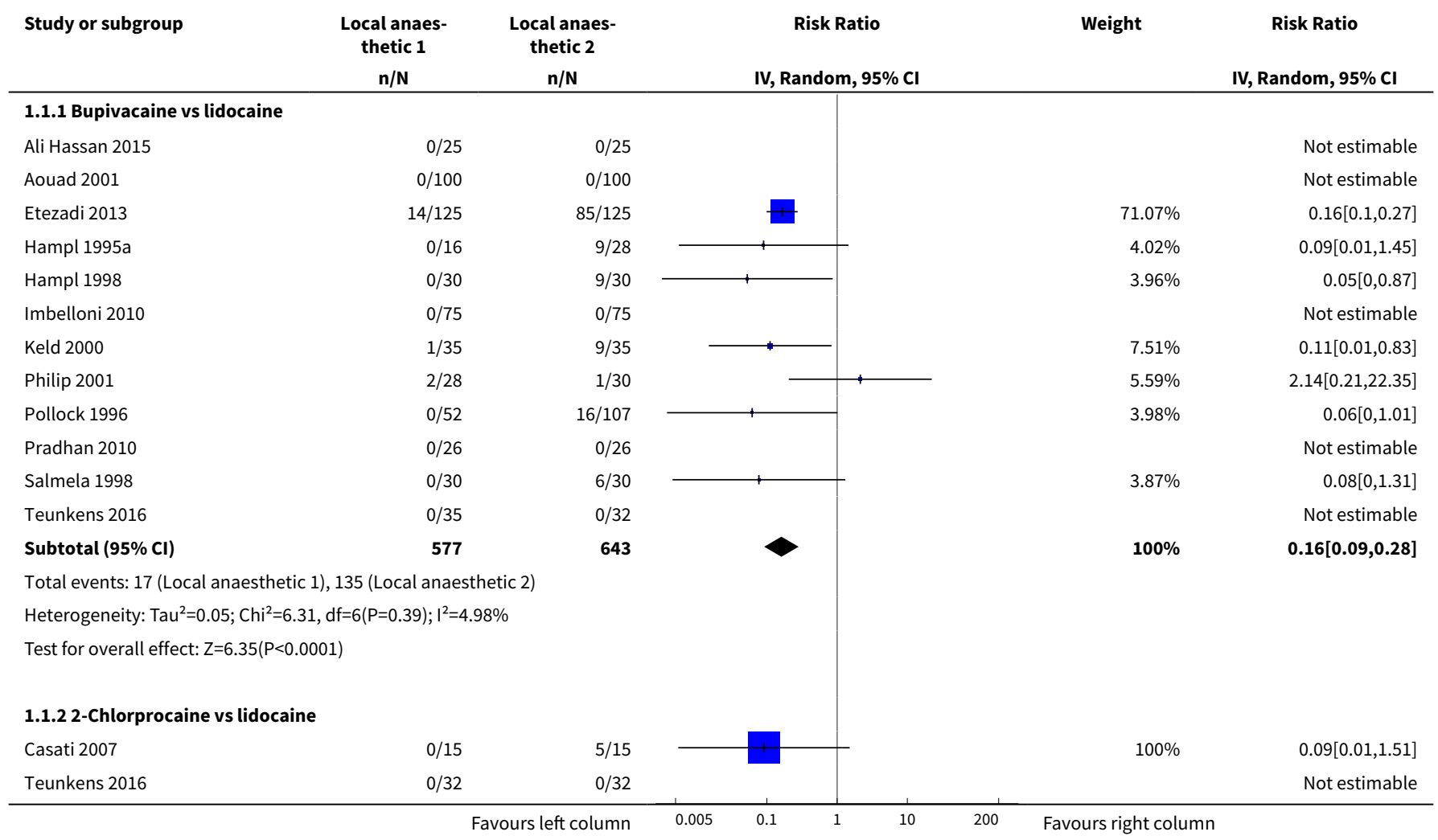




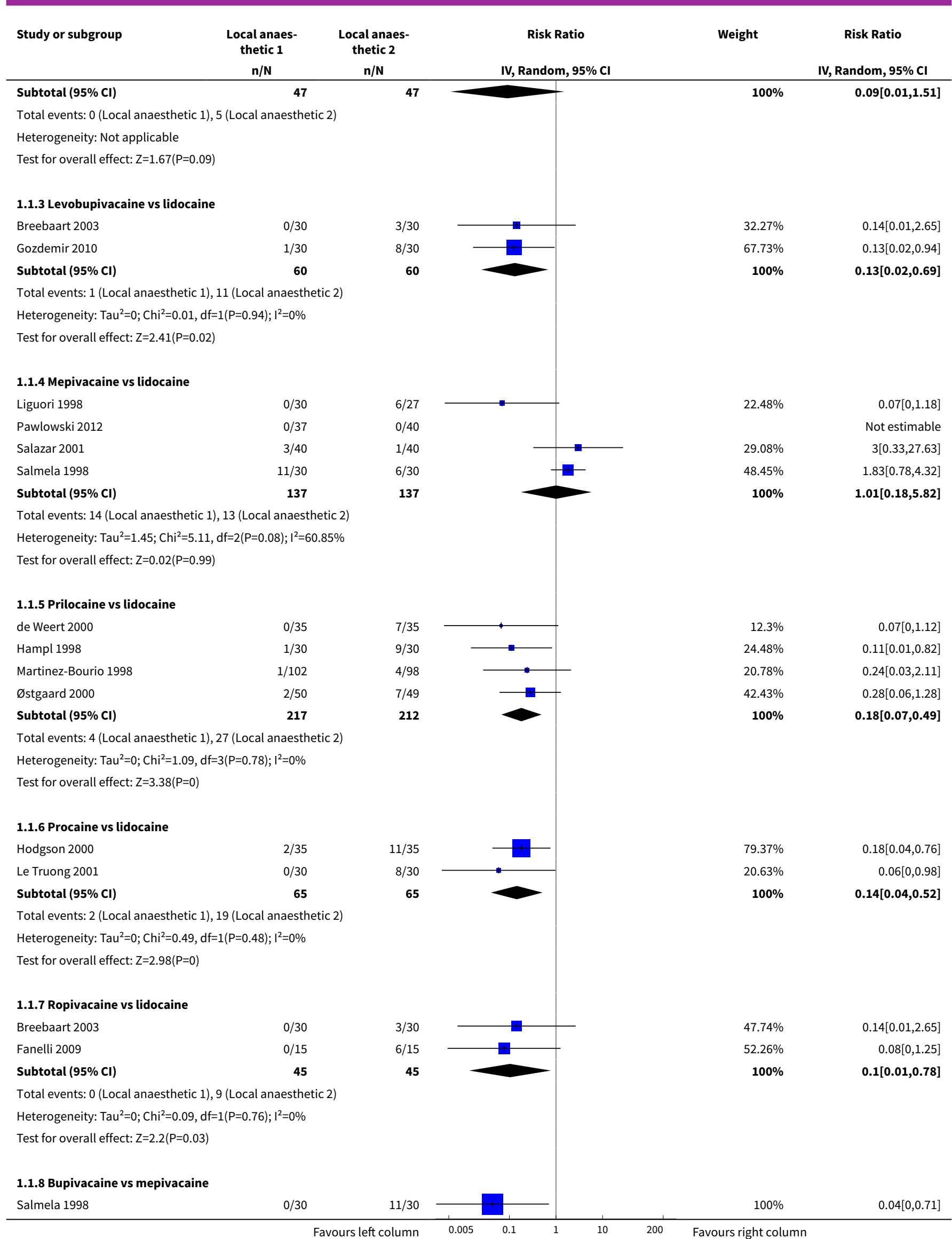

Transient neurological symptoms (TNS) following spinal anaesthesia with lidocaine versus other local anaesthetics in adult surgical

Copyright $\odot 2019$ The Cochrane Collaboration. Published by John Wiley \& Sons, Ltd. 


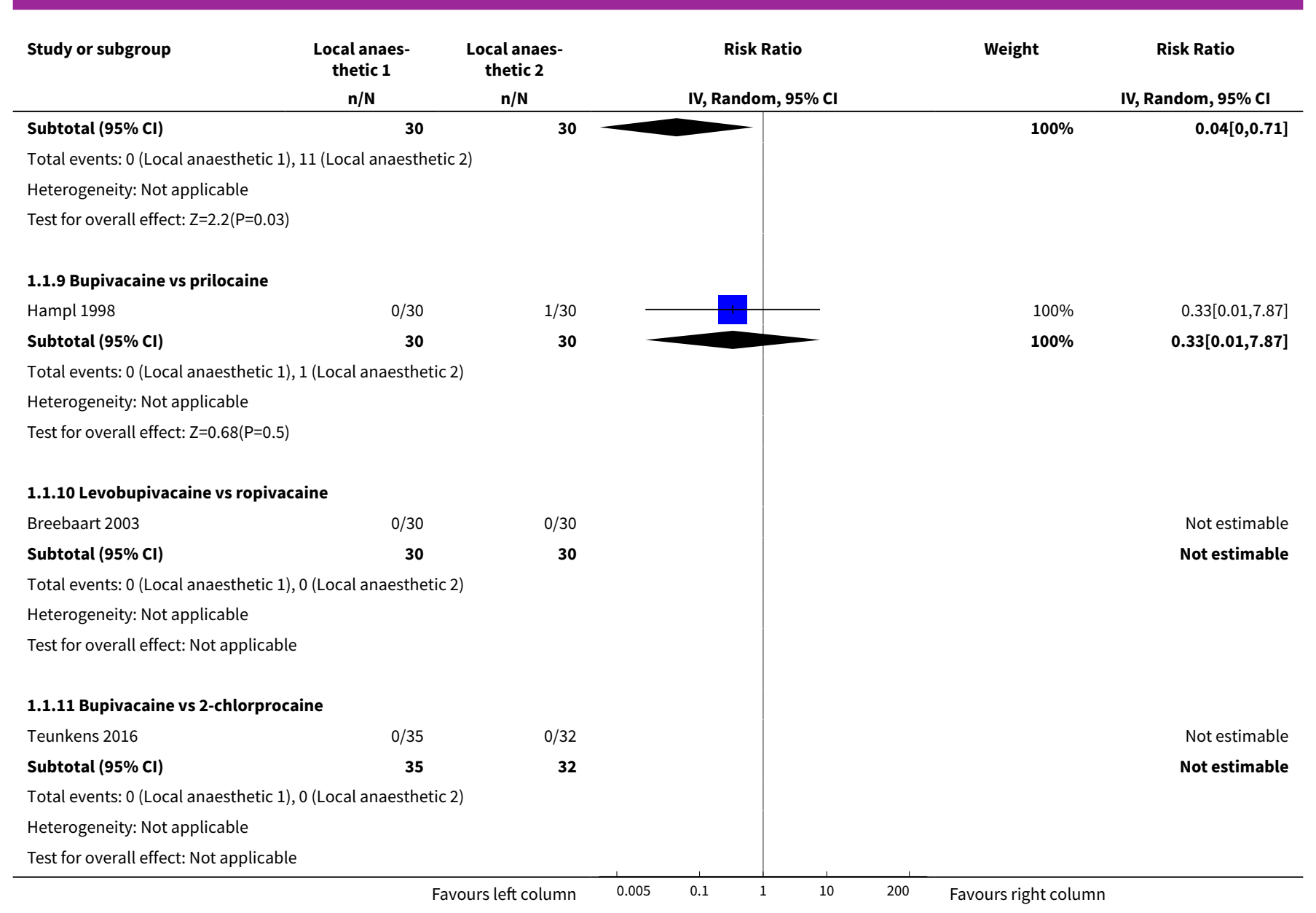

\section{ADDITIONAL TABLES}

Table 1. Studies reporting transient neurological symptoms after intrathecal lidocaine

\begin{tabular}{|c|c|c|c|c|}
\hline Study ID & TNS \#/N (\%) & Pain score (0-10) & TNS duration & Therapy \\
\hline Aouad 2001 & $0 / 100(0)$ & - & - & - \\
\hline Breebaart 2003 & $3 / 30(10)$ & Not tallied & 1 day & Not described \\
\hline Casati 2007 & $5 / 15(33)$ & Not tallied & Up to 7 days & NSAIDs \\
\hline de Weert 2000 & $7 / 35(20)$ & $\begin{array}{l}\text { Day } 1 \text { mean VPS } 5.3 \\
\text { (range } 2-8 \text { ) }\end{array}$ & Maximum duration 3 days & Not described \\
\hline Etezadi 2013 & $85 / 135(63)$ & Mean VAS 6-7 & Maximum duration 5 days & NSAIDs \\
\hline Fanelli 2009 & $6 / 15(40)$ & Not tallied & Resolved within 7 days & Not described \\
\hline Gozdemir 2010 & $8 / 30(27)$ & Median VPS 3 (range 1-6) & Resolved within 7 days & Not described \\
\hline Hampl 1995a & $9 / 28(32)$ & Not tallied & Maximum duration 4 days & Not described \\
\hline
\end{tabular}


Table 1. Studies reporting transient neurological symptoms after intrathecal lidocaine (Continued)

\begin{tabular}{|c|c|c|c|c|}
\hline Hampl 1998 & $9 / 30(30)$ & Mean maximum VAS 3.75 & Maximum duration 2 days & Not described \\
\hline Ali Hassan 2015 & $0 / 25(0)$ & - & - & - \\
\hline Hodgson 2000 & $11 / 35(31)$ & Mean VPS 5 & Mean duration 2 days & Not described \\
\hline Imbelloni 2010 & $0 / 75(0)$ & - & - & - \\
\hline Keld 2000 & $9 / 35(26)$ & Mean VPS 3.5 (range 2-8) & Maximum duration 4 days & Not described \\
\hline Le Truong 2001 & $8 / 30(27)$ & Not tallied & Unspecified & Not described \\
\hline Liguori 1998 & $6 / 27(22)$ & Not tallied & Maximum duration 5 days & NSAIDS \\
\hline Martinez-Bourio 1998 & $4 / 98(4)$ & Not tallied & Maximum duration 10 days & NSAIDS \\
\hline Østgaard 2000 & $7 / 49(14)$ & VPS range 5-9.5 & Maximum duration 3 days & Not described \\
\hline Pawlowski 2012 & $0 / 40(0)$ & - & - & - \\
\hline Philip 2001 & $1 / 30(3)$ & Maximum VAS 3 & Maximum duration 2 days & Not described \\
\hline Pollock 1996 & $16 / 107(15)$ & Mean VPS 6.2 (range 1-9) & Maximum duration 4 days & $\begin{array}{l}\text { NSAIDs and opi- } \\
\text { oids }\end{array}$ \\
\hline Pradhan 2010 & $0 / 26(0)$ & - & - & - \\
\hline Salazar 2001 & $1 / 40(3)$ & Maximum VAS 9-10 & Maximum duration 1 day & NSAIDs \\
\hline Salmela 1998 & $6 / 30(20)$ & Moderate pain & Maximum duration 1 day & $\begin{array}{l}\text { NSAIDs and opi- } \\
\text { oids }\end{array}$ \\
\hline Teunkens 2016 & $0 / 32(0)$ & - & - & - \\
\hline
\end{tabular}

$\mathrm{N}$ : number of participants; NSAIDs: non-steroidal anti-inflammatory drugs; TNS: transient neurological symptoms; VAS: visual analogue scale; VPS: verbal pain scale.

Table 2. Network meta-analysis, random-effects model

\begin{tabular}{llll}
\hline Treatment & RR & 95\% Cl & 95\% PI \\
\hline bupi & 0.19 & 0.12 to $0.29^{a}$ & 0.12 to 0.30 \\
\hline chloro & 0.18 & 0.02 to 1.53 & 0.02 to 1.75 \\
\hline levo & 0.17 & 0.04 to $0.70^{a}$ & 0.04 to 0.77 \\
\hline mepi & 1.54 & 0.76 to 3.12 & 0.73 to 3.27 \\
\hline prilo & 0.23 & 0.10 to $0.55^{a}$ & 0.09 to 0.58 \\
\hline pro & 0.17 & 0.05 to $0.56^{a}$ & 0.05 to 0.60 \\
\hline ropi & 0.10 & 0.01 to $0.78^{a}$ & 0.01 to 0.89 \\
\hline
\end{tabular}

Transient neurological symptoms (TNS) following spinal anaesthesia with lidocaine versus other local anaesthetics in adult surgical 
bupi: bupivacaine; chloro: 2-chloroprocaine; $\mathrm{Cl}$ : confidence Interval; levo: levobupivacaine; lido: lidocaine; mepi: mepivacaine; PI: prediction interval; prilo: prilocaine; pro: procaine, ropi: ropivacaine.

a Null hypothesis of no difference rejected. 


\begin{tabular}{|c|c|c|c|c|c|c|c|c|c|c|c|}
\hline Comparison & $\mathbf{k}$ & pro & NMA & $95 \% \mathrm{Cl}$ & $\begin{array}{l}\text { Di- } \\
\text { rect }\end{array}$ & $95 \% \mathrm{Cl}$ & $\begin{array}{l}\text { Indi- } \\
\text { rect }\end{array}$ & $95 \% \mathrm{Cl}$ & RoR $95 \% \mathrm{Cl}$ & $\mathbf{z}$ & $\begin{array}{l}\text { P } \\
\text { val- } \\
\text { ue }\end{array}$ \\
\hline bupi:chloro & 1 & 0.32 & 1.08 & 0.12 to 9.63 & 0.92 & $\begin{array}{l}0.02 \text { to } \\
44.90\end{array}$ & 1.17 & 0.08 to $1.6 \mathrm{e}+01$ & $\begin{array}{cl}0.78 & 0.01 \text { to } 8.6 e \\
& +01\end{array}$ & $\begin{array}{l}- \\
0.10\end{array}$ & - \\
\hline bupi:levo & 0 & 0 & 1.15 & 0.26 to 5.18 & - & - & 1.15 & 0.26 to $5.2 \mathrm{e}+00$ & $-\quad-$ & - & - \\
\hline bupi:lido & 12 & 1.00 & 0.19 & 0.12 to 0.29 & 0.19 & $\begin{array}{l}0.13 \text { to } \\
0.30\end{array}$ & 0.00 & 0.00 to $1.8 \mathrm{e}+01$ & $\begin{array}{l}42.580 .01 \text { to } 1.7 e \\
+05\end{array}$ & 0.89 & 0.38 \\
\hline bupi:mepi & 1 & 0.09 & 0.12 & 0.05 to 0.28 & 0.04 & $\begin{array}{l}0.00 \text { to } \\
0.71\end{array}$ & 0.14 & 0.06 to $3.2 \mathrm{e}-01$ & $\begin{array}{cl}0.32 & 0.02 \text { to } 5.9 e \\
& +00\end{array}$ & $\begin{array}{l}- \\
0.77\end{array}$ & 0.44 \\
\hline bupi:prilo & 1 & 0.09 & 0.83 & 0.31 to 2.17 & 0.33 & $\begin{array}{l}0.01 \text { to } \\
7.87\end{array}$ & 0.91 & 0.33 to $2.5 \mathrm{e}+00$ & $\begin{array}{ll}0.37 & 0.01 \text { to } 1.0 \mathrm{e} \\
& +01\end{array}$ & - & 0.55 \\
\hline bupi:pro & 0 & 0 & 1.10 & 0.32 to 3.83 & - & - & 1.10 & 0.32 to $3.8 \mathrm{e}+00$ & $-\quad-$ & - & - \\
\hline bupi:ropi & 0 & 0 & 1.83 & 0.23 to 14.32 & - & - & 1.83 & 0.23 to $1.4 \mathrm{e}+01$ & $-\quad-$ & - & - \\
\hline chloro:levo & 0 & 0 & 1.06 & 0.08 to 14.27 & - & - & 1.06 & 0.08 to $1.4 \mathrm{e}+01$ & $-\quad-$ & - & - \\
\hline chloro:lido & 2 & 0.90 & 0.18 & 0.02 to 1.53 & 0.21 & $\begin{array}{l}0.02 \text { to } \\
2.02\end{array}$ & 0.04 & 0.00 to $3.8 \mathrm{e}+01$ & $\begin{array}{cl}4.88 & 0.00 \text { to } 6.3 e \\
& +03\end{array}$ & 0.43 & 0.66 \\
\hline chloro:mepi & 0 & 0 & 0.11 & 0.01 to 1.11 & - & - & 0.11 & 0.01 to $1.1 \mathrm{e}+00$ & $-\quad-$ & - & - \\
\hline chloro:prilo & 0 & 0 & 0.76 & 0.07 to 7.82 & - & - & 0.76 & 0.07 to $7.8 \mathrm{e}+00$ & $-\quad-$ & - & - \\
\hline chloro:pro & 0 & 0 & 1.02 & 0.09 to 11.87 & - & - & 1.02 & 0.09 to $1.2 \mathrm{e}+01$ & - & - & - \\
\hline chloro:ropi & 0 & 0 & 1.69 & 0.09 to 32.35 & - & - & 1.69 & 0.09 to $3.2 \mathrm{e}+01$ & $-\quad-$ & - & - \\
\hline levo:lido & 2 & 1.00 & 0.17 & 0.04 to 0.70 & 0.17 & $\begin{array}{l}0.04 \text { to } \\
0.71\end{array}$ & 0.00 & 0.00 to $1.3 \mathrm{e}+12$ & $\begin{array}{l}266.30 .00 \text { to } 5.8 \mathrm{e} \\
+17\end{array}$ & 0.31 & 0.76 \\
\hline levo:mepi & 0 & 0 & 0.11 & 0.02 to 0.54 & - & - & 0.11 & 0.02 to $5.4 \mathrm{e}-01$ & $-\quad-$ & - & - \\
\hline levo:prilo & 0 & 0 & 0.72 & 0.13 to 3.87 & - & - & 0.72 & 0.13 to $3.9 \mathrm{e}+00$ & $-\quad-$ & - & - \\
\hline
\end{tabular}




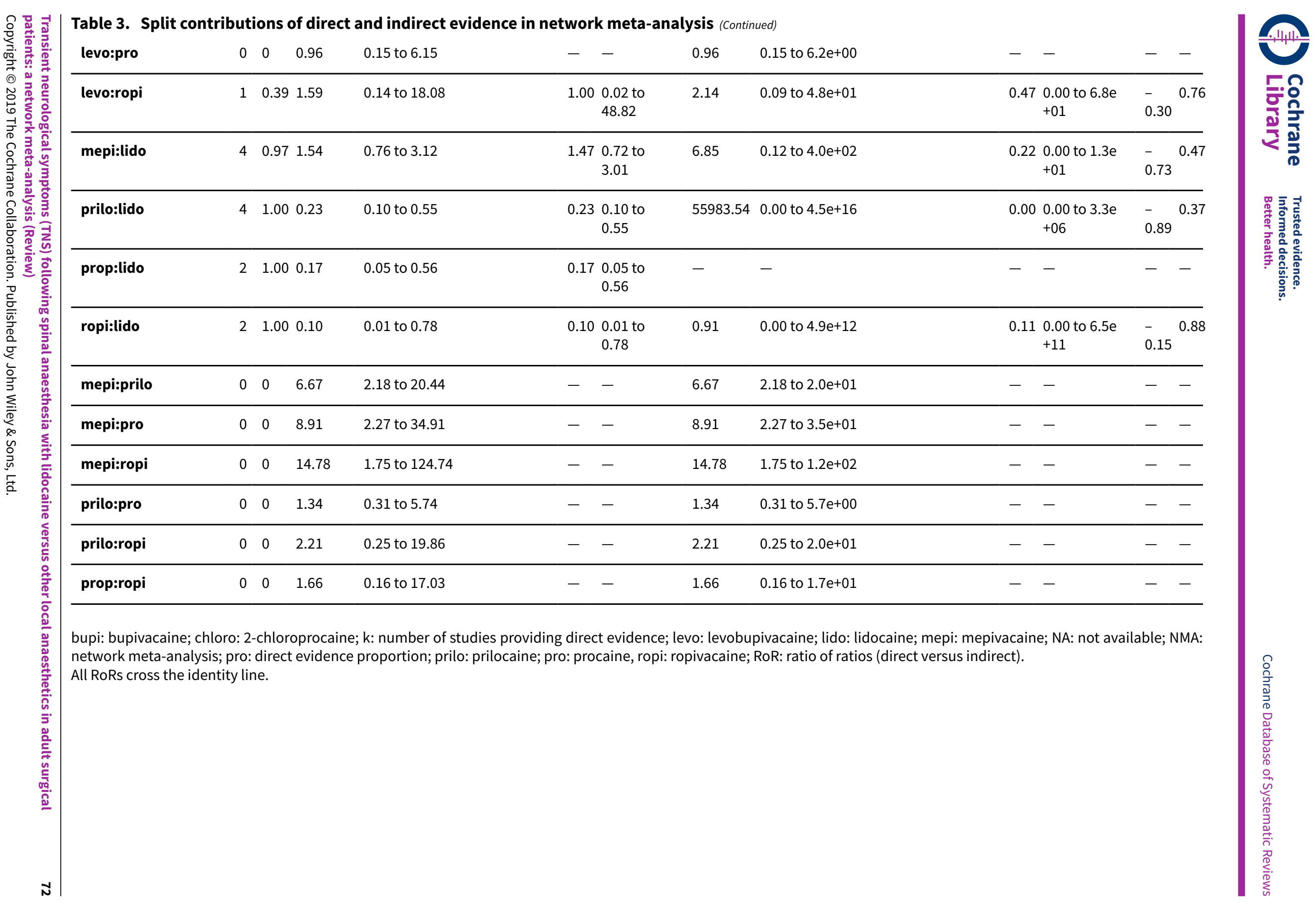


Table 4. Tests of homogeneity of whole network, homogeneity within designs and homogeneity/inconsistency between designs

\begin{tabular}{llll}
\hline & $\mathbf{Q}$ & $\mathbf{d f}$ & P value \\
\hline Total & 18.4 & 21 & 0.6232 \\
\hline Within designs & 14.8 & 13 & 0.3209 \\
\hline Between designs & 3.6 & 8 & 0.8897 \\
\hline
\end{tabular}

df: degrees of freedom; Q: Cochran's Q heterogeneity statistic.

Table 5. P score (treatment ranking)

\begin{tabular}{ll}
\hline Treatment & P score \\
\hline ropi & 0.772 \\
\hline levo & 0.657 \\
\hline pro & 0.647 \\
\hline chloro & 0.624 \\
\hline bupi & 0.610 \\
\hline prilo & 0.528 \\
\hline lido & 0.138 \\
\hline mepi & 0.022 \\
\hline
\end{tabular}

bupi: bupivacaine; chloro: 2-chloroprocaine; levo: levobupivacaine; lido: lidocaine; mepi: mepivacaine; prilo: prilocaine; pro: procaine, ropi: ropivacaine.

\section{APPENDICES}

\section{Appendix 1. Search strategy for CENTRAL, the Cochrane Library}

\#1 MeSH descriptor Lidocaine explode all trees

\#2 Lidocain*

\#3 MeSH descriptor Anesthesia, Spinal explode all trees

\#4 (Spinal near An?esth*)

\#5 (\#1 OR \#2 OR \#3 OR \#4)

\#6 (transient neurologic symptom*) or TNS

\#7 transitory radicular irritation

\#8 Cauda Equina syndrome

\#9 MeSH descriptor Polyradiculopathy, this term only

\#10 MeSH descriptor Drug Toxicity, this term only

$\# 11 \mathrm{MeSH}$ descriptor Postoperative Complications, this term only

\#12 (\#6 OR \#7 OR \#8 OR \#9 OR \#10 OR \#11)

\#13 (\#6 AND \#12) 


\section{Appendix 2. Search strategy for OvidSP MEDLINE}

1 exp Lidocaine/ or (Lidocain* or xylocain* or lignocain*).tw,kw.

2 exp Anesthesia, Spinal/ or ((Spinal or lumbar) adj3 (an?esth* or block*)).tw,kw.

31 or 2

4 ((neurologic ${ }^{\star}$ adj2 (symptom* or sign* or complication* or syndrome*)) or TNS).tw,kw.

5 Cauda Equina/de, su or Cauda Equina syndrom*.tw,kw.

6 Polyradiculopathy/ or Polyradiculopath*.tw,kw.

7 (transi ${ }^{\star}$ radicular irritation* or TRI).tw,kw.

8 Postoperative Complications/

9 "Drug-Related Side Effects and Adverse Reactions"/ or (toxic* adj2 drug*).tw,kw.

$10\left(\left(\right.\right.$ motor block ${ }^{\star}$ and (surgery or surgical)) or (return adj4 function $\left.\left.{ }^{\star}\right)\right)$.tw,kw.

114 or 5 or 6 or 7 or 8 or 9 or 10

123 and 11

13 ((randomized controlled trial or controlled clinical trial).pt. or random*.ab. or placebo.ab. or clinical trials as topic.sh. or random allocation.sh. or trial.ti.) not (exp animals/ not humans.sh.)

1412 and 13

\section{Appendix 3. Search strategy for Elsevier Embase}

1 'spinal an*sth*' OR 'lumbar an*sth*' OR 'spinal block'/exp OR 'spinal block' OR 'lumbar block'

2 'local anaesthetic agent'/exp OR 'local an?esth*' OR 'lidocaine'/exp OR 'lidocain*' OR 'lignocain*'

3 'cauda equina syndrome'/exp OR 'cauda equina syndrome' OR 'drug toxicity'/exp OR 'drug toxicity' OR 'postoperative complication'/exp OR 'postoperative complication' OR transient OR tns OR transitory OR cauda OR 'postoperative randomised controlled trial' OR 'complicat ${ }^{\star \prime}$ OR 'post-operative complicat ${ }^{* \prime}$ OR 'drug toxic ${ }^{* \prime}$

4 'randomized controlled trial'/exp

51 and 2 and 3 and 4

\section{Appendix 4. Search strategy for LILACS (via BIREME interface)}

LIDOCAIN or LIDOCAINE or ((Tw anesth\$ OR Tw anaesth\$) and Tw spinal) or "anestesia espinal" and (Tw postoperativ\$ AND Tw complication \$) OR (Tw cauda equina OR Tw "cauda equina sindrome") OR (TW tansit\$ AND (Tw radical AND Tw irritation\$)) OR "DRUG TOXICITY/" or (complicação posoperativa) or (complicación postvigente)

\section{Appendix 5. Search strategy for ClinicalTrials.gov}

1 'spinal an*sth*' OR 'lumbar an*sth*' OR 'spinal block'/exp OR 'spinal block' OR 'lumbar block'

2 'local anaesthetic agent'/exp OR 'local an?esth*' OR 'lidocaine'/exp OR 'lidocain*' OR 'lignocain *'

3 'cauda equina syndrome'/exp OR 'cauda equina syndrome' OR 'drug toxicity'/exp OR 'drug toxicity' OR 'postoperative complication'/exp OR 'postoperative complication' OR transient OR tns OR transitory OR cauda OR 'postoperative randomised controlled trial' OR 'complicat ${ }^{\star \prime}$ OR 'post-operative complicat ${ }^{\star \prime}$ OR 'drug toxic*' OR 'neurologic symptoms' OR 'neurologic outcomes'

4 'randomised controlled trial'/exp

51 and 2 and 3 and 4

\section{Appendix 6. Risk of bias}

\section{Assessment of random sequence generation}

The sufficiency of the method in producing two comparable groups before intervention.

\section{Grading}

- Low risk of bias: description of a truly random process in the sequence generation (e.g. random number table, random computer number generator, coin tossing, shuffling of cards/envelopes, throwing of dice).

- High risk of bias: description of any non-random process in the sequence generation (e.g. date of birth, date of admission, hospital or clinic record number, judgement of clinician, preference of participant, results of series of tests, availability of the intervention).

- Unclear risk of bias: insufficient information about the sequence generation process.

\section{Allocation concealment}

Allocation method prevented investigators or participants from foreseeing the assignment.

\section{Grading}

- Low risk of bias: adequately concealed allocation (e.g. central allocation, sealed envelopes, serially numbered or otherwise convincing concealment of allocation).

Transient neurological symptoms (TNS) following spinal anaesthesia with lidocaine versus other local anaesthetics in adult surgical 
- High risk of bias: inadequately concealed allocation (e.g. open allocation schedule, unsealed envelopes, alternation of rotation, date of birth, case record number, other unconcealed procedure).

- Unclear risk of bias: no information on allocation method or no clear distinction of the method.

\section{Blinding of participants and personnel, blinding of outcome assessment}

Knowledge of the allocated intervention was adequately prevented during the study.

\section{Grading}

- Low risk of bias: adequate blinding in which participants, personnel, and assessor were unaware of intervention allocations after inclusion of participants in the study; or no blinding that is unlikely to introduce bias.

- High risk of bias: inadequate or no blinding (e.g. not double-blind, open-label study, no use of placebo, or an intervention disguised in the same manner as placebo).

- Unclear risk of bias: insufficient description of the blinding procedure.

\section{Incomplete outcome data}

The completeness of outcome data for each main outcome, including attrition and exclusions from the analysis.

\section{Grading}

- Low risk of bias: the numbers and the reasons for dropouts and withdrawals in the intervention groups were described, or it was specified that no dropouts or withdrawals occurred.

- High risk of bias: no description of dropouts and withdrawals was provided.

- Unclear risk of bias: the report gave the impression that no dropouts or withdrawals occurred, but this was not specifically stated.

\section{Selective reporting}

The possibility of selective outcome reporting.

\section{Grading}

- Low risk of bias: the reported outcomes were those prespecified in an available study protocol, or, if this was not available, the published report included all expected outcomes.

- High risk of bias: not all prespecified outcomes were reported, or they were reported using subscales that were not prespecified, or they were reported incompletely or failed to include a key outcome that would be expected to have been reported for such a study.

- Unclear risk of bias: it was not clear whether all predefined or clinically relevant and reasonably expected outcomes were reported or were not reported fully, or it was unclear whether data on these outcomes were recorded.

\section{Appendix 7. Network meta-analysis}

Original data (with adjusted standards for multiarm studies) 


\begin{tabular}{|c|c|c|c|c|c|c|c|}
\hline Study & treat1 & treat2 & TE & SeTE & seTE.adj & narms & multiarm \\
\hline Ali Hassan 2015 & bupi & lido & 0.00 & 1.9807 & 1.198 & 2 & - \\
\hline Aouad 2001 & bupi & lido & 0.00 & 1.9950 & 2.00 & 2 & - \\
\hline Etezadi 2013 & bupi & lido & -1.77 & 0.2545 & 0.25 & 2 & - \\
\hline Hampl 1995a & bupi & lido & -2.41 & 1.4184 & 1.42 & 2 & - \\
\hline Hampl 1998 & bupi & lido & -2.94 & 1.4285 & 1.51 & 3 & * \\
\hline Imbelloni 2010 & bupi & lido & 0.00 & 1.9934 & 1.99 & 2 & - \\
\hline Keld 2000 & bupi & lido & -1.85 & 0.8464 & 0.85 & 2 & - \\
\hline Philip 2001 & bupi & lido & 0.58 & 1.0000 & 1.00 & 2 & - \\
\hline Pollock 1996 & bupi & lido & -2.78 & 1.4257 & 1.43 & 2 & - \\
\hline Pradhan 2010 & bupi & lido & 0.00 & 1.9814 & 1.43 & 2 & - \\
\hline Salmela 1998 & bupi & lido & -2.56 & 1.4455 & 2.54 & 3 & * \\
\hline Teunkens 2016 & bupi & lido & -0.09 & 1.9854 & 2.43 & 3 & * \\
\hline Casati 2007 & chloro & lido & -2.40 & 1.4342 & 1.43 & 2 & - \\
\hline Teunkens 2016 & chloro & lido & 0.00 & 1.9848 & 2.43 & 3 & * \\
\hline Breebaart 2003 & levo & lido & -1.95 & 1.4904 & 1.57 & 3 & * \\
\hline Gozdemir 2010 & levo & lido & -1.73 & 0.8484 & 0.85 & 2 & - \\
\hline Liguori 1998 & lido & mepi & 2.67 & 1.4443 & 1.44 & 2 & - \\
\hline Pawlowski 2012 & lido & mepi & -0.08 & 1.9875 & 1.99 & 2 & - \\
\hline Salazar 2001 & lido & mepi & -0.85 & 0.9506 & 0.95 & 2 & - \\
\hline Salmela 1998 & lido & mepi & -0.57 & 0.4199 & 0.42 & 3 & * \\
\hline
\end{tabular}




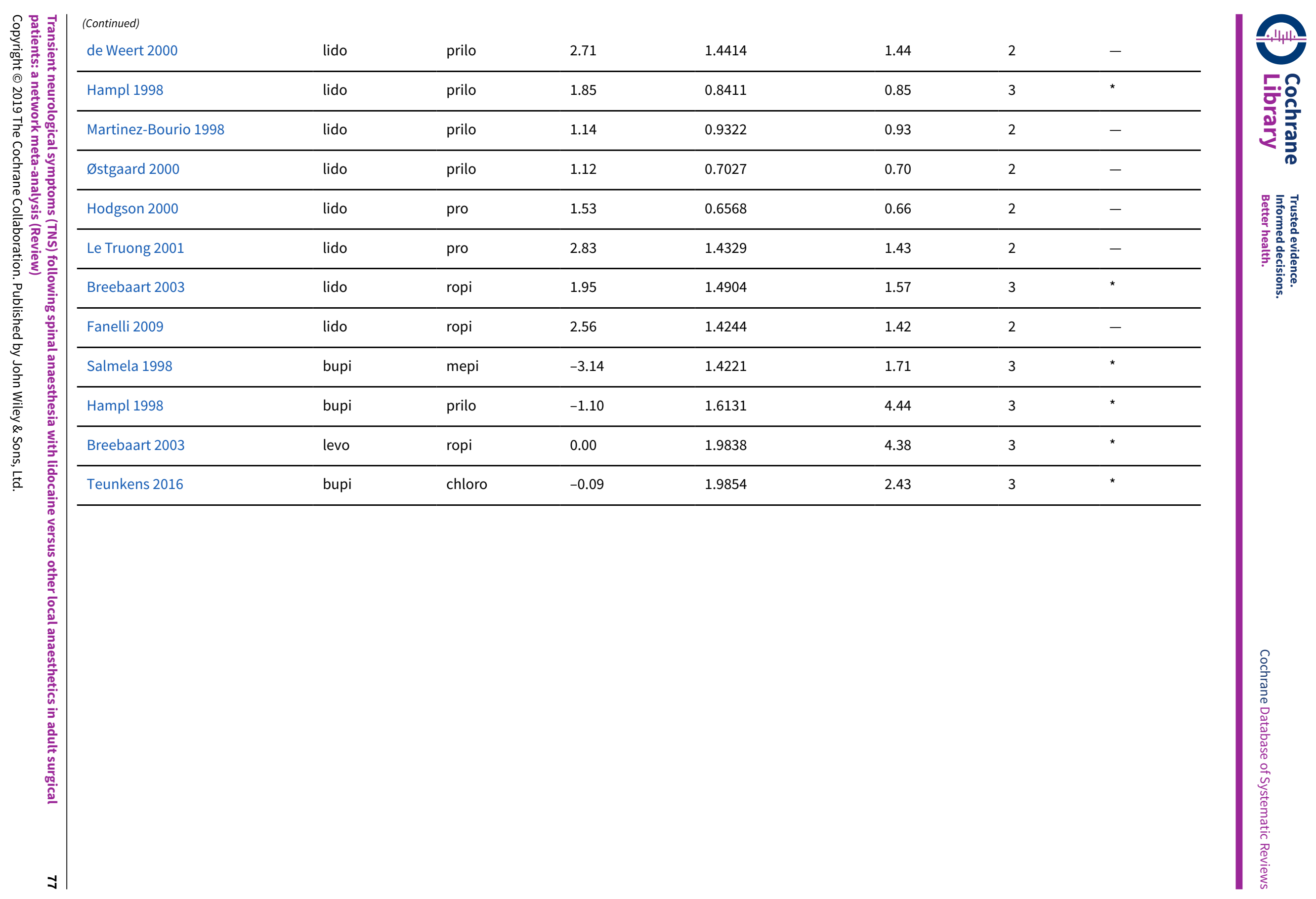


Treat1, Treat2: bupi: bupivacaine; chloro: 2-chloroprocaine; levo: levobupivacaine; lido: lidocaine; mepi: mepivacaine; prilo: prilocaine; pro: procaine; ropi: ropivacaine.

multiarm: studies with more than two arms; narms: number of study arms; seTE: log(RR)SE; seTE.adj: adjusted seTE; TE: log(RR).

\section{WHAT'S NEW}

\begin{tabular}{lll}
\hline Date & Event & Description \\
\hline 3 December 2019 & Amended & Resolution of several figures updated. \\
\hline
\end{tabular}

\section{H IST O R Y}

Protocol first published: Issue 2, 2001

Review first published: Issue 2, 2003

Date Event Description

25 November $2018 \quad$ New search has been performed

Change in authors; the previous published version was authored by Zaric D, Christiansen C, Pace NL, Punjasawadwong Y (Zaric 2005).

This updated version is authored by Forget P, Borovac JA, Thackeray EM, Pace NL.

We modified the Embase search strategy and ran it in Elsevier Embase for 2008 to 2016. We edited Appendix 3 to show our revised search strategy.

We searched to 25 November 2018.

We included eight new studies in this updated version (Etezadi 2013; Fanelli 2009; Gozdemir 2010; Ali Hassan 2015; Imbelloni 2010; Pawlowski 2012; Pradhan 2010; Teunkens 2016). Two studies are awaiting classification (Frisch 2018; Gozdemir 2016); and one is ongoing (Gozdemir 2016).

We undertook a network meta-analysis.

We added full risk of bias tables. We added a 'Summary of findings' table.

$\begin{array}{ll}25 \text { November } 2018 & \begin{array}{l}\text { New citation required but conclusions } \\ \text { have not changed }\end{array}\end{array}$

24 November $2008 \quad$ New search has been performed
The conclusions are not changed by the inclusion of the eight new studies.
Searches rerun until August 2008.

One new randomized controlled trial was included that compared 2-chloroprocaine to lidocaine (Casati 2007). This new study does not change the results. Eight new references have been added to the Additional references (Kopacz 2005; Moore 1982; Reisner 1980; Sell 2008; Smith 2004; Winnie 2001; Yoos 2005).

Change in authors; the previous published version was authored by Zaric D, Christiansen C, Pace NL, Punjasawadwong Y (Zaric 2005). 


\begin{tabular}{|c|c|c|}
\hline Date & Event & Description \\
\hline & & $\begin{array}{l}\text { This updated version is authored by Forget } \mathrm{P} \text {, Borovac JA, Thack- } \\
\text { eray EM, Pace NL. }\end{array}$ \\
\hline 2 July 2008 & Amended & Converted to new review format. \\
\hline \multirow[t]{2}{*}{2 August 2005} & New search has been performed & $\begin{array}{l}\text { This review was first updated in Issue } 4,2005 \text {. The literature } \\
\text { search for this updated review resulted in the inclusion of one } \\
\text { further randomized controlled trial (Breebaart 2003). The occur- } \\
\text { rence of transient neurological symptoms (TNS) after intrathecal } \\
\text { lidocaine was compared to that after two new local anaesthetics: } \\
\text { levobupivacaine and ropivacaine. This addition did not change } \\
\text { the results of this review. }\end{array}$ \\
\hline & & $\begin{array}{l}\text { Three new references have been added to the review: one in the } \\
\text { Included studies tables (Breebaart 2003), one in the Excluded } \\
\text { studies tables (Tong 2003), and one to the Additional references } \\
\text { (Freedman 1998). }\end{array}$ \\
\hline 28 April 2004 & $\begin{array}{l}\text { New citation required and conclusions } \\
\text { have changed }\end{array}$ & Substantive amendment \\
\hline
\end{tabular}

\section{CONTRIBUTIONSOF AUTHORS}

Undertaking manual searches: all authors.

Screening search results: all authors.

Screening retrieved papers against inclusion criteria: all authors.

Appraising quality of papers: all authors.

Abstracting data from papers: all authors.

Data management for the review: all authors.

Entering data into Review Manager 5 (Review Manager 2014): all authors.

Review Manager 5 statistical data (Review Manager 2014): all authors.

Interpretation of data: all authors.

Statistical inferences and network meta-analysis: NLP.

Writing the review: all authors.

Guarantor for the review: PF.

Person responsible for reading and checking review before submission: PF.

\section{DECLARATIONS OF INTEREST}

PF: none.

JAB: none.

EMT: taught a 'safe sedation simulation' course to doctors and nurses as a consultant for Applied Medical Visualizations.

NLP: is a tenured professor (University of Utah) and has no conflicts of interest regarding the topic of this review. He has received payment for the development of educational presentations (Barash, Cullen, Toelting Clinical Anaesthesia 8th Edition) and provided consultancy (St Marks Hospital, Salt Lake City, UT; JB3 Bioscience Inc, Salt Lake City, UT; Elute, Salt Lake City, UT) on topics unrelated to the current review. 
He has received financial supplements to attend Cochrane meetings. He also has stocks and shares in companies who have no interests in the topic of this review (TIAA-CREF, Fidelity, Vanguard, USAA, Morgan Stanley).

\section{SOURCES OF SUPPORT}

\section{Internal sources}

- EMT, USA.

The author has no source of internal support to declare.

- JAB, Croatia.

The author has no source of internal support to declare.

- NLP, USA.

The author has no source of internal support to declare.

- PF, UK.

The author has no source of internal support to declare.

\section{External sources}

- EMT, USA.

The author has no source of external support to declare.

- JAB, Croatia.

The author has no source of external support to declare.

- PF, UK.

The author has no source of external support to declare.

- NLP, USA.

The author has no source of external support to declare.

\section{DIFFERENCES BETWEEN PROTOCOL AND REVIEW}

We made the following changes to the published review (Zaric 2009).

- Changed the title to: Transient neurological symptoms (TNS) following spinal anaesthesia with lidocaine versus other local anaesthetics in adult surgical patients.

- Changed authors to: Forget P, Borovac JA, Thackeray EM, Pace NL.

- Updated the inclusion criteria for studies to: two or more treatment arms that used a distinct local anaesthetic (irrespective of the concentration and baricity of the solution) for spinal anaesthesia in preparation for surgery.

- Added network meta-analysis.

- Incorporated GRADE assessments.

- Updated the review according to the MECIR standards.

\section{N D EX TERMS}

\section{Medical Subject Headings (MeSH)}

Anesthesia, Spinal [ ${ }^{\star}$ adverse effects]; Anesthetics, Local [ ${ }^{*}$ adverse effects]; Leg [ ${ }^{*}$ innervation]; Lidocaine [ ${ }^{\star}$ adverse effects]; Pain [*chemically induced]; Peripheral Nervous System Diseases [ ${ }^{\star}$ chemically induced]; Randomized Controlled Trials as Topic

\section{MeSH check words}

Humans

Transient neurological symptoms (TNS) following spinal anaesthesia with lidocaine versus other local anaesthetics in adult surgical 